\title{
A Review of Current Trends with Type 2 Diabetes Epidemiology, Aetiology, Pathogenesis, Treatments and Future Perspectives
}

\section{Josh Reed (D) \\ Stephen Bain (D) \\ Venkateswarlu \\ Kanamarlapudi $\mathbb{D}$}

Institute of Life Science I, Medical School, Swansea University, Swansea, SA2 8PP, UK
Correspondence: Venkateswarlu

Kanamarlapudi

Tel +44 1792295012

Email k.venkateswarlu@swansea.ac.uk

\begin{abstract}
Type 2 diabetes (T2D), which has currently become a global pandemic, is a metabolic disease largely characterised by impaired insulin secretion and action. Significant progress has been made in understanding T2D aetiology and pathogenesis, which is discussed in this review. Extrapancreatic pathology is also summarised, which demonstrates the highly multifactorial nature of T2D. Glucagon-like peptide (GLP)-1 is an incretin hormone responsible for augmenting insulin secretion from pancreatic beta-cells during the postprandial period. Given that native GLP-1 has a very short half-life, GLP-1 mimetics with a much longer half-life have been developed, which are currently an effective treatment option for T2D by enhancing insulin secretion in patients. Interestingly, there is continual emerging evidence that these therapies alleviate some of the post-diagnosis complications of T2D. Additionally, these therapies have been shown to induce weight loss in patients, suggesting they could be an alternative to bariatric surgery, a procedure associated with numerous complications. Current GLP-1-based therapies all act as orthosteric agonists for the GLP-1 receptor (GLP-1R). Interestingly, it has emerged that GLP-1R also has allosteric binding sites and agonists have been developed for these sites to test their therapeutic potential. Recent studies have also demonstrated the potential of bi- and tri-agonists, which target multiple hormonal receptors including GLP-1R, to more effectively treat T2D. Improved understanding of T2D aetiology/ pathogenesis, coupled with the further elucidation of both GLP-1 activity/targets and GLP-1R mechanisms of activation via different agonists, will likely provide better insight into the therapeutic potential of GLP-1-based therapies to treat T2D.
\end{abstract}

Keywords: diabesity, GLP-1, GLP-1R, incretin effect, insulin, metabolic homeostasis

\section{Introduction}

Type 2 diabetes (T2D) is the most common and clinically important metabolic disorder which has become a global pandemic in recent decades and a major healthcare burden worldwide. In 2013, there were an estimated 382 million patients with diabetes globally. ${ }^{1}$ Concerningly, the T2D incidence continues to increase, and it is projected that there will be $>590$ million patients diagnosed with this condition by 2035 . $^{1,2}$ The World Health Organisation (WHO) defines diabetes as a "metabolic disorder of multiple aetiology characterised by chronic hyperglycaemia with disturbance of carbohydrate, fat, and protein metabolism resulting from defects in insulin secretion, insulin action, or both." 3 The most prevalent form of diabetes is type 2 , as an estimated $90 \%$ of diabetes patients are diagnosed with this form, ${ }^{2}$ and the majority of the remaining $10 \%$ of patients have type 1 diabetes (T1D), although there are other rare types. ${ }^{4} \mathrm{~T} 2 \mathrm{D}$ is 
largely caused by impaired insulin production and secretion by pancreatic beta-cells, as well as peripheral tissue insulin resistance. ${ }^{5,6}$ Given that $\sim 90 \%$ of patients are obese or overweight at T2D diagnosis, the aetiology of T2D is largely thought to be linked to diets involving excessive nutrient consumption combined with insufficient energy expenditure. ${ }^{7}$ There are a range of effective treatments that reduce hyperglycaemia in T2D patients, which mediate their effects by improving insulin secretion or decreasing peripheral tissue insulin resistance. ${ }^{8}$ Despite this, post-diagnosis complications, especially long-term complications, are prevalent globally. As a result, diabetes remains a leading cause of blindness, end-stage renal disease, lower limb amputation and cardiovascular disease. ${ }^{3}$

T2D and obesity have such an interdependent relationship that the term "diabesity" has been coined. ${ }^{9}$ In recent decades, the number of people with T2D has more than doubled, and the increased global burden of T2D is thought to be largely due to an increase in obesity., ${ }^{9,10}$ Obesity has become a global pandemic over recent decades. Weight loss is associated with an improved prognosis for overweight T2D patients and obese individuals. Better glycaemic control has been reported in T2D patients who have lost weight, and excess body weight is associated with the risk of cardiometabolic complications, which are major causes of morbidity and mortality in T2D and obese individuals. ${ }^{11,12}$ Bariatric surgery has proven to be an effective treatment for diabesity, but it is expensive and there are numerous post-surgery complications: for example, vomiting and dumping syndrome, iron and B12 deficiency, and secondary hyperparathyroidism. ${ }^{13}$ GLP-1 analogues (eg liraglutide and exenatide) are used to treat $\mathrm{T} 2 \mathrm{D}$ as they promote insulin secretion and induce weight loss. ${ }^{3}$ Since the GLP-1 receptor (GLP-1R) agonists are effective in treating diabesity, they could be pharmacological alternatives to bariatric surgery but without the postsurgery complications. ${ }^{3,13,14}$

The current literature on T2D epidemiology, aetiology, pathogenesis and treatment is discussed in this review.

\section{Obesity}

Obesity is caused by excessive energy intake and subsequent storage coupled with insufficient energy expenditure resulting in weight gain. It has become a huge healthcare concern over the last few decades, especially in developed countries. However, in some obese individuals, excessive dietary intake may have a genetic aetiology, such as leptin deficiency. ${ }^{15-17}$ Obese individuals have a BMI of $\geq 30 \mathrm{~kg} /$ $\mathrm{m}^{2}$, and individuals with a BMI of $\geq 25$ and $<30$ are classified as overweight. ${ }^{16}$ Obesity and overweight incidences have more than doubled since 1980, giving rise to $>2.1$ billion individuals with a BMI of $>25$ globally, as stated by the WHO. ${ }^{15,18}$ The WHO estimated that there were $\sim 600$ million obese individuals in 2014 , and this number will continue to rise in the future. ${ }^{18}$ Obesity is associated with an increased risk for T2D, hypertension, dyslipidaemia, cardiovascular diseases, musculoskeletal disorders (such as osteoarthritis), certain types of cancer, and premature mortality. ${ }^{19,20}$ It is well established that there is a generally directly proportional relationship between BMI and both fasting and postprandial insulin levels. ${ }^{21,22} \mathrm{~A}$ similar relationship also exists between BMI and the degree of insulin resistance. ${ }^{22}$ The hyperinsulinemia associated with rising BMI is necessary to overcome insulin resistance and maintain normoglycemia. ${ }^{22}$ Not all obese individuals develop insulin resistance though; ${ }^{23}$ one study reported that 19,34 and $60 \%$ of individuals with a BMI of $<30, \geq 30-35$ and $>35$, respectively, were insulin resistant. ${ }^{22}$ Insulin hypersecretion also becomes more frequent with increasing BMI $;{ }^{24} 28,49$ and $80 \%$ of individuals with a BMI of $<30,>30-35$ and $>35$, respectively, exhibited insulin hypersecretion. ${ }^{22}$ Of the 2.1 billion individuals that are obese or overweight $<25 \%$ have been diagnosed with T2D. ${ }^{1,18}$ The rise in T2D over the last few decades is generally thought to be attributed to an increase in the percentage of overweight individuals in the global population. ${ }^{3,25}$ Figure 1 shows how the percentage of overweight and obese individuals in the population vary between countries.

\section{Type 2 Diabetes}

Diabetes mellitus was first reported over 3000 years ago in an Egyptian manuscript. ${ }^{26}$ However, it was not until 1936 that the distinction between T1D and T2D was made. ${ }^{27} \mathrm{~T} 2 \mathrm{D}$ is by far the most common form of diabetes and accounts for $\sim 90 \%$ of diabetes cases. ${ }^{2,7} \mathrm{~T} 2 \mathrm{D}$ is a chronic metabolic complex multifactorial disease, involving many organs, that has become a global pandemic in recent decades. ${ }^{1,28} \mathrm{~T} 2 \mathrm{D}$ is characterised by pancreatic beta-cell dysfunction, increased pancreatic alpha-cell function, and peripheral tissue insulin resistance. These alterations result in (1) hyperglycaemia due to impaired peripheral glucose uptake, (2) dyslipidaemia (hypertriglyceridemia and low high-density lipoprotein [HDL]-cholesterol) due to impaired peripheral fat uptake, (3) impaired amino acid uptake and ATP production into peripheral tissues, such as skeletal muscle, due to the 


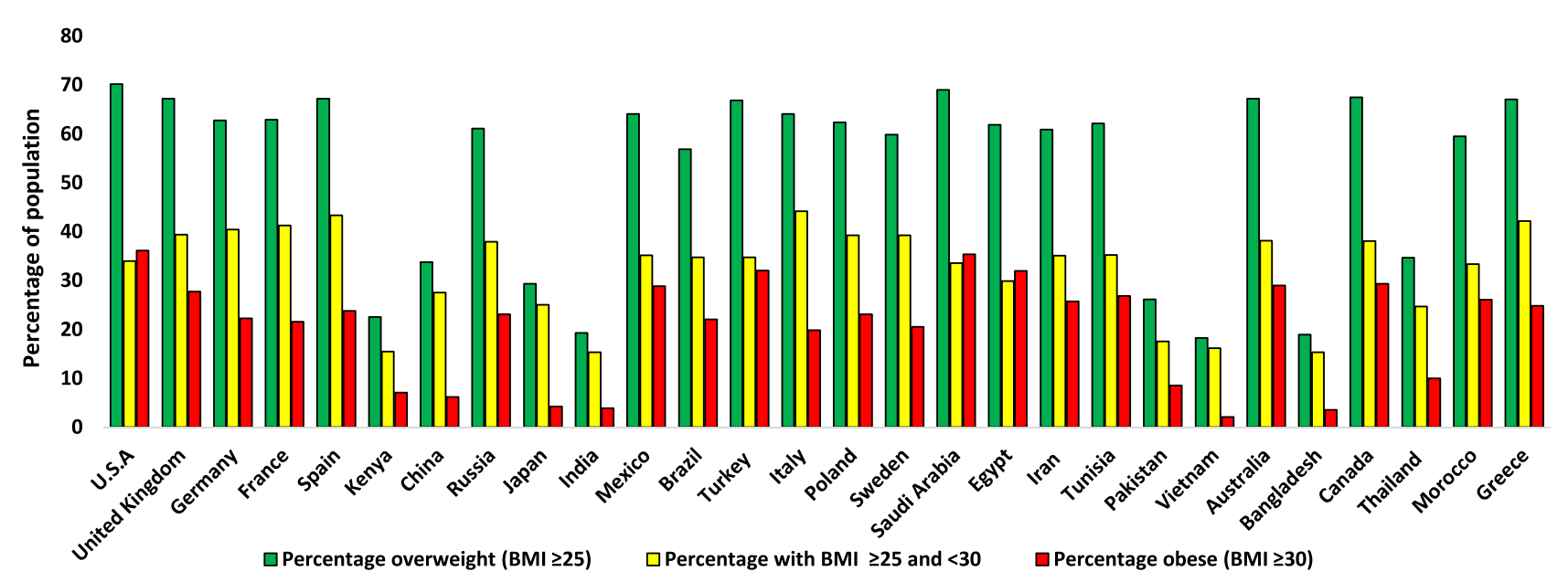

Figure I Variation in the percentage of obese and overweight individuals over 18 years of age in the population between different countries in $2016 .{ }^{325}$ Values displayed are an average of the male and female percentage of the population for each country, which were taken from the WHO data. ${ }^{325}$

impaired nutrient uptake, and (4) increased glucagon production, which further amplifies hyperglycaemia and hyperlipidaemia. ${ }^{29-32} \mathrm{~T} 2 \mathrm{D}$ is thought to be largely provoked by diets involving excessive nutrient consumption, as $\sim 90 \%$ of patients are obese or overweight in western countries. $^{3,9,16,33}$ In contrast to that observed in western countries, a study in China found that $50.3 \%$ of T2D patients were not overweight, ${ }^{34}$ and other Asian countries also have a high percentage of T2D patients with a BMI of $<25 .^{35}$ It has become clear that genetic factors also play a role in conferring susceptibility, although no important risk genes have yet been identified. ${ }^{36,37}$ T2D is considered to be a heterogeneous disease as the severity of insulin deficiency, treatment requirements and prognosis varies between patients. $^{38,39}$

Although treatments are available, diabetes remains a leading cause of blindness, end-stage renal disease, lower limb amputation and cardiovascular disease. ${ }^{40}$ One study in the UK found that $48.9 \%$ of amputations from 2007 to 2010 were carried out on people with diabetes and diabetes conferred a $23.3 x$ risk for amputations. ${ }^{41}$ Additionally, diabetic patients also usually exhibit impaired wound healing, susceptibility to infection, neuropathology and impotence. ${ }^{3}$ T2D has also been identified as a risk factor for Alzheimer's and Parkinson's diseases. ${ }^{42,43}$ Cardiovascular disease (CVD) accounts for 75\% of all related deaths in diabetic patients and on average individuals with T2D have an increased risk of shorter life expectancy. ${ }^{44,45}$ There are a range of treatments available which improve insulin secretion and/or decrease peripheral tissue insulin resistance, which reduces hyperglycaemia. ${ }^{46,47}$ However, maintaining glycaemic control in patients is no easy task, as hypo- or hyperglycaemia can result from administration of the currently available treatments resulting in either too much or not enough, respectively, of an anti-hyperglycaemic effect.${ }^{3,48}$ Regardless of the treatment regime, longitudinal studies in humans have demonstrated that beta-cell function generally deteriorates over time. ${ }^{49,50}$ It has been postulated that chronic hyperglycaemia and dyslipidaemia lead to a progressive decline in beta-cell function post-diagnosis. ${ }^{50}$

\section{Epidemiology of T2D}

It has been estimated that there were $\sim 382$ million T2D patients globally in 2013 and that number has more than doubled in the last few decades. ${ }^{1}$ The incidence and prevalence of T2D continue to increase. By 2035, it is estimated that there will be $>590$ million T2D people diagnosed. ${ }^{1,2}$ Although the prevalence and incidence of T2D vary between countries, T2D is still considered to be a global disease. ${ }^{28}$ T2D used to be considered as a disease induced by 'western lifestyles' (highcalorie diets and sedentary lifestyles). ${ }^{3}$ Interestingly, the rise in prevalence of $\mathrm{T} 2 \mathrm{D}$ is estimated to be almost $4 \mathrm{x}$ as high in developing as in developed countries. ${ }^{1,25,51}$ This is thought to be due to developing countries adopting 'western lifestyles' and the increase in obesity and the number of people being overweight in their populations. ${ }^{1,28,52}$ In general, the age group with the highest risk of developing T2D is 40-60 years in developed countries and 60+ years in developing countries. ${ }^{53}$ Although T2D is considered to be a disease associated with adulthood and the incidence of T2D increases with age, it is becoming more common for children to be affected. ${ }^{54,55}$ It is, however, likely that the number of cases of individuals 
diagnosed with T1D in adulthood is underestimated: it has been speculated that $5-15 \%$ of adult patients are misdiagnosed as having T2D when they may actually have T1D, which is currently an area of controversy in the literature..$^{56,57}$

Diabetes in young people was previously thought to be T1D. ${ }^{58}$ Until the early 1990s, it was rare for paediatric centres to have T2D patients. However, this has drastically changed since the late 1990s onwards with paediatric T2D accounting for up to $45 \%$ of newly diagnosed paediatric diabetes cases in the USA. The "youth T2D" is not just a phenomenon limited to the USA. ${ }^{59}$ Staggeringly, $80 \%$ of all new diabetes cases in Japan in children and adolescents were reported as T2D and other countries have also reported an increase in youth $\mathrm{T} 2 \mathrm{D} .{ }^{60}$ However, many studies from Europe have reported that youth T2D is much rarer, accounting for only $1-2 \%$ of all diabetes mellitus cases. ${ }^{55,60}$ China has the highest number of T2D patients ( $\sim 98$ million) and India has the second-highest (around 65 million). ${ }^{1}$ The USA was estimated to have around 24.4 million T2D patients in $2013 .{ }^{61}$ Tokelau has

\section{A}

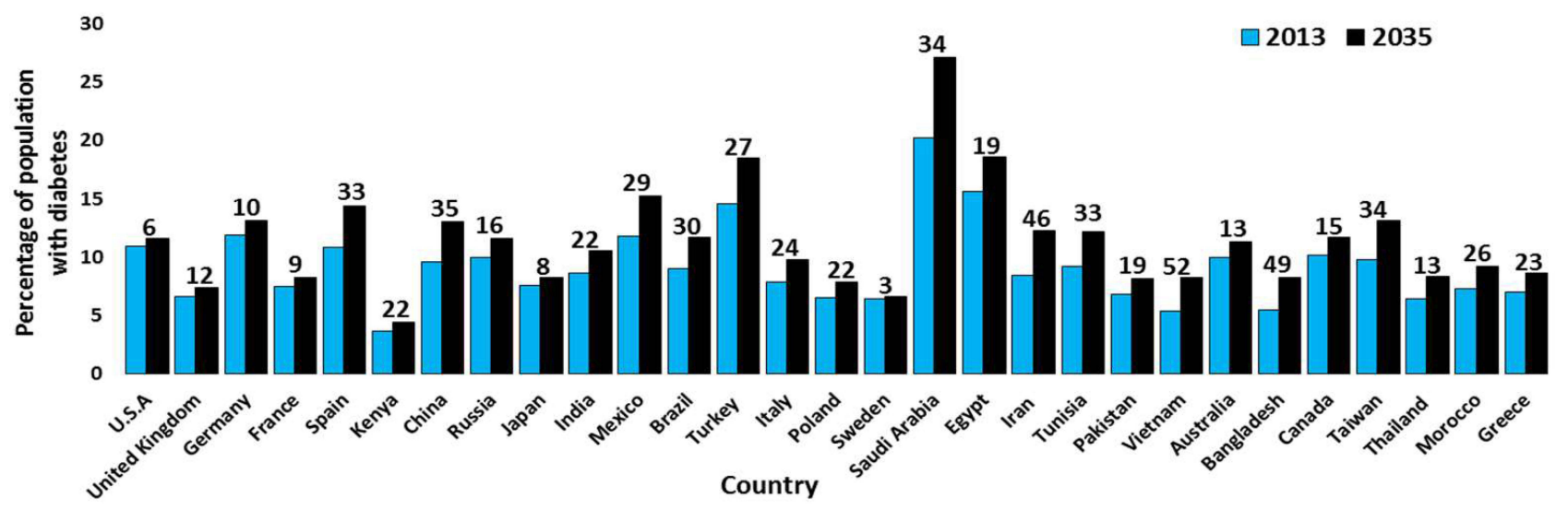

B

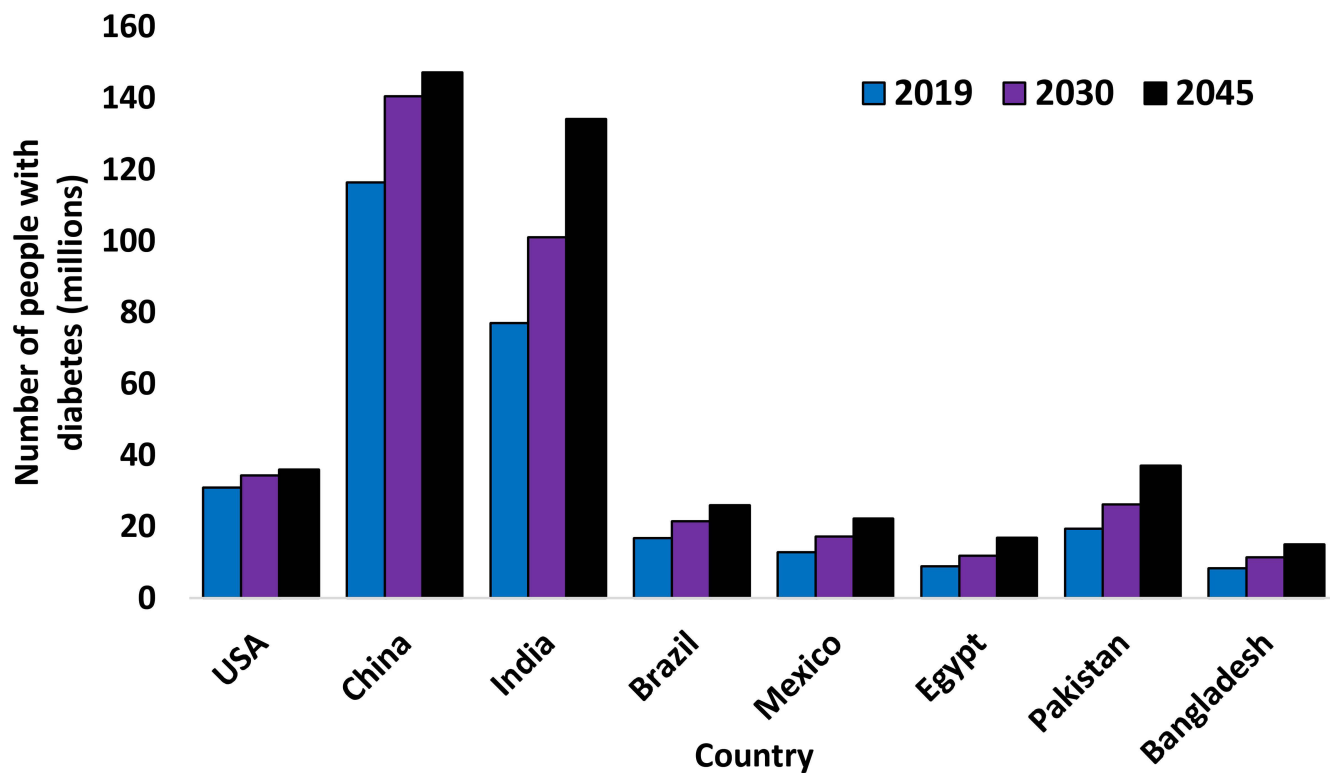

Figure 2 (A) The varying estimated prevalence of T2D in 2013 and projections for 2035, between ages 20-79 years.' (B) The varying estimated prevalence of T2D in 2019 and projections for 2030 and 2045, between ages 20-79 years. ${ }^{62}$ The numbers above are the values for each country, indicating the percentage increase of diabetes patients from 2013 to 2035 (A) or from 2019 to 2045 (B) for any given country, rounded to the nearest whole number. Data from these studies. ${ }^{1,62}$ 
been reported in 2013 as the country with the greatest prevalence of $\mathrm{T} 2 \mathrm{D}(37.5 \%)$ in the national population. The Federated States of Micronesia, the Marshall Islands, and Kiribati all have T2D prevalence rates in their national populations of $35,34.9$ and $28.8 \%$, respectively. ${ }^{1}$ All other countries had T2D national population prevalence rates of under $26 \%$ in $2013 .{ }^{1}$ Globally, the number of people with diabetes was estimated to be $285,366,382,415$ and 425 million in the years 2009, 2011, 2013, 2015 and 2017, respectively. ${ }^{62}$ Figure 2 shows how T2D prevalence varied between countries in 2013 and 2019, and predictions for future data on T2D prevalence are also shown. ${ }^{1,62}$

Diabetes was considered to be rare in the first half of the twentieth century in the USA; less than $1 \%$ of the population was diagnosed with diabetes in $1958 .{ }^{63,64}$ However, both the incidence and prevalence of $\mathrm{T} 2 \mathrm{D}$ increased throughout the second half of the 20th century in developed countries, becoming an epidemic towards the end of the century and remaining as such into the 21st century. ${ }^{1,63}$ Over recent decades, T2D incidence and prevalence have also increased in developing countries, becoming a comparable health burden in these countries. In $1980,<1 \%$ of China's population had diabetes but this increased to almost $10 \%$ by $2008 .{ }^{25}$ In urban areas of South India, almost $20 \%$ of the population was estimated to be affected by diabetes in $2008 .^{65}$ In 2014 , a study revealed that $46 \%$ of newly diagnosed T2D patients in India were under 40 years of age, ${ }^{66}$ which is a contrast with the notion that patients in developing countries are usually over $60 .^{53} \mathrm{~T} 2 \mathrm{D}$ incidence and prevalence have continued to increase globally in the 21 st century as well. By 2045, it has been estimated that there will be over 700 million T2D patients worldwide. ${ }^{1,62}$ However, as highlighted in Tables 1 and 2, the future increase in the number of T2D patients will be partly due to the rise in the global population and not just increasing incidence. ${ }^{1}$

Studies have demonstrated that the incidence of T2D potently increased globally in the latter half of the $20^{\text {th }}$ century (especially paediatric cases), and one study even reported the incidence of diabetes rose from 2.6 to $9.4 \%$ between 1980 and 1988 in the USA. ${ }^{59,67}$ Although life expectancy has generally increased globally over the last few decades, this does not fully explain the rise in T2D incidence and prevalence given the drastic increase in childhood cases, but it likely accounts for at least part of the rise in T2D in developing countries where patients are generally aged $60+$ years. ${ }^{47}$ Globally, it was estimated that diabetes accounted for $\sim 12 \%$ of health expenditures in 2010 (at least $\$ 376$ billion), and the healthcare cost will continue to rise to $\sim \$ 490$ billion in $2030 .{ }^{28}$ Many developing

Table I Variation of T2D Prevalence Between Global Regions in 2013 and Projections for 2035

\begin{tabular}{|c|c|c|c|c|c|c|}
\hline Region & $\begin{array}{l}\text { Population } 2013 \\
\text { (20-79 Years) } \\
\text { Millions }\end{array}$ & $\begin{array}{l}\text { Diabetes } \\
\text { Patients (20-79 } \\
\text { Years) Millions }\end{array}$ & $\begin{array}{l}\text { Comparative } \\
\text { Diabetes Prevalence } \\
\text { (20-79 Years) \% }\end{array}$ & $\begin{array}{l}\text { Population } 2035 \\
\text { (20-79 Years) } \\
\text { Millions }\end{array}$ & $\begin{array}{l}\text { Diabetes } \\
\text { Patients (20-79 } \\
\text { Years) Millions }\end{array}$ & $\begin{array}{l}\text { Comparative } \\
\text { Diabetes Prevalence } \\
\text { (20-79 Years) \% }\end{array}$ \\
\hline Africa & 407.8 & 19.8 & 5.7 & 775.5 & 41.5 & 6 \\
\hline Europe & 658.7 & 56.3 & 6.8 & 668.7 & 68.9 & 7.1 \\
\hline $\begin{array}{l}\text { North } \\
\text { America and } \\
\text { Caribbean }\end{array}$ & 334.9 & 36.7 & 9.6 & 404.5 & 50.4 & 12.3 \\
\hline $\begin{array}{l}\text { Middle-East } \\
\text { and North } \\
\text { Africa }\end{array}$ & 347.5 & 34.6 & 10.9 & 583.7 & 67.9 & 11.3 \\
\hline $\begin{array}{l}\text { South-East } \\
\text { Asia }\end{array}$ & 883.2 & 72.1 & 8.7 & 1216.9 & 123 & 9.4 \\
\hline $\begin{array}{l}\text { South and } \\
\text { Central } \\
\text { America }\end{array}$ & 300.5 & 24.1 & 8.2 & 394.2 & 38.5 & 8.2 \\
\hline $\begin{array}{l}\text { Western } \\
\text { Pacific }\end{array}$ & 1613.2 & 138.2 & 8.1 & 1818.2 & 201.8 & 8.4 \\
\hline
\end{tabular}

Notes: Adapted from Diabetes Res Clin Pract, I03(2), Guariguata L, Whiting DR, Hambleton I, Beagley J, Linnenkamp U, Shaw JE. Global estimates of diabetes prevalence for 2013 and projections for 2035. Diabetes Res Clin Pract. 137-149. Copyright (2014), with permission from Elsevier. ${ }^{\text {I }}$ 
Table 2 Variation of T2D Prevalence Between Global Regions in 2019 and Projections for 2030 and 2045

\begin{tabular}{|c|c|c|c|c|c|c|}
\hline Region & $\begin{array}{l}\text { Diabetes Patients } \\
\text { in } 2019(20-79 \\
\text { Years) Millions }\end{array}$ & $\begin{array}{l}\text { Comparative } \\
\text { Diabetes } \\
\text { Prevalence (20-79 } \\
\text { Years) \% }\end{array}$ & $\begin{array}{l}\text { Diabetes Patients } \\
\text { in } 2030 \text { (20-79 } \\
\text { Years) Millions }\end{array}$ & $\begin{array}{l}\text { Comparative } \\
\text { Diabetes } \\
\text { Prevalence (20-79 } \\
\text { Years) \% }\end{array}$ & $\begin{array}{l}\text { Diabetes Patients } \\
\text { in } 2045 \text { (20-79 } \\
\text { Years) Millions }\end{array}$ & $\begin{array}{l}\text { Comparative } \\
\text { Diabetes } \\
\text { Prevalence (20-79 } \\
\text { Years) \% }\end{array}$ \\
\hline Africa & 19.4 & 4.7 & 28.6 & 5.1 & 47.1 & 5.2 \\
\hline Europe & 59.3 & 6.3 & 66 & 7.3 & 68.1 & 7.8 \\
\hline $\begin{array}{l}\text { North } \\
\text { America and } \\
\text { Caribbean }\end{array}$ & 47.6 & 11.1 & 56 & 12.3 & 63.2 & 13 \\
\hline $\begin{array}{l}\text { Middle-East } \\
\text { and North } \\
\text { Africa }\end{array}$ & 54.8 & 12.2 & 76 & 13.3 & 107.6 & 13.9 \\
\hline $\begin{array}{l}\text { South-East } \\
\text { Asia }\end{array}$ & 87.6 & 11.3 & 115.1 & 12.2 & 152.8 & 12.6 \\
\hline $\begin{array}{l}\text { South and } \\
\text { Central } \\
\text { America }\end{array}$ & 31.6 & 8.5 & 40.2 & 9.5 & 49.1 & 9.9 \\
\hline $\begin{array}{l}\text { Western } \\
\text { Pacific }\end{array}$ & 162.2 & 11.4 & 196.5 & 12.4 & 212.2 & 12.8 \\
\hline
\end{tabular}

Notes: Adapted from Diabetes Res Clin Pract, 2, Saeedi P, Petersohn I, Salpea P, et al. Global and regional diabetes prevalence estimates for 2019 and projections for 2030 and 2045: results from the International Diabetes Federation Diabetes Atlas, 9th edition. 157, copyright (2019), with permission from Elsevier. ${ }^{62}$

countries do not have adequate infrastructure to treat this pandemic, meaning that diabetes is a serious concern for the future. ${ }^{28}$ Additionally, there is continuing emerging evidence that the prevalence and incidence of diabetes are likely higher in developing countries than currently documented due to undiagnosed diabetes. Studies conducted in Africa estimated that $18 \%$ of adult diabetes patients in Libya and $75 \%$ of adult diabetes patients in Tunisia were undiagnosed. ${ }^{68}$ Generally, the incidence of T2D continues to increase globally but at a steadier rate than in previous decades - this statement could be incorrect due to the uncertain global prevalence and incidence of undiagnosed diabetes. ${ }^{1}$ The rise in the prevalence and incidence of T2D throughout the $20^{\text {th }}$ and $21^{\text {st }}$ centuries globally currently classifies this disease as a global pandemic; the rise in this increase is generally thought to be due to an increase in the percentage of the global population being overweight accompanied by individuals adopting more sedentary lifestyles. $^{28}$

\section{Aetiology}

Many risk factors have been identified for T2D. ${ }^{3,69}$ The main risk factor is obesity as being obese can increase the risk of developing T2D by 90 -fold, and the majority of patients are overweight or obese. ${ }^{9,15}$ T2D risk is positively correlated with increasing BMI, and the risk rises exponentially with increasing BMI above $30 .{ }^{15}$ In Western countries, it has been estimated that $\sim 50 \%$ of T2D patients have a BMI of $>30$ and $30-40 \%$ have a BMI of $25-30 . .^{70}$ However, in some Asian countries, $\sim 50 \%$ of patients are not overweight. ${ }^{34,35}$ Surprisingly, underweight T2D patients have even been reported. $^{71,72}$ Increased deposition of fat in the ectopic regions of the body (particularly visceral fat) also increases T2D risk by more than double., ${ }^{3,73}$ Genetics are known to play an important role in T1D but this is also the case for T2D. ${ }^{37,74}$ The concordance rate between monozygotic twins with T2D is higher (around 70\%) compared with T1D (between 30 and 50\%), and additionally, the lifetime risk of individuals for developing T2D with one affected parent is $40 \%$ and almost $70 \%$ if both parents are affected - these observations suggest that genetics play an important role in T2D susceptibility. ${ }^{75,76}$ Concordance rates between dizygotic twins with T2D (between 20 and 30\%) are also higher than T1D (around 10\%). ${ }^{7,75,76}$ However, the highest odds ratio reported for a risk locus for T2D is 1.57 - this implies that more currently untested variants underlie T2D susceptibility. ${ }^{37}$ The increased risk of developing T2D for relatives of type 2 diabetic patients may be due to them sharing similar diets and lifestyles as well as genetics. ${ }^{7,77}$ 
One study demonstrated the importance of genetics in T2D susceptibility independently of the diet as there was a higher prevalence of the disease in the twin population compared to the singleton population ${ }^{77}$ - both populations had similar average BMI scores (26.1-26.3) with comparable standard deviation values (3.9-4.7). A cohort study found that alcohol and smoking also increased the risk of T2D, even in individuals who were classified as having low-risk diet and physical activity profiles. ${ }^{78}$

Interestingly, longitudinal studies have demonstrated that "psychological stress-related circumstances" (such as stressful working conditions) or mental health problems (such as depression) increase the risk of T2D. ${ }^{79}$ Globally, more males are diagnosed with T2D than females, and 14 million more men were diagnosed with this disease than the number of women in $2013 .{ }^{80}$ Evidence demonstrates that adult men are at higher risk of T2D than women, which is at least partly thought to be due to differential adiposity storage patterns in men. ${ }^{81}$ Studies have shown that men with T2D are more likely to develop CVD, but women with T2D who do develop CVD are more likely to have a worse prognosis, which is thought to be at least partly due to men being more likely to achieve medical targets in T2D (such as desirable plasma glucose control and blood pressure). ${ }^{80,81}$ The seasonality of T2D onset is not well studied, but a study conducted in Hungary found that seasonality followed a sinusoidal pattern; the peak month was March, and the trough month was August. ${ }^{82}$ A recent study also found that Chinese individuals born outside of summer had a $9 \%$ increased chance of developing adult T2D than individuals born in summer. ${ }^{83}$ Environmental changes over the last few decades could also play a role in T2D aetiology due to the use of pesticides, drugs and food additives in food processing and packaging. ${ }^{84}$ However, minimal evidence exists linking T2D aetiology to altered food processing/ packaging in recent decades. ${ }^{84}$ Some environmental pollutants have been shown to alter $\beta$-cell function, and the best example is bisphenol A (used in food container manufacturing), which can cause impaired beta-cell function in animals. ${ }^{85}$ However, it has not yet been determined whether prevailing environmental concentrations of these types of compounds can be a risk factor for diabetes. ${ }^{84}$ Associations have been made between certain pathogens and T2D risk: herpes simplex virus type 1 and hepatitis $\mathrm{C}$ virus are risk factors for T2D, although it is not clear how this can be mechanistically explained. ${ }^{86,87}$ However, it has been established that hepatitis $\mathrm{C}$ promotes insulin resistance in the liver, which is thought to increase T2D risk. ${ }^{88,89}$ If this is the case, then this implies that T2D manifestation can be initiated by insulin resistance in the liver alone, which therefore suggests that the liver may play a much more important role in T2D aetiology/pathogenesis than is currently thought.

\section{Pathogenesis}

The main focus here is the current and future therapeutic potential of modulation of GLP-1R activity in T2D, but the altered activity of hormones involved in metabolic homeostasis observed in T2D are also discussed, as well as other factors, such as the nervous system and uncoupling protein 2 (UCP2), to highlight the complexity of its pathogenesis.

Typically, T2D does not manifest acutely in individuals but is preceded by an insidious phase of prediabetes. ${ }^{90}$ Prediabetes is characterised by raised blood glucose levels (fasting plasma glucose levels of 6.1-6.9 mmol/L and two hours post glucose ingestion levels between $7.8-11 \mathrm{mmol} / \mathrm{L}$ ) due to declining islet beta-cell mass and function but not enough to warrant a diagnosis of T2D. ${ }^{90,91}$ Patients with prediabetes are asymptomatic but ${ }^{90} \sim 5-10 \%$ progress to T2D each year. ${ }^{90,91}$ Studies have demonstrated that weight loss and exercise can usually delay progression to T2D, or even prevent T2D from manifesting; lifestyle interventions reduce the risk of T2D progression in $40-70 \%$ of adults with prediabetes. ${ }^{91,92}$ It has been estimated that $\sim 70 \%$ of individuals with persistent prediabetes will eventually develop $\mathrm{T} 2 \mathrm{D}$, and that $>470$ million people will have prediabetes by 2030. ${ }^{91}$ Progressing to T2D is characterised by blood glucose levels of $>7 \mathrm{mmol} / \mathrm{L}$ during fasting and a two hours post glucose ingestion reading of $>11 \mathrm{mmol} / \mathrm{L} .^{90,93}$ The consensus in the literature is that T2D clinical manifestation is provoked by peripheral tissue insulin resistance, which is in turn, usually induced by obesity. 6,30,94 Obesity is characterised by elevated levels of cytokines and fatty acids, and it is thought that elevated levels of both provoke insulin resistance. ${ }^{94}$ However, it has still not been determined how this occurs mechanistically. ${ }^{95}$ Following the induction of insulin resistance, islet beta-cells can maintain normoglycaemia and metabolic homeostasis by increasing their secretion of insulin and/or by increasing their number. ${ }^{49,96,97}$ Obesity has been estimated to induce an $\sim 50 \%$ increase in islet betacell volume due to increased neogenesis. ${ }^{49}$ However, over time islet beta-cells are seemingly unable to compensate for the insulin resistance and their ability to secrete insulin decreases and many islet beta-cells undergo apoptosis, which is thought to be a result of a variety of stressors, such as increased insulin demand, oxidative, endoplasmic 
reticulum, dyslipidemic, amyloidal, and inflammatory stress. $^{98,99}$ The characteristic consequences of beta-cell pathology during T2D include impaired first-phase insulin secretion, ongoing insufficient insulin secretion to promote normolipidaemia (normal triglyceride levels, normal LDL cholesterol, and normal HDL-cholesterol) and normoglycaemia, dysfunctional glucose-sensing, and an increased proportion of proinsulin secretion. ${ }^{98}$

During prediabetes, pancreatic beta-cell number and function decline slowly, usually over a few years before T2D manifests. ${ }^{91}$ It has been reported that the decline in islet beta-cell function can begin an average of 12 years before T2D diagnosis. ${ }^{49}$ Interestingly, there have been reports of individuals who do not progress to T1D for $>10$ years despite persistent islet autoimmunity (slow progressors). ${ }^{100}$ This demonstrates that the rate of islet beta-cell death can vary greatly between individuals before T1D or T2D diagnosis, enabling some individuals to remain disease-free for longer, possibly by similar mechanisms. The gradual decline in islet beta-cell number and function results in insulin levels becoming too low to promote metabolic homeostasis and T2D results. ${ }^{49,91}$ Hyperproinsulinemia has been reported in both T2D patients and individuals with prediabetes, suggesting that defective islet beta-cell insulin processing is integral to the early stages of disease pathology. ${ }^{101,102}$ In healthy subjects, proinsulin accounts for up to $20 \%$ of the insulin levels in circulation, but in T2D this value can reach up to $50 \%$ and total proinsulin levels have shown to be higher in T2D patients than healthy controls, which suggests that dysfunctional processing and secretion of insulin by the remaining islet beta-cell population further contributes to the decreased insulin levels observed in this disease. ${ }^{101,103}$ Symptoms of T2D manifest when insulin levels become too low to prevent hyperglycaemia, which includes dehydration, excessive thirst, increased susceptibility to infection, excessive urination, lethargy and blurred vision. ${ }^{3,47}$ Chronic superphysiological glucose concentrations also

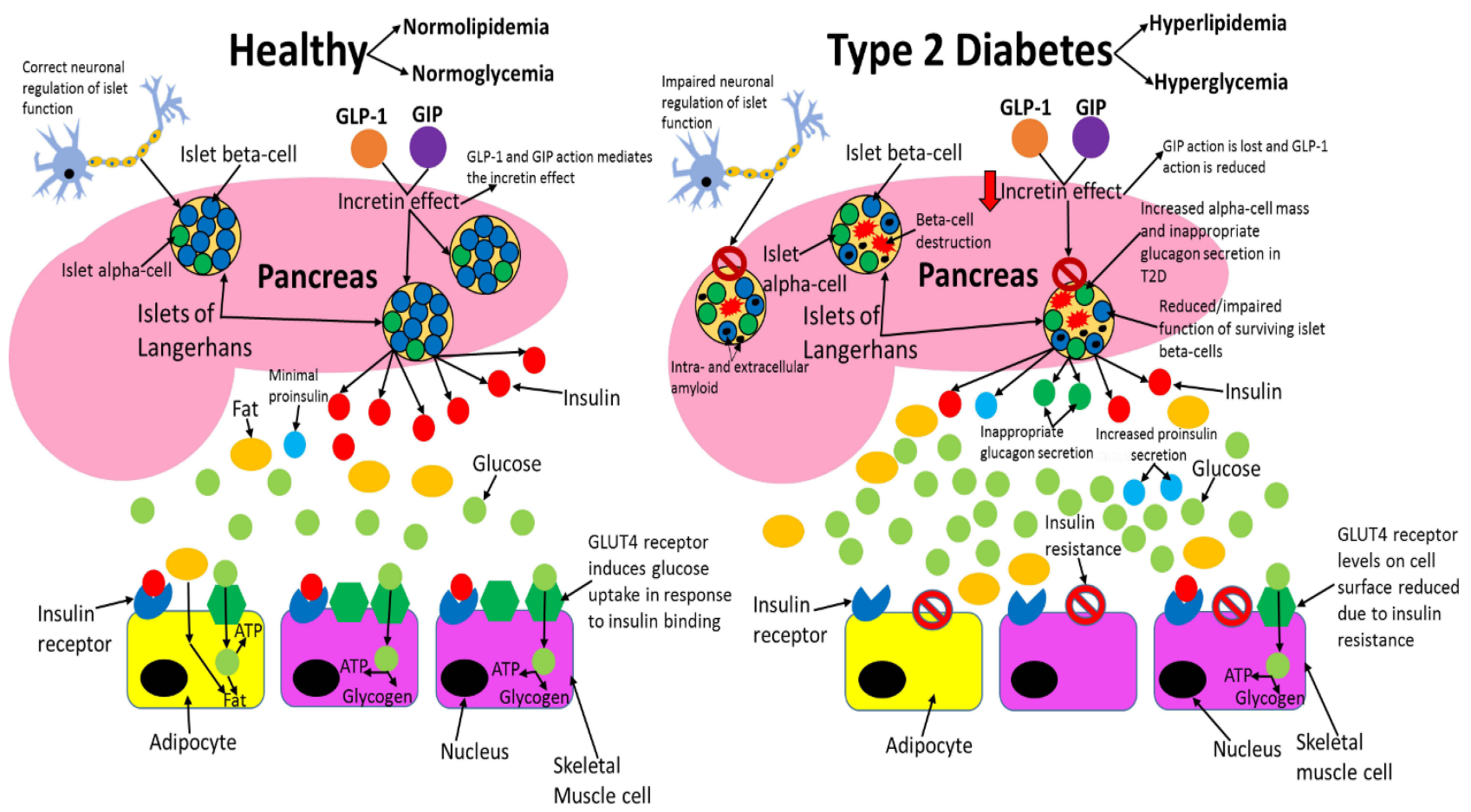

Figure 3 Comparing healthy and type 2 diabetic phenotypes. In healthy individuals, insulin is produced and secreted by beta-cells in the islets of Langerhans (found in the pancreas) when blood glucose levels are above $5 \mathrm{mM}$. Beta-cells are the most abundant cell type in the islets ( 70\%) and alpha-cells (responsible for glucagon secretion) are the second most abundant ( 20\%). Insulin then binds to the insulin receptor (IR), which allows uptake of glucose into tissues by inducing translocation of GLUT4 receptors from intracellular vesicles to the plasma membrane. GLUT4 is primarily found in adipose tissue as well as skeletal and cardiac muscle. Glucose is then transported into the cell by GLUT4 from the bloodstream and catabolised in the cell for ATP production, which provides the fuel for intracellular processes, or glucose can be converted to either glycogen or fat for fuel storage after uptake. In individuals with T2D, many islet beta-cells have undergone apoptosis and the function of the surviving cells is impaired, which results in markedly reduced insulin levels in circulation. Additionally, peripheral tissue insulin resistance impairs the action of insulin, resulting in reduced uptake of glucose from circulation, as a result of decreased GLUT4 translocation to the membrane. Reduced insulin levels and action result in hyperglycaemia and hyperlipidaemia, and subsequent T2D associated symptoms manifest in the patient. Inappropriate glucagon secretion, diminished incretin hormone action, increased proinsulin secretion, impaired pancreatic islet neural regulation, and islet amyloid deposition are also characteristic of T2D. This figure and information in its legend are with data adapted from these studies. $^{105,106,111,326-328}$ 
negatively affect the ability of islet beta-cells to secrete insulin, which further worsens hyperglycaemia and promotes T2D. ${ }^{104}$ Peripheral tissues dependent on insulin to uptake nutrients from circulation can no longer do so to the same extent as before T2D. ${ }^{47,105}$ Hence, peripheral tissues adapt to rely on fat and catabolism of intracellular stored macromolecules, such as proteins, to generate the ATP they need. ${ }^{3,32}$ This results in weight loss (due to the breaking down of macromolecules), excessive eating and lethargy. ${ }^{3,32,105,106}$ Figure 3 compares healthy and type 2 diabetic phenotypes.

It has been demonstrated that the insulin released during the early and late postprandial period by T2D patients is $\sim 25$ and $40 \%$, respectively, of that produced by healthy individuals with a similar BMI. ${ }^{107}$ Fasting insulin levels in T2D patients are $~ 50 \%$ of that observed in healthy subjects with a similar BMI, ${ }^{107}$ demonstrating that $\mathrm{T} 2 \mathrm{D}$ has a more significant effect on impairing the insulin response during the postprandial period in the early stages of the disease. Interestingly, insulin levels are higher in diabesity patients than in normal-weight T2D subjects, ${ }^{21}$ implying that the islet beta-cell pathology is more severe in the latter group and that peripheral tissue insulin resistance contributes more to the disease phenotype in overweight T2D patients. Although it is known that the postprandial insulin response is similarly impaired in overweight and normal-weight T2D patients (determined by measuring the increase in insulin levels in comparison to fasting levels), absolute insulin levels are higher in overweight patients compared to disease-free normal-weight subjects, during both fasting and the postprandial period, ${ }^{21}$ which strongly suggests that in overweight T2D subjects peripheral tissue insulin resistance is central to the clinical manifestation of this disease. T1D is more "severe" than T2D, as $~ 90 \%$ of beta-cells are destroyed by autoimmunity, which results in vastly reduced insulin levels. ${ }^{108}$ Insulin treatment is essential for survival in T1D, as the absolute insulin deficiency results in the induction of ketoacidosis in an attempt to provide tissues dependent on insulin with adequate fuel. ${ }^{106}$ Ketoacidosis is necessary during starvation to provide fuel to tissues when there is no adequate nutrient supply. ${ }^{109}$ However, prolonged ketoacidosis is fatal due to the lowering of blood $\mathrm{pH}$, which is why T1D is considered to be a deadlier form of diabetes than type 2, although a subset of T2D patients can develop ketoacidosis. ${ }^{106,110}$ Although ketoacidosis is largely considered to be a pathological response, fatality is inevitable under these circumstances, as impaired ATP production is fatal. ${ }^{32,106,111}$
It has been firmly established that T2D is caused by the dysfunctional exocrine function of the pancreas, and peripheral insulin resistance is a requisite precursor for the development of this disease. ${ }^{105,112}$ Skeletal muscle insulin resistance has been associated with intracellular lipid accumulation. ${ }^{94}$ However, endurance-trained insulin-sensitive athletes may have as much, if not more, lipid content in their skeletal muscles as insulin-resistant T2D patients. ${ }^{13,114}$ Thus, it seems that a high rate of ATP turnover in athletes prevents skeletal muscle insulin resistance, but a decreased demand for ATP in typically sedentary obese individuals with and without T2D induces insulin resistance. ${ }^{94}$ It is reasonable to assume that insulin resistance in obese individuals without T2D may be desirable in skeletal muscle that has an abundance of stored nutrients and a low rate of ATP turnover, as the tissue's ATP demands are met and hypertrophy would result from any further nutrient uptake. However, it is correct to state that peripheral tissue insulin resistance is pathological in T2D as it contributes to the disease phenotype ${ }^{30,47}$ The insulin resistance in peripheral and hepatic tissues is present in obese and non-obese T2D patients, but not to the same extent. ${ }^{115}$ Studies have shown that BMI is correlated to the degree of insulin resistance in Korean patients, even within the non-obese range. ${ }^{116}$ Weight loss has been shown to decrease insulin resistance in both obese T2D patients and obese T2D-free individuals, suggesting that insulin resistance is related to increased nutrient storage. ${ }^{117}$ Interestingly, insulin resistance is also observed in a proportion of T2D-free individuals within the normal weight range (BMI $>18.5-25$ ) and is reasonable to assume that this is pathological as, in theory, peripheral tissues are not at risk of hypertrophy due to insulin action and require continual nutrient influx to maintain ATP supply to meet their metabolic demands, as these individuals are not overweight and do not have an abundance of stored nutrients within their tissues. ${ }^{23,118}$ One study demonstrated that normalisation of both beta-cell function and hepatic insulin sensitivity in T2D patients was achieved by 8 weeks of dietary energy restriction alone $(600 \mathrm{kcal}$ a day), accompanied by decreased pancreatic and liver triacylglycerol stores. ${ }^{119}$ After cessation of the low-calorie diet and returning to a normal diet for 12 weeks, 7 out of 10 participants remained in remission. Given that lipid accumulation both in and around the pancreas is associated with beta-cell pathology and confers T2D risk, ${ }^{120}$ the observation that T2D remission was accompanied by a decrease in pancreatic fat content suggests that increased pancreatic fat storage is an important component of T2D aetiology/pathogenesis. In healthy individuals, insulin sensitivity varies naturally, 
which is thought to be beneficial for promoting metabolic homeostasis. ${ }^{121-123}$ The general consensus in the literature is that chronic insulin resistance, induced by obesity, is thought to be pathological overall in the metabolic syndrome, which is a syndrome characterised by a range of disorders that collectively predispose risk to $\mathrm{T} 2 \mathrm{D}$ and cardiovascular pathology. ${ }^{94}$

A study examined pancreatic tissue from 124 autopsies: 91 obese cases $\left(\mathrm{BMI}>27 \mathrm{~kg} / \mathrm{m}^{2} ; 41\right.$ with $\mathrm{T} 2 \mathrm{D}, 15$ with impaired fasting glucose [IFG], and 35 non-diabetic subjects) and 33 lean cases (BMI $<25 \mathrm{~kg} / \mathrm{m}^{2} ; 16$ types 2 diabetic and 17 non-diabetic subjects. ${ }^{124}$ Obese humans with IFG and T2D had a 43 and $60 \%$, respectively, decrease in islet beta-cell volume compared to obese nondiabetic individuals. This decrease in islet beta-cell volume in obese T2D patients was found to be due to a decreased number of islet beta-cells, and interestingly the volumes of these cells were found to be similar between non-diabetic obese and diabetic obese individuals. The frequency of islet beta-cell replication was found to be similar between obese nondiabetic and T2D patients. However, it was estimated that there was an $\sim 3$-fold increase in apoptosis in obese T2D individuals. The majority of diabesity cases were found to have islet amyloid in their islets $(\sim 80 \%)$, whereas only $\sim 10 \%$ of obese individuals without T2D had amyloid deposits. Amyloid deposits had a similar prevalence in IFG obese individuals to that observed in T2D-free obese individuals. Islet beta-cell dysfunction in diabesity patients is therefore attributed to increased rates of apoptosis and amyloid deposition, and not to rates of replication and new islet formation as this is similar to non-diabetic controls.

Currently, why individuals of normal weight develop T2D is largely elusive, but pathogenesis appears to be similar to diabesity patients, although there are some striking differences according to the study conducted in 2003. ${ }^{124}$ Islet beta-cell mass was shown to be decreased in lean T2D patients by $\sim 41 \%$ in comparison to lean T2Dfree controls, due to a decreased number of these cells. Islet amyloid was present in $88 \%$ of lean T2D patients but only $13 \%$ of lean healthy controls. New islet formation and beta-cell replication were similar between lean T2D patients and lean T2D-free individuals, but the frequency of beta-cell apoptosis was increased by 10 -fold in lean T2D patients. Hence, lean T2D is also characterised by an increased rate of beta-cell apoptosis with a normal, but too slow a replication rate of these cells to restore their numbers to normal levels. It is not known if islet amyloid deposits are produced due to the chronic hyperglycaemia associated with this disease. It is also not clear if these deposits affect the prognosis of T2D. ${ }^{124,125}$

What has become clear is that islet amyloid deposits are very likely to be directly involved in the pathogenesis of T2D, although it has not been well established how mechanistically. ${ }^{124,126,127}$ Islet amyloid polypeptide (IAPP) (more commonly known as amylin) is co-secreted with insulin from islet beta-cells in healthy individuals during the fed state and acts as an anti-hyperglycaemic agent by decreasing gastric motility, promoting satiety and inhibiting glucagon secretion. ${ }^{128}$ The amylin analogue pramlintide is used for T1D and T2D treatment adjunct with insulin therapy in the USA if patients are not achieving adequate glucose control despite optimal insulin therapy. ${ }^{129}$ Virtually all T2D patients have IAPP-containing plaques in their islets. ${ }^{128}$ IAPP appearance was first noticed in the 1980s to correlate with hyperglycaemia in primates. ${ }^{130}$ Several lines of transgenic mice have been generated which produce human IAPP, and they were shown to have islet amyloid accumulation, increased beta-cell apoptosis, decreased beta-cell mass, impaired glucose tolerance, and some developed diabetes. ${ }^{128}$ The current consensus in the literature is that extracellular plaques of IAPP are not causative of beta-cell pathology, but rather intracellular oligomers of this protein observed in T2D patients (but not in T2D-free individuals) produce the cytotoxic effects. ${ }^{128,131}$ It has been elucidated that beta-cells are usually protected from IAPP oligomers by autophagy processes, so it seems that these processes are defective in prediabetes and T2D, which is likely pivotal for the pathogenesis of T2D. ${ }^{128,132}$ Both T1D and T2D manifest due to beta-cell apoptosis and the activated apoptotic pathways are thought to share similarities, but the aetiology of apoptosis is different between the two diseases. $^{133}$

Although obesity is a major risk factor for T2D, paradoxically overweight and obese patients have been reported to have had a lower mortality rate than normalweight patients due to cardiovascular pathology associated with T2D and this phenomenon was termed "the obesity paradox". 134,135 Furthermore, weight loss has been reported to increase mortality and morbidity in T2D and cardiovascular co-morbidity patients. ${ }^{136}$ Additionally, a study found that the risk of amputation in non-elderly diabetic men decreased with increasing body weight. ${ }^{137}$ Peripheral and hepatic insulin resistance is present in obese and non-obese T2D patients, but not to the same 
extent in non-obese subjects. ${ }^{115}$ Studies have shown that BMI is correlated to the degree of insulin resistance in Korean patients, even within the non-obese range. ${ }^{116}$ Interestingly, a study from India found that fasting and postprandial plasma glucose levels were higher in T2D patients with a BMI $<18.5 .^{71}$ The aetiology of $\mathrm{T} 2 \mathrm{D}$ patients with a BMI of under 25 is thought to be largely attributed to beta-cell dysfunction, which is thought to be greater than that observed in obese patients. ${ }^{71}$ A study conducted in Chicago found that glycaemic control was worse in T2D patients with a BMI of 18-25 than in individuals with a BMI of over 25 , but these patients had lower insulin resistance. ${ }^{138}$ The study found that smoking and alcoholism confer an increased risk for non-obese T2D than obese T2D, chronic alcoholism induces islet beta-cell dysfunction and apoptosis. ${ }^{139}$ Strikingly, T2D has been shown to manifest in non-overweight individuals in the absence of insulin resistance, although this is thought to be rare. ${ }^{140}$ This implies that pancreatic exocrine dysfunction can induce T2D independent of both insulin resistance and a BMI $>25$. Whether or not weight loss in T2D patients with a BMI of under 25 improves prognosis has not been determined. ${ }^{71}$ It has been well established that Asians are at increased risk of non-overweight T2D. In Japan, more than $50 \%$ of patients have a BMI of under 25 , but they have more abdominal fat at the equivalent BMI to Caucasians. ${ }^{35,71}$

T2D is not only attributed to beta-cell dysfunction but also alpha-cell dysfunction. ${ }^{141,142}$ Pathologically high plasma concentrations of glucagon are observed in T1D, advanced T2D, and diabetic ketoacidosis. ${ }^{142}$ It is well established that islet alpha-cell populations increase in T1D, whereas in T2D, patients can have alpha-cell numbers increased or unaltered. ${ }^{141}$ Paradoxically, T2D patients have increased levels of glucagon during the postprandial period, leading to augmentation of postprandial hyperglycaemia associated with impaired insulin secretion. ${ }^{142,143}$ Hence, it is correct to state that the behaviour of diabetic islet alphacells is different for healthy individuals, as an abundance of nutrients during the postprandial period prevents glucagon secretion in healthy individuals by raising ATP levels (as discussed earlier in this review). ${ }^{144}$ Therefore, in T2D, the islet alpha-cells must have altered biochemical pathways inducing altered mechanisms of glucagon secretion. Studies have estimated that postprandial hyperglucagonemia may contribute to $\sim 50 \%$ of the pathological increase in plasma glucose levels after glucose ingestion. ${ }^{145-147}$ Interestingly, fasting hyperglucagonemia has been reported in some T2D patients with moderate glycaemic control, and glucagon levels are $\sim 50 \%$ higher in diabetic subjects. ${ }^{146,148}$ The dysfunctional glucagon secretion in T2D could be due to the decreased insulin levels, as insulin suppresses alpha-cell function. ${ }^{105,149}$ However, islet alpha-cells should have their exocytotic function suppressed during the fed state, as intracellular ATP levels should be high as a result. ${ }^{144}$ However, studies have demonstrated that blocking insulin signalling in islet alpha-cells in mice results in defective suppression of the fed state on glucagon secretion, highlighting the pivotal role of insulin in the regulation of the alpha-cell. ${ }^{105,149}$

Interestingly though, dysregulated glucagon secretion is not significant in adolescents with T2D. ${ }^{150}$ There is some evidence that the liver is more sensitive to glucagon in T2D patients, further exacerbating the hyperglycaemia, although there have been conflicting findings with this observation. ${ }^{142}$ Both T1D and T2D induce major changes in the structure of animal and human pancreatic islets. ${ }^{141}$ The changes in the islets of T2D patients have been postulated to induce altered signalling within the islets, which contributes to the phenotype of this disease. ${ }^{141}$ The increase in alpha-cell mass likely results in increased alpha-alpha cell contacts at the expense of beta-beta cell contacts, which may alter intra-islet signalling. ${ }^{151}$ The amyloid deposits in the islets have also been postulated to alter intra-islet signalling. ${ }^{124}$ Islet alphacells are usually found in the periphery of the islets, but in diabetes, many of the alpha-cells are found in the centre as well; in rodent models, this can be reversed by restoring normoglycaemia. ${ }^{141,152}$ The proportion of delta-delta and delta-alpha cell contacts also increases, likely as a result of the beta-cell destruction in T2D. ${ }^{151}$ In T2D rodent models, delta-cells were reported to migrate from the periphery of the islets to the centre. ${ }^{152}$ How the morphology, migration and number of islet gamma- and epsilon-cells are altered in T2D is not well studied. ${ }^{141}$ Although there have been reports suggesting that the delta-cell number is increased in diabetes, other studies suggested that the number of these cells was unaltered in patients' islets. ${ }^{153,154}$ Interestingly, a recent study found that the delta-cell number and volume were decreased in baboons with impaired fasting glucose by $\sim 41 \%$, and this was due to apoptosis. ${ }^{155}$ Evidence is emerging that a subset of islet beta-cells may undergo conversion into other endocrine islet cell types in T2D, which may account for the increased alpha-cell population observed in some T2D patients and their distorted insulin-to-glucagon ratios. ${ }^{156}$ Figure 4 compares pancreatic islet architecture between healthy and type 2 diabetic individuals. 


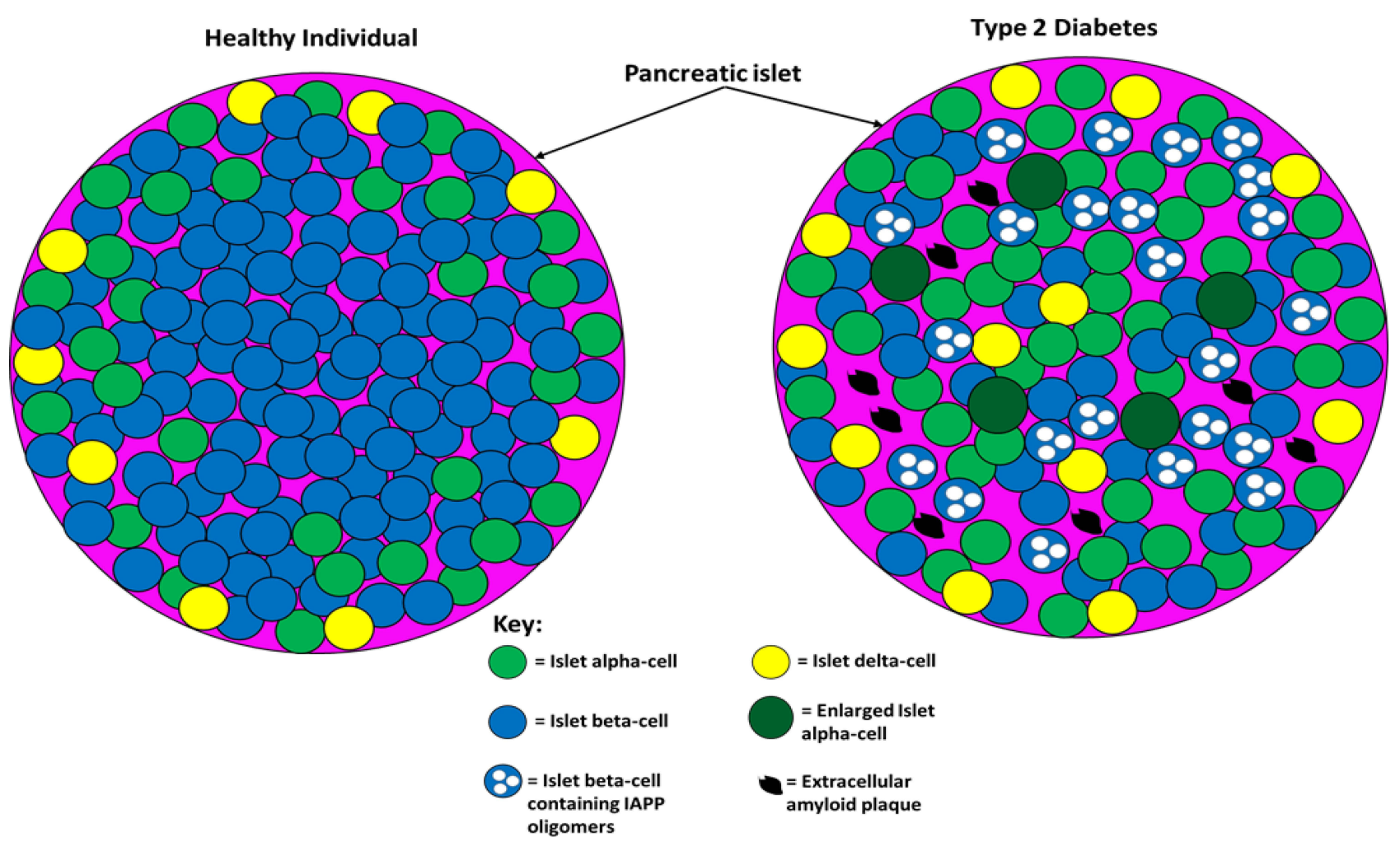

Figure 4 The difference between pancreatic islet architecture in healthy individuals and individuals with T2D. In healthy individuals, beta-cells are situated centrally and peripherally and are the most abundant cell type ( $70 \%$ ). Non-beta cells are found in the periphery of the islets and constitute $\sim 30 \%$ of the cell population ( $20 \%$ alpha-cell and $10 \%$ other cell types). Islet architecture is altered in T2D with a greatly diminished population of beta-cells, more alpha-cells, more delta-cells, migration of alpha- and delta-cells into the centre, extracellular amyloid plaque deposits, intracellular IAPP oligomers in beta-cells, and enlarged alpha-cells. The altered architecture in T2D produces different intra-islet paracrine signalling which impairs metabolic homeostasis. This figure and information in its legend are with data adapted from Brereton et al. ${ }^{141}$

The incretin effect is greatly diminished in T2D where GLP-1 and GIP account for $<20 \%$ of the insulin release after glucose ingestion in patients. ${ }^{157}$ The current consensus in the literature is that GLP-1 and GIP circulation levels are comparable between T2D patients and nondiabetic controls in response to nutrient challenges. ${ }^{158}$ Hence, the diminished incretin effect is due to dysfunctional betacells. ${ }^{159}$ GLP-1 infusions can normalise blood glucose levels, and GLP-1 analogues are used to treat T2D. ${ }^{3}$ However, GIP action is lost in T2D and even infusions of GIP that result in supraphysiological concentrations fail to elicit a significant insulin secretory response in T2D patients. ${ }^{160}$ Studies have demonstrated that intensive insulin administration treatment results in improved insulin secretion from islet beta-cells after GIP infusion. ${ }^{161,162}$ It has been established that hyperglycaemia induces downregulation of GIPR expression in beta-cells, so it is plausible that in this study GIPR expression may have been upregulated in these cells due to reducing plasma glucose levels. ${ }^{159}$ Therefore, although it is clear that GIP action is lost in T2D it could still have future therapeutic potential for treating T2D. GIP action in prediabetes has not been established to date, so it is currently not clear if impaired GIP action is involved in T2D pathogenesis or manifests post-diagnosis.

Additionally, pancreatic neuronal activity is also impaired in T2D. ${ }^{163}$ The pancreas is richly innervated by the sympathetic and parasympathetic nervous system. ${ }^{164}$ The cephalic phase of insulin secretion is lost in T2D and glucagon secretion is not suppressed during the fed state. ${ }^{163}$ This implies that if the nervous system does suppress glucagon secretion in an insulin-independent manner during the fed state in healthy individuals then this is absent in T2D. The parasympathetic activity also plays a role in stimulating betacell proliferation in adult animals, which is at least partly regulated by acetylcholine binding to muscarinic receptors on beta-cells. ${ }^{164,165}$ The neuronal activity has also been postulated to modulate the alpha-cell number. ${ }^{163}$ This demonstrates that the nervous system is needed for both islet function and islet-cell proliferation when appropriate. Parasympathetic and sympathetic nervous systems are known to influence endocrine pancreas postnatal 
development and plasticity in adult animals. ${ }^{163}$ Dysfunctional regulation of the pancreatic islet by the nervous system contributes to the clinical phenotype of T2D, but whether or not this occurs before or after T2D diagnosis remains elusive, although it is reasonable to assume that it does, influencing the altered islet architecture observed in T2D. ${ }^{141,163}$ It has been confirmed that glucose-sensing cells in the central nervous system (CNS) are excited by either a rise (glucose excited neurons) or decrease (glucose inhibited neurons) in plasma glucose levels, and it has been postulated that these neurons regulate the sympathetic and parasympathetic branches of the autonomic nervous system, which are known to influence insulin and glucagon secretion. ${ }^{163}$ It is likely that the pathology of these central neurons contributes to the T2D phenotype and may partly, or even exclusively, induce T2D pathogenesis by currently unknown mechanisms. One study clearly demonstrated the importance of the nervous system's ability to regulate islet beta-cell number and function: GLUT2 neuronal knockout mice exhibited impaired glucose-stimulated insulin secretion (GSIS), hyperglucagonemia, and decreased beta-cell proliferation and mass in comparison to controls. ${ }^{166}$ Importantly, treatment of the control mice with the ganglionic blocker chlorisondamine reduced the proliferation rate of beta-cells by $50 \%$, but in GLUT2 neuronal knockout mice, chlorisondamine did not further reduce the proliferation rate. This study clearly shows that the activity of the neuronal glucose-sensing cells and islet alpha- and beta-cells function synergistically to promote appropriate plasma insulin and glucagon levels - this synergism is known to be dysfunctional in T2D. ${ }^{163}$ Figure 5 summarises the differential neural regulation of the pancreas between healthy and type 2 diabetic individuals.

The notion that glucolipotoxicity conditions in circulation (associated with obesity) induces islet beta-cell dysfunction has been an attractive area of research. ${ }^{167} \mathrm{~A}$ number of in vitro studies, using insulin-secreting cells
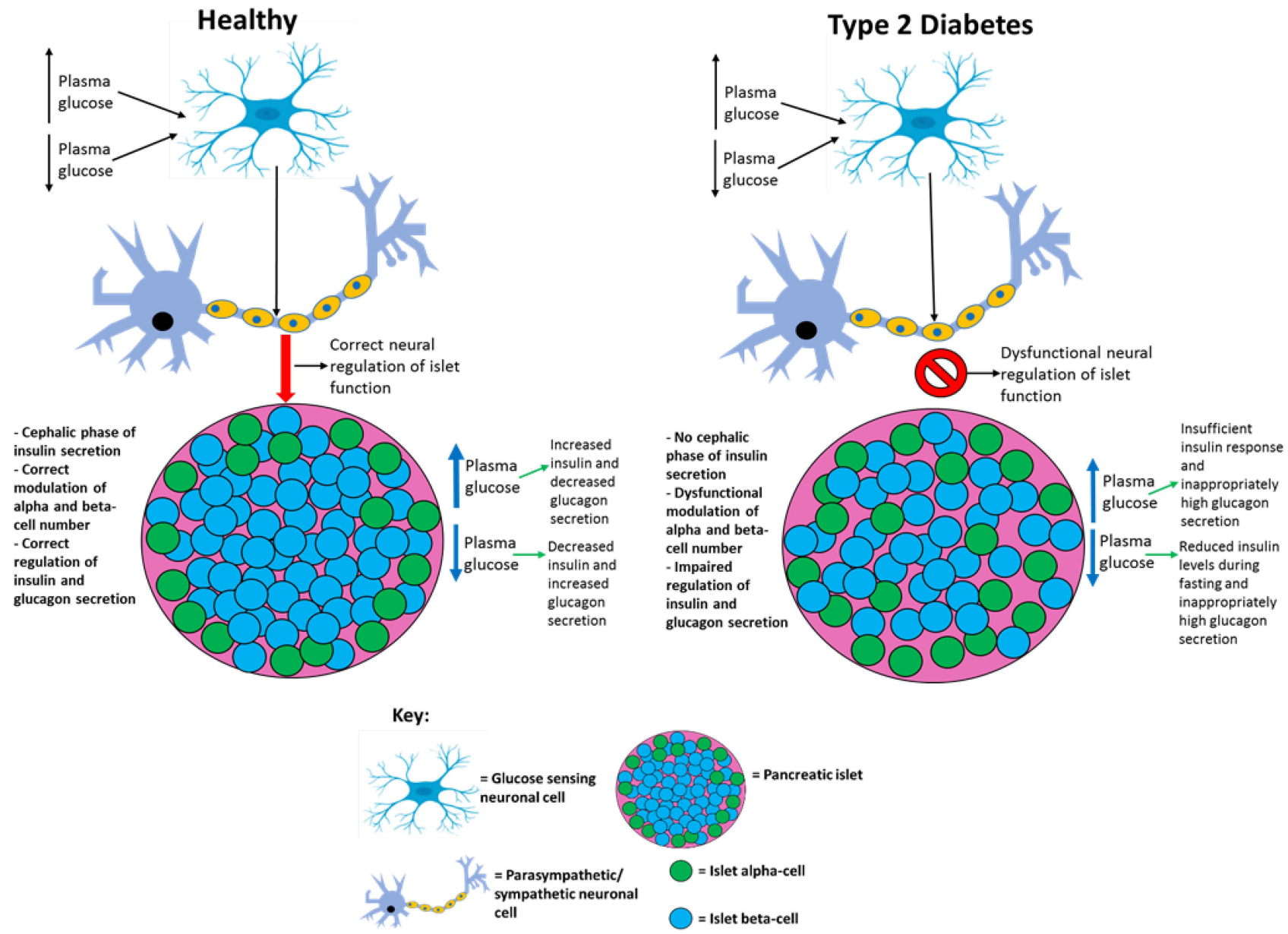

Figure 5 Comparing the differential neural regulation of pancreatic islets in healthy and type 2 diabetic individuals. T2D patients do not exhibit the cephalic phase of insulin secretion and based on the findings from studies it is possible that dysfunctional neuronal regulation of pancreatic islets contributes to the impaired GSIS, hyperglucagonemia, and decreased beta-cell proliferation and mass observed in this disease. This figure and information in its legend are with data adapted from these studies. ${ }^{163,166}$ 
and isolated islets, have found that exposure of islet betacells to glucolipotoxicity conditions results in impaired GSIS, impaired insulin expression, and cell death by apoptosis. ${ }^{167,168}$ Importantly, several of these studies have demonstrated that fatty acids do not induce betacell dysfunction in the absence of elevated glucose, highlighting that fatty acids and glucose are not cytotoxic independently. ${ }^{168,169}$ The application of these experiments to in vivo situations is questionable as it has been demonstrated that non-diabetic obese subjects exhibit increased insulin secretion and an increase in beta-cell number and mass, and islet amyloid deposits are rare in these individuals as aforementioned in this review. Thus, it is reasonable to assume that glucolipotoxicity diets do not induce beta-cell pathology before the prediabetes phase and preT2D diagnosis. However, in vivo studies on healthy rats have demonstrated similar findings to that of in vitro when studying the effects of glucolipotoxicity on insulin secretion. ${ }^{170}$ Given that weight loss and a controlled diet improve glycaemic control in overweight T2D patients, it seems likely that glucolipotoxicity diets worsen the disease phenotype post-diagnosis. ${ }^{12}$ However, attributing T2D pathogenesis to glucolipotoxicity diets does not explain how individuals with a BMI of under 25 develop this disease. To further complicate the issue, data obtained from humans in lipid infusion studies have produced conflicting results as to whether or not glucolipotoxicity conditions impair or boost insulin secretion. ${ }^{171}$

Studies conducted by Affourtit and colleagues attempted to explain mechanistically how glucolipotoxicity conditions might impair GSIS. ${ }^{172,173}$ Interestingly, they have found that the impaired GSIS observed during in vitro studies involving exposing pancreatic beta-cell line INS-1E to glucolipotoxicity conditions (palmitate + high glucose) was found not to be dependent on mitochondrial dysfunction. ${ }^{173}$ From the observations of this study, it seems that whatever role glucolipotoxicity may have in impairing GSIS in T2D is disconnected from mitochondrial dysfunction, which is surprising given the role of the mitochondria in ATP and reactive oxygen species (ROS) generation needed for both phases of insulin secretion. ${ }^{174,175}$ The concept of "beta-cell rest" to treat T2D has emerged given the observations from both in vitro and in vivo studies. ${ }^{98}$ Isolating islets from diabetic rodents and exposing them to euglycemic conditions for 8-12 $\mathrm{h}$ resulted in the return of both normal insulin secretory capacity and betacell function. ${ }^{89}$ Furthermore, bariatric surgery (which results in reduced food intake post-surgery) and low-calorie diets can induce T2D remission, which can be viewed as in vivo evidence that reducing demand on the beta-cell (ie, "beta-cell rest") improves endogenous insulin secretory capacity. ${ }^{98}$ Administering diazoxide (which inhibits endogenous insulin secretion and therefore induces a degree of transient "beta-cell rest") to T2D patients resulted in a 280 and $500 \%$ increase in insulin levels over baseline after stimulation tests in T2D low and high beta-cell reserve groups, respectively. ${ }^{176}$ This study provides in vivo evidence that "beta-cell rest" can at least temporarily allow insulin secretory capacity recovery, and in vitro studies examining the effect of diazoxide on diabetic human islets produced similar findings. ${ }^{177}$ Another in vivo study found comparable effects on improved beta-cell function following short-term continuous subcutaneous insulin infusion in T2D patients that were uncontrolled by conventional oral therapies. ${ }^{88}$ This resulted in near euglycemia being achieved in the participants and glycaemic control was improved after cessation of insulin infusion. Islet beta-cell function tests conducted 2 days after cessation of insulin infusion revealed that the peak insulin response was notably improved. Reducing demand on the islet beta-cells by improving insulin sensitivity through weight loss and/or pharmacological means has been reported to improve T2D prognosis and delay/prevent pre-diabetic individuals progressing to T2D, suggesting that inducing "beta-cell rest" to even a degree alleviates the pathology that is associated with this disease. ${ }^{92,98}$ Despite the evidence generated by both in vitro and in vivo studies supporting that glucolipotoxicity impairs beta-cell function, these findings likely do not apply to non-obese/overweight diabetic individuals.

$\mathrm{UCP} 2$ is a protein present in the beta-cell mitochondria inner membrane, which was postulated to dampen GSIS by dissipating mitochondrial proton motive force as heat (due to its analogy with UCP1), thereby reducing the efficiency of ATP production. Approximately $20 \%$ of the proton leak in beta-cells is thought to occur due to the presence of UCP2.$^{178,179}$ The detection of this protein in islet beta-cells is puzzling as sufficient ATP levels are vital for the correct function of these cells, and studies have shown that overexpression of UCP2 in isolated beta-cells impairs GSIS. ${ }^{180-182}$ It has been shown that a high proton motive force (PMF) results in the production of ROS, and as UCP2 activity can lower the PMF by increasing proton leak, it can then lower intracellular ROS, as well as increased production of ROS, is thought to be at least partly dependent on an increased mitochondrial PMF in islet beta-cells. ${ }^{180,183-185}$ As ROS are largely thought to be 
cytotoxic molecules, it was assumed that the fact UCP2 attenuates ROS production could mean that this protein has a protective role in the cell. ${ }^{32,185,186}$ This notion had led to a debate as to whether or not the presence of UCP2 in these cells is pathological given its ability to decrease ATP production or beneficial given its ability to regulate levels of ROS. ${ }^{179}$ However, it has been demonstrated that UCP2 does not appear to regulate GSIS, as palmitate + high glucose impaired GSIS to the same extent in INS-1E cells with and without UCP2 (UCP2 was knocked down via RNAi). ${ }^{187}$ UCP2 knockdown was shown to only minimally and not significantly increase the coupling efficiency $(<10 \%)$ when INS-1E cells were exposed to $28 \mathrm{mM}$ glucose and palmitate. Oddly, it was found that palmitate with $28 \mathrm{mM}$ glucose dampened the coupling efficiency in UCP2 depleted cells more than in UCP2 positive cells. Based on these findings, it appears that UCP2 is not involved in either GSIS or regulation of the efficiency of mitochondrial energy transduction in INS-1E cells in vitro.

It has been postulated that UCP2 may not be an uncoupling protein despite its analogy with UCP1, but it likely functions as a carbon skeleton exporter from the mitochondrial matrix, and there is experimental evidence for this. ${ }^{188}$ To further complicate the role of UCP2 in GSIS, in vivo studies have found that global UCP2 knockout mice exhibit either improved glucose tolerance and GSIS, or unaltered glucose tolerance and impaired GSIS depending on their genetic background. ${ }^{179,187}$ Beta-cell specific ablation of UCP2 produces glucose-intolerant mice that have increased proton gradients across their inner mitochondrial membranes (suggesting that this protein does mediate premature proton leak), but oddly, ATP levels and respiration rates are unaltered. ${ }^{184}$ The enhancement of GSIS in the beta-cells of these mice was suggested to be due to the increased ROS levels associated with UCP2 knockout. The glucose intolerance observed in these mice was thought to be due to a greater alpha-cell area and higher glucagon content in the islets, and glucagon was secreted by alpha-cells even during high plasma glucose, suggesting that UCP2 presence in beta-cells is necessary to maintain appropriate alpha-cell behaviour during the fed state. Affourtit and colleagues have demonstrated that mitochondrial function plays an important role in cell viability, as palmitate-induced mitochondrial superoxide formation results in reduced viability; this can be prevented by co-exposure to palmitoleate (an unsaturated fatty acid). ${ }^{172}$ Hence, mitochondrial activity during glucolipotoxicity may play an important role in beta-cell survival in vitro and in vivo. A critical gap in
$\mathrm{UCP} 2$ research is that studies have not taken into account the glutathionylation state of this protein. ${ }^{189}$ Glutathionylation and deglutathionylation are thought to deactivate and activate proton leak, respectively. ${ }^{189,190}$ There is evidence that this post-translational modification is regulated by intracellular ROS levels (increased ROS causes deglutathionylation and decreased ROS does the opposite); hence, it is now relatively well established mechanistically how ROS levels can regulate themselves in these cells. ${ }^{189,190}$ It is important that future studies examining UCP2 activity and levels also monitor glutathionylation status as well, which could explain any unexpected phenotypes. Currently, the role of UCP2 in healthy individuals and T2D patients is unclear, but if this protein behaves pathologically in T2D by inducing decreased ATP production, then this could explain the dysfunctional insulin secretion observed. Figure 6 proposes how UCP2 activity and quantity alter in T2D.

Glucolipotoxicity conditions induce beta-cell dysfunction in vitro but it is not clear if this is the case in vivo due to the reasons aforementioned. Additionally, GSIS defects in vitro do not appear to be attributable to the mitochondria, but this has not been confirmed in vivo, and the role of UCP2 and its glutathionylation state in GSIS in vivo is currently a source of confusion.

\section{Extrapancreatic Tissues Involvement in T2D: Aetiologyl Pathogenesis and Post-Diagnosis Complications}

Whilst it is firmly established that pathological pancreatic function and peripheral tissue insulin resistance are central to T2D aetiology/pathogenesis, there is increasing evidence that other extrapancreatic pathologies may contribute..$^{30,191,192}$ The diabetic phenotype includes systemic pathology, such as in the CVS, skeletal muscle, nervous system (central and peripheral), skin, kidneys and gastrointestinal tract (GIT), which further exacerbates the disease phenotype and/or induces post-diagnosis complications. ${ }^{30,193-195}$ However, research evidence over the last few decades suggests that some of these pathologies manifest during the prediabetic phase and is possibly therefore involved in both the disease pathogenesis and aetiology. ${ }^{191,192}$ For example, skin and liver pathology can manifest during the prediabetic stage, and even in individuals with metabolic syndrome before islet beta-cell dysfunction occurs. ${ }^{191,196}$ 

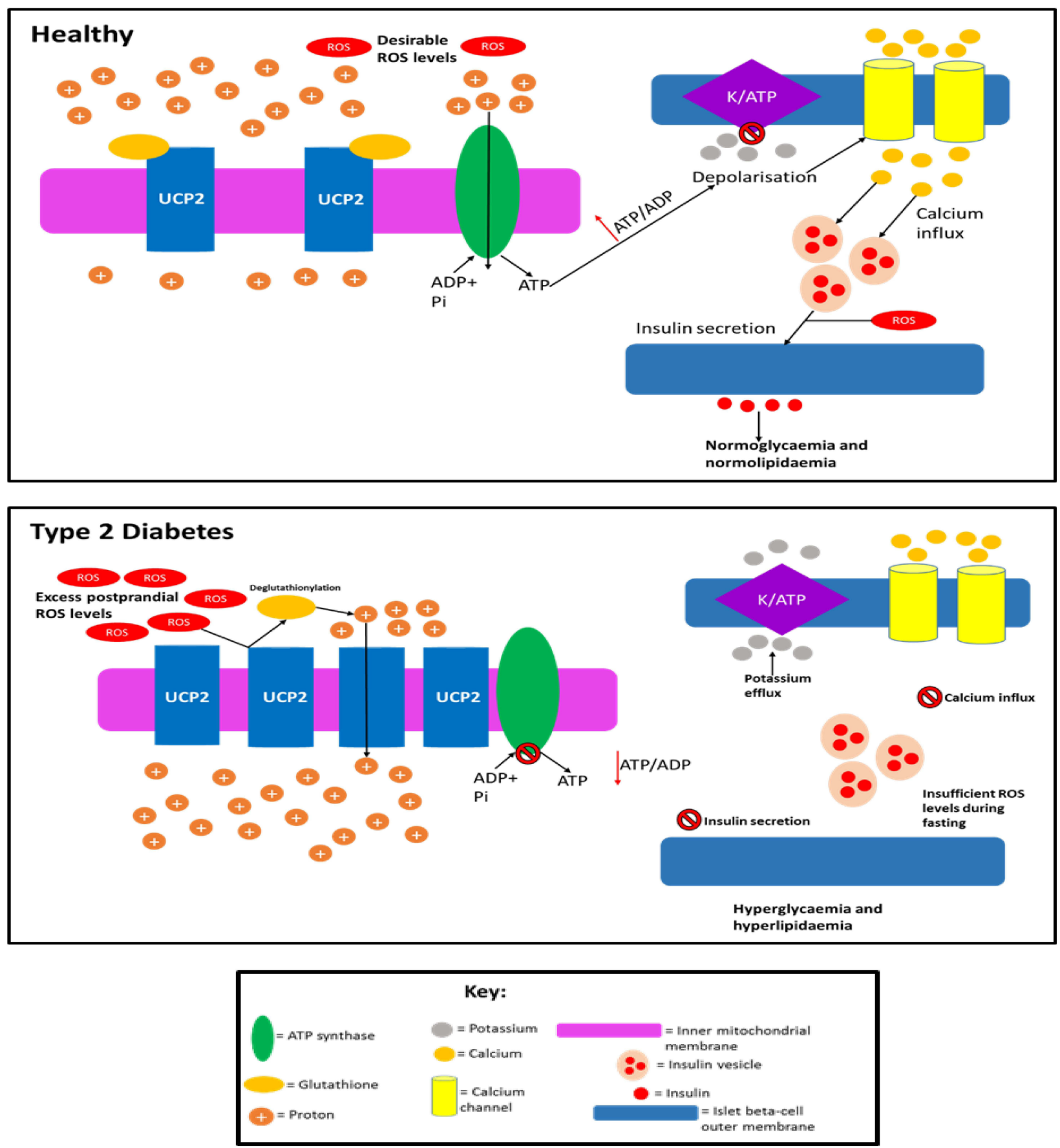

Figure 6 Speculation of how UCP2 activity and quantity is altered in T2D. In healthy individuals: UCP2 levels are basal, UCP2 is glutathionylated, ROS levels are low enough so that they do not cause cell damage but the levels are sufficient so that these molecules can amplify insulin secretion, and proton leak exists ( $\sim 55 \%$ of islet beta cells' metabolism is wasted due to proton leak which is not caused by UCP2) but is minimal, so enough of the protons can move down the gradient through ATP synthase to generate sufficient ATP levels. In T2D, UCP2 is deglutathionylated (due to increased ROS levels) and upregulated allowing for much greater proton leak. Consequently, the majority of the protons prematurely leak through the inner mitochondrial membrane and do not pass through ATP synthase, although there is likely a period before the UCP2 deglutathionylation where ATP production occurs, it is unlikely that enough ATP is generated during this time to promote adequate insulin secretion. Hence, overall ATP production is impaired in the cell resulting in the inadequate insulin secretion observed in T2D during both the postprandial period and fasting. ROS levels are likely too high (leading to cytotoxic damage) during the postprandial period as a result of severe nutrient oversupply to islet beta-cells, due to the enhanced hyperglycaemia and hyperlipidaemia in T2D during this period. The excess ROS levels result in UCP2 deglutathionylation and a subsequent dissipated PMF, meaning that ROS formation during fasting is impaired and insulin secretion is not amplified by ROS to alleviate the chronic hyperglycaemia and hyperlipidaemia in fasting T2D subjects. Although UCP2 may become glutathionylated upon ROS levels decreasing during fasting, this likely reverses during subsequent feeding as ROS levels once again become undesirably high, restarting this cycle. This figure and information in its legend are with data adapted from these studies. $32,175,178,179,189,190,329,330$ 
It is firmly established that chronic insulin resistance in skeletal muscle of people with T2D contributes to the diabetic phenotype and results in poor exercise tolerance., ${ }^{3,197}$ However, the altered metabolism of skeletal muscle in patients results in a reduced capacity to oxidise fat and promote fat storage, which further exacerbates the disease phenotype. ${ }^{192}$ This behaviour of skeletal muscle is more pronounced in T2D as diabesity patients have a reduced ability to oxidise fat than obese-matched controls during exercise. ${ }^{192,198}$ Impaired energy utilisation results in decreased exercise tolerance and increased fat storage, which further promotes insulin resistance. ${ }^{192}$ Interestingly, this pathological behaviour of skeletal muscle has also been detected in individuals with prediabetes, suggesting that these alterations may play a role in the development of both prediabetes and T2D. ${ }^{192,199}$ However, contradictory to this, some studies have shown that fat oxidation is increased in the muscle of T2D patients. ${ }^{200}$ Additionally, metabolic inflexibility is also characteristic of T2D patients, whereby patients' ability to switch from lipid to carbohydrate oxidation during insulin stimulation is impaired, which also further contributes to impaired exercise tolerance. ${ }^{192}$ Obese normoglycemic individuals were shown to have better metabolic flexibility than weight-matched T2D patients. ${ }^{201}$ However, studies have found that metabolic inflexibility of glucose is largely due to defective glucose transport, ${ }^{201,202}$ which suggests that skeletal muscle is unable to promote sufficient insulin secretion from type 2 diabetic islet-beta cells via any signalling mechanisms, in which it likely attempts to achieve given its need for increased glucose uptake., ${ }^{3,197}$ Additionally, given that metabolic inflexibility can be improved by weight loss and exercise, this further supports the notion that impaired glucose uptake largely accounts for this phenomenon, as these activities result in improved insulin sensitivity. ${ }^{203}$

The phenomenon of metabolic inflexibility has also been observed in individuals with prediabetes, implying that this may play a role in the aetiology/pathogenesis of both prediabetes and T2D. ${ }^{204}$ Mild muscle atrophy is common in middleaged T2D patients and becomes more significant during older age and diabetic neuropathy. ${ }^{205,206}$ Although inflammation and chronic insulin resistance are thought to promote muscle atrophy in T2D patients, ${ }^{206}$ it is reasonable to assume that the impaired energy utilisation promotes the degradation of intracellular proteins to yield sufficient ATP levels, which would contribute to the observed muscle atrophy. Evidence is also emerging that type 2 diabetic muscle may have detrimental effects on beta-cell function via secretion of myokines into circulation: myokine profiles differ between T2D patients and controls. ${ }^{207}$ TNF $\alpha$ secretion from T2D subjects was higher than healthy controls, ${ }^{207,208}$ and one in vitro study has shown that this myokine impairs beta-cell function. ${ }^{208}$ Decreased numbers of mitochondria have been observed in the muscle cells of T2D patients, which has created the notion that a decreased population of mitochondria induces insulin resistance. ${ }^{200}$ However, rodent studies have found that an increase in mitochondrial biogenesis occurs concomitantly with the development of muscle insulin resistance, implying that this notion is incorrect. ${ }^{209,210}$ This increase in mitochondria is postulated to be an early, transient event that is lost as the insulin resistance progresses. ${ }^{211}$ Furthermore, decreasing the mitochondrial population or disrupting mitochondrial function increases basal and insulin-stimulated glucose uptake into rodent skeletal muscle. ${ }^{200}$

Decreased insulin secretion is known to result in increased hepatic glucose production, which contributes to hyperglycemia, but type 2 diabetic livers also exhibit hepatic insulin resistance, which further increases glucose production during the fasting and postprandial period, giving the liver a direct role in contributing to the disease phenotype. ${ }^{192,212}$ Interestingly, insulin-induced suppression of gluconeogenesis and glycogenolysis has also been shown to be impaired in individuals with prediabetes, suggesting that altered liver function is an important component during the initial stages of T2D pathology. ${ }^{191}$ The diabetic phenotype promotes fat storage in the liver due to elevated fatty acid levels in circulation and $\sim 70 \%$ of T2D patients develop non-alcoholic fatty liver disease (NAFLD). ${ }^{213,214}$ Elevated plasma lipid levels in T2D result in increased delivery of fatty acids to the liver, which is largely caused by reduced suppression of lipolysis in adipose tissue due to decreased insulin action/secretion in diabetes. ${ }^{213}$ NAFLD is an established risk factor for CVD and so increases the risk of cardiovascular complications in T2D patients. ${ }^{214,215}$ T2D also increases the risk of NAFLD progressing to non-alcoholic steatohepatitis and subsequent liver cirrhosis. ${ }^{214}$ The increased fat storage in the liver of T2D patients further promotes hepatic insulin resistance and induces impaired hepatic fatty acid oxidation, which in turn, further increases hepatic fat storage and exacerbation of insulin resistance, which worsens hyperglycemia as a result. ${ }^{213,216}$

Proinflammatory cytokines, produced by adipose tissue as a consequence of obesity, are known to be cytotoxic to beta-cells, and they likely contribute to T2D pathogenesis and islet dysfunction post-diagnosis. ${ }^{99,217}$ There is also evidence that these cytokines play a role in the induction of insulin resistance. ${ }^{218}$ Thus, the adipose tissue also likely contributes to T2D aetiology/pathogenesis, but to what extent remains currently 
unknown. ${ }^{94}$ The reduced insulin levels also result in increased lipolysis and decreased fat storage in adipocytes, resulting in hyperlipidaemia and increased deposition of fat into other tissues, such as skeletal muscle and liver. ${ }^{219,220}$ There is also evidence that altered gut microbiota profiles observed in T2D patients and overweight subjects also promote systemic inflammation and proinflammatory cytokine production, which is thought to encourage the disease pathogenesis and contribute to the disease phenotype post-diagnosis. ${ }^{221} \mathrm{~T} 2 \mathrm{D}$ patients exhibit alterations in bone behaviour, which is believed to increase the risk of fracture and promote bone fragility: older adults with T2D have up to an $80 \%$ increase in the risk of extremity fracture. ${ }^{222}$ Decreased levels of the parathyroid hormone have been seen in T2D, indicating decreased bone turnover, and increased levels of sclerostin in patients also indicate inhibited bone formation. ${ }^{222-224}$ Decreased insulin-like growth factor (IGF)-1 levels in T2D also likely results in decreased bone formation in T2D. ${ }^{222-224}$

Evidence is now emerging that T2D induces premature ageing of the CNS, as some (but not all) studies have found that patients exhibit impaired cognitive performance and electrophysiological defects in the hippocampus, as well as pathological brain morphological abnormalities - all of which are reminiscent of the changes observed during normal ageing. ${ }^{225}$ Interestingly, GLP-1R is downregulated in the hypothalamus of T2D patients in comparison to healthy controls, suggesting that the reduced ability of GLP-1 to induce satiety may contribute to the dysfunctional feeding behaviours and metabolic homeostasis observed in these patients. ${ }^{226}$ Whether or not this downregulation occurs before or after T2D diagnosis is unknown.

Peripheral neuropathy is a common complication of T2D, and an estimated $50 \%$ of patients develop diabetic neuropathy after 25 years of being diagnosed. ${ }^{227,228}$ Neuropathy may result from excessive levels of nutrients in circulation (resulting in complications such as oxidative damage) and impaired cardiovascular function (resulting in complications such as hypoxia), discussed in detail elsewhere. ${ }^{228}$ Diabetic neuropathy can have a range of consequences depending on the neurons affected: sensory neuropathy results in numbness or pain, motor neuron neuropathy results in impaired muscle movement and autonomic neuropathy results in dysfunctional regulation of involuntary activities, such as internal organ function. ${ }^{229,230}$

A recent study found that activation of preproglucagon (PPG) neurons in the brainstem of rodents reduced basal hepatic glucose production, enhanced intraperitoneal glucose tolerance, and augmented hepatic insulin sensitivity. This suggests that PPG neuron-mediated circuitry has an important physiological role in promoting glycaemic control and insulin sensitivity and that neuronal activity can promote metabolic homeostasis via extrapancreatic methods. ${ }^{104}$ Another recent study found that the activation of cholinergic preganglionic neurons in rodents via the melanocortin-4 receptor agonist lorcaserin reduced hepatic glucose production, increased glucose disposal and improved insulin sensitivity. ${ }^{129}$ Lorcaserin has also been reported to improve glycaemic control and induce weight loss in obese T2D subjects, and this drug was additionally shown to both reduce the risk of prediabetic individuals progressing to $\mathrm{T} 2 \mathrm{D}$ and increase the likelihood of these subjects being able to revert to euglycemia. ${ }^{129,231}$ Given the likely role of these neurons in promoting metabolic homeostasis in humans, it is likely that PPG and cholinergic preganglionic neuronal activity is impaired or absent in $\mathrm{T} 2 \mathrm{D}$, possibly as a result of the disease phenotype, or dysfunction of these neurons could occur at an early stage and play a role in the disease's aetiology/pathogenesis.

The diabetic phenotype greatly increases the risk of atherosclerotic plaque formation due to dyslipidaemia in patients, which results in increased plasma levels of the small dense atherogenic form of LDL cholesterol, and these molecules can easily penetrate the arterial wall and promote atherosclerosis. ${ }^{232}$ Hyperglycaemia also promotes atherosclerosis. ${ }^{233}$ The chronic inflammatory state associated with T2D is also thought to encourage plaque growth and formation. ${ }^{232}$ The impaired insulin secretion and action induce pathology in the microvasculature, as nitric oxide (NO) production is dependent upon insulin signalling. ${ }^{234}$ Chronic NO-deficiency in T2D results in a hyper-constricted state of the microvasculature; therefore, the delivery of oxygen and nutrients to tissues is impaired, contributing to diabetic neuropathies and the poor exercise tolerance observed in patients, as well as elevated blood pressure. ${ }^{232,235,236}$ Diabetic autonomic neuropathy (DAN) also contributes to dysregulated autoregulation of blood flow in the vasculature. ${ }^{237}$ Also, diabetic patients exhibit capillary basement membrane thickening due to chronic hyperglycemia, further impairing the exchange between the circulation and tissues. ${ }^{232}$ The excess nutrient levels in the circulation in $\mathrm{T} 2 \mathrm{D}$ are also thought to damage cells throughout the cardiovascular system due to excessive ROS production caused by increased metabolism, as a result of increased mitochondrial nutrient supply. ${ }^{232,238}$ The cardiovascular system in T2D is also in a hypercoagulable state and patients are at increased risk of thrombosis as a result. ${ }^{232} \mathrm{~T} 2 \mathrm{D}$ patients are also at increased risk of heart failure due to diabetic cardiomyopathy, where myocardial 
disease manifests in the absence of any other known CVD, likely due to hyperglycemia, microvascular damage and autonomic neuropathy associated with diabetes. ${ }^{232,239}$

Diabetic nephropathy (DN) is the most common cause of end-stage renal disease globally, with $10-20 \%$ of T2D patients developing this disease. ${ }^{195}$ Kidney pathology can result due to nerve and blood vessel damage in this organ caused by the diabetic phenotype. ${ }^{195,228,232}$ The diabetic phenotype also promotes $\mathrm{DN}$ by inducing pathology in kidney cells directly involved with glomerular filtration, as, for example, hyperglycemia promotes fibrosis in the kidney via inducing activation of specific intracellular pathways - the mechanisms by which T2D induces DN are reviewed in detail elsewhere. ${ }^{195,240}$ In addition, urinary tract infections are more common in diabetic patients, which is at least partly thought to be due to increased glucose levels in the urine. ${ }^{241}$ Figure 7 summarises the pathological effects that T2D has on different organs and systems throughout the body.

\section{Pharmacological Treatments and Lifestyle Changes for T2D}

After the T2D diagnosis, initial treatments usually involve altering diet and lifestyle, as well as increasing physical activity in combination with metformin. ${ }^{3}$ Metformin decreases hepatic glycogenolysis, decreases peripheral tissue insulin resistance, increases GLP-1 postprandial secretion (which augments insulin secretion), and delays digestion. ${ }^{8}$ Exercise and weight loss also reduce insulin resistance and reduce the risk of T2D associated postdiagnosis complications. ${ }^{242,243}$ If this treatment regime is ineffective at promoting normoglycaemia then sulfonylureas and meglitinides are usually the next treatments tried which act as insulin secretagogues. ${ }^{3}$ Common side effects of insulin secretagogues include weight gain and hypoglycaemia, and these drugs are only usually effective in the short term. ${ }^{8}$ Insulin therapy, in the form of multiple daily subcutaneous injections, is effective at lowering plasma glucose levels and is usually required in the majority of patients when the aforementioned treatment regimens fail, but there are several side effects, such as weight gain, hypoglycaemia and increased risk of colorectal cancer. ${ }^{3,244}$ It has been estimated that $50 \%$ of patients require insulin therapy within 10 years of T2D diagnosis. ${ }^{245}$ Recently, rodent and human studies have found that orally administered insulin could be a viable option to treat T2D. This is due to the advent of novel delivery systems that allow oral insulin to resist degradation in the GIT, be transported into

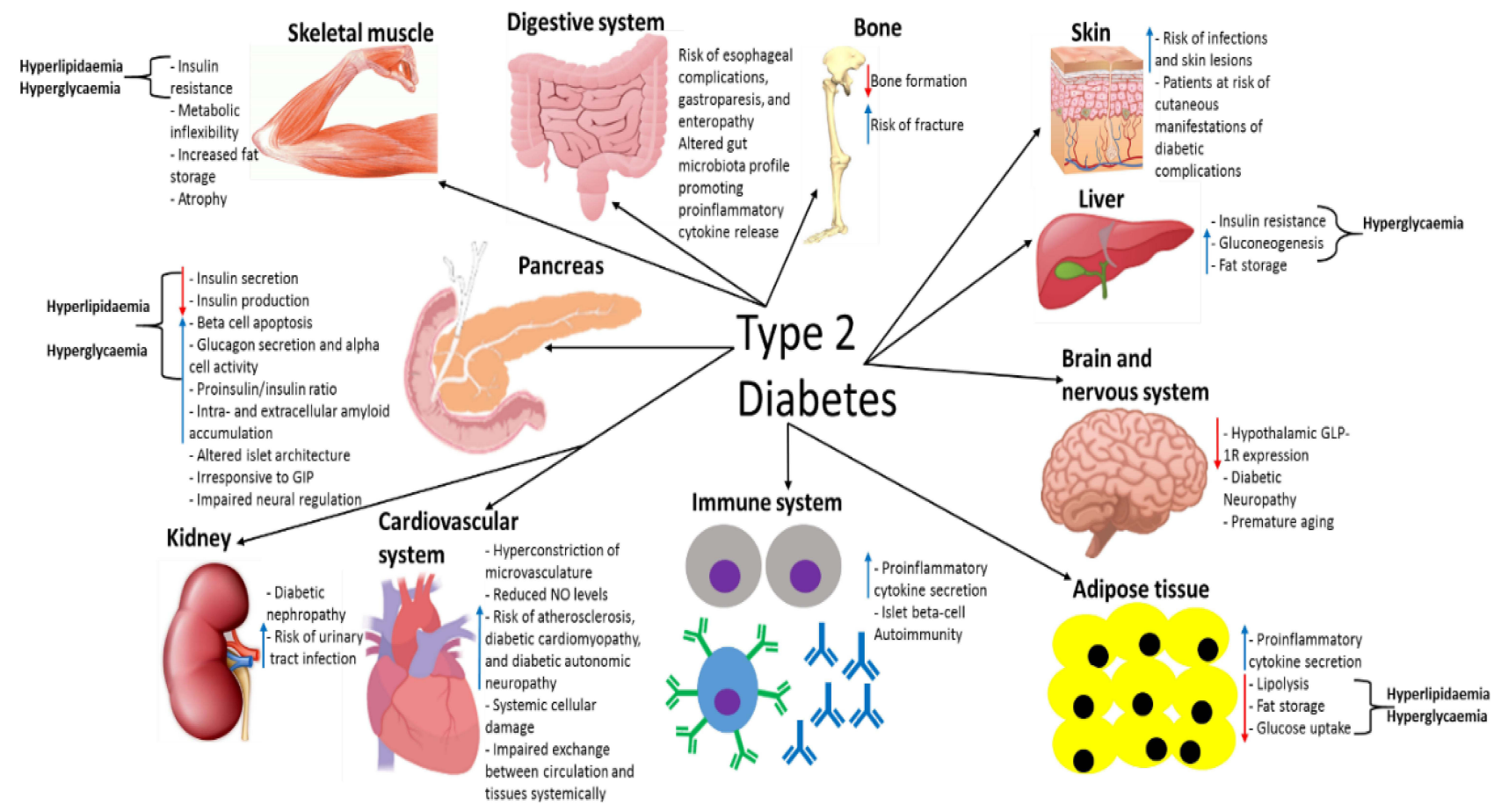

Figure $7 \mathrm{~A}$ summary of the pathological effects that T2D has on different organs and systems throughout the body, some of which directly contribute to the diseaseassociated dyslipidaemia/hyperglycaemia and subsequent clinical symptoms. This figure and information in its legend are with data adapted from these studies. ${ }^{94,105,106,111,192-}$ $195,206,214,219-222,225,228,232,241,326-328,331$ 
circulation, and then act when desired depending on plasma glucose concentration, which is desirable given the complications associated with multiple daily invasive insulin injections. ${ }^{246-249}$ Modulating GLP-1R activity is the most recent therapy used to treat T2D. ${ }^{3}$ The first therapy is based on the use of DPP-IV inhibitors to delay GLP-1 breakdown from its active to inactive form. ${ }^{250}$ DPP-IV inhibitors increase GLP-1 levels by 2-3-fold over 24 hours and have been shown to significantly decrease plasma glucose levels. ${ }^{3}$ Long-term administration of these drugs will likely have adverse effects as this enzyme is expressed in many tissues and has a variety of functions, but no important side effects have been seen after over 10 years of use. ${ }^{3}$ The efficacy of GLP-1 analogues is generally greater than DPP-IV inhibitors, due to the supraphysiological concentrations of GLP-1 achieved after administration of the former. ${ }^{251}$ Hence, the preferred therapy for modulating GLP-1R activity involves the administration of GLP-1 analogues (exenatide and liraglutide, lixisenatide, dulaglutide, albiglutide and semaglutide) to T2D patients, which improve glycaemic control by augmenting insulin secretion and dampening glucagon secretion, as well as delaying gastric emptying. ${ }^{252,253}$

Exenatide and liraglutide mimic the endogenous GLP-1 activity by binding to GLP-1R on various tissues, but these analogues are resistant to degradation. ${ }^{252}$ GLP-1 has a half-life of 1-2 minutes, whereas exenatide has a half-life of 3.4-4 hours and liraglutide's half-life is $11-13$ hours. ${ }^{3}$ Hence, these GLP-1 analogues vastly prolong the GLP-1 response promoting normoglycaemia in $\mathrm{T} 2 \mathrm{D}$ patients during fasting and after nutrient ingestion. An advantage of using GLP-1R agonists (and DPP-IV inhibitors) is that they only mediate their insulinotropic effects when glucose levels are elevated, meaning that the risk of hypoglycaemia is minimal, and these therapies have the lowest reported rates of hypoglycaemia for T2D treatments. ${ }^{254}$ Liraglutide and exenatide (synthetic exendin-4) have 97 and 52\%, respectively, homology with GLP-1. ${ }^{255,256}$ GLP-1R agonists used in T2D treatment are either derivatives of native GLP-1 (liraglutide, albiglutide, semaglutide and dulaglutide), which have been modified to be resistant to DPP-IV inactivation or derivatives of exendin-4 (exenatide, lixisenatide and exenatide-LR). ${ }^{257,258}$ Exendin-4 was originally isolated from the saliva of the Gila monster lizard and is resistant to the action of DPP-IV. ${ }^{257,259}$ Key pharmacological and clinical features of clinically available GLP-1R agonists are presented in Table 3 and Figure 8 compares the amino acid sequence of native GLP-1 and the GLP-1 analogues liraglutide and exenatide.

These GLP-1 analogues are effective insulinotropic agents and successfully suppress glucagon secretion in a glucose-dependent manner. ${ }^{260-261}$ GLP-1 analogues also induce weight loss, which is associated with improved T2D prognosis. ${ }^{252,262,263}$ GLP-1R activity is thought to mediate weight loss by induction of satiety. ${ }^{3,252}$ Interestingly, it has been shown that chronic liraglutide treatment in diabetic mice prevents loss of pancreatic beta-cell mass, increases proliferation of the beta-cells and decreases apoptosis after alloxan injection. ${ }^{264}$ Inhibition of the beta-cell apoptosis in isolated human pancreatic cells was also reported after

Table 3 Current Glucagon-Like Peptide I Receptor (GLP-IR) Agonists Used in Type 2 Diabetes Therapy

\begin{tabular}{|c|c|c|c|}
\hline $\begin{array}{l}\text { GLP-IR Agonist Generic } \\
\text { Name (Trade Name) }\end{array}$ & Dosing & Half-Life & $\begin{array}{l}\text { Administration Required } \\
\text { Before Meals? }\end{array}$ \\
\hline \multicolumn{4}{|l|}{ Short-acting } \\
\hline Exenatide (Byetta) & Twice daily & 2.4 hours & Yes \\
\hline Lixisenatide (Lyxumia) & Once-daily & 4 hours & Yes \\
\hline \multicolumn{4}{|l|}{ Intermediate-acting } \\
\hline Liraglutide (Victoza) & Once-daily & 12 hours & No \\
\hline \multicolumn{4}{|l|}{ Long-acting } \\
\hline Exenatide-LAR (Bydureon) & Once weekly & 96 hours & No \\
\hline Albiglutide (Tanzeum)* & Once weekly & $6-8$ days & No \\
\hline Dulaglutide (Trulicity) & Once weekly & 90 hours & No \\
\hline Semaglutide (Ozempic) & Once weekly & $165-184$ hours & No \\
\hline
\end{tabular}

Notes: Adapted with permission from Reed J, Bain S, Kanamarlapudi V. Recent advances in understandingthe role of glucagon-like peptide I. Fl000Research. 2020;9:239. ${ }^{257}$ *This product was globally withdrawn in July 2018 for commercial reasons. 

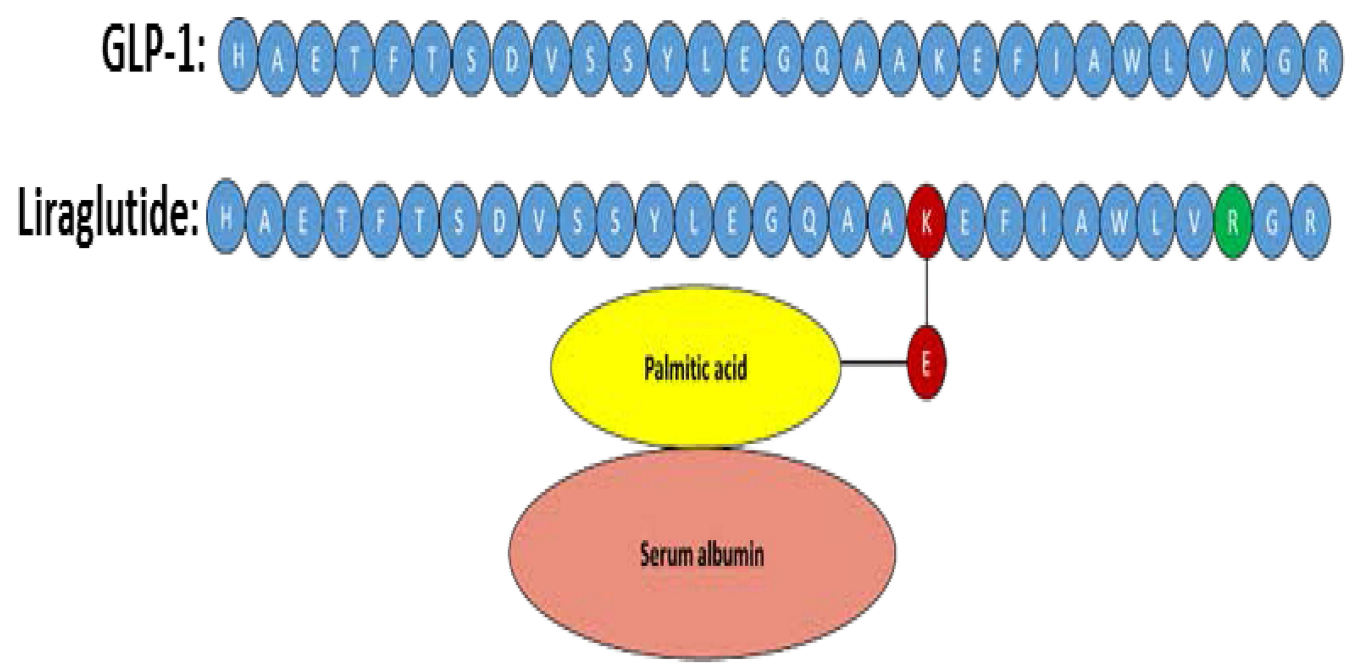

\section{Exenatide:}

Figure 8 The amino acid sequence of GLP-I, liraglutide and exenatide. Amino acids highlighted green in exenatide indicate altered amino acids from the GLP-I sequence. The purple amino acids in exenatide indicate amino acids that have been added. The amino acid highlighted red in liraglutide is modified by the addition of palmitic acid enabling binding to albumin which results in an increased half-life of liraglutide in circulation. This figure is with data adapted from Lorenz et al. ${ }^{332}$

liraglutide administration, and the beta-cell proliferation rate was increased up to three-fold after incubation for $24 \mathrm{~h}^{265} \mathrm{In}$ streptozocin-induced type 1 diabetic rats and isolated human pancreatic ducts, exendin-4 treatment has also been shown to increase the number of insulin producing cells. ${ }^{266}$ Side effects of GLP-1 analogue administration are dyspepsia and nausea, but the effects usually subside after continuous administration. ${ }^{3}$ Additionally, it was implicated that GLP-1 analogue therapy increased the risk of acute pancreatitis, but subsequent studies using larger cohorts did not confirm this finding. ${ }^{8,267}$ However, there is evidence that GLP-1 analogues increase the risk of medullary thyroid cancer, which is a cause for concern. ${ }^{268}$

The development of GIP analogues for T2D treatment was initially not a desirable field of research due to GIP action being thought to be lost in T2D and GIPs ability to augment glucagon secretion. ${ }^{3,261}$ However, unexpectedly, preclinical data from a study in 2013 found that GLP-1/ GIP dual agonist treatment induce better glycaemic control and body weight reduction in diet-induced-obesity mice compared to liraglutide only treated controls. ${ }^{269} \mathrm{Co}$-agonism of GLP-1R and GR was also shown to reduce body weight synergistically in rodent obesity models. These coagonists also improved glycaemic control in humans. ${ }^{269}$ Additionally, a recent study found that co-agonism of GLP-1R and GR was reported to ameliorate diet-induced dyslipidemia and atherosclerosis by increasing energy expenditure, reducing liver inflammation and regulating bile homeostasis in rodents. ${ }^{270}$

A recent study found that exenatide increased adiponectin secretion from adipose tissue in both in vivo and in vitro studies. ${ }^{271}$ Adiponectin is a peripheral tissue insulin sensitizer, and its levels are known to decrease in obese and T2D patients. ${ }^{272}$ This study demonstrated that modulating GLP$1 \mathrm{R}$ activity has the potential to improve both insulin secretion and action in T2D and that GLP-1 analogues may also be able to induce weight loss by augmenting adiponectin secretion, as well as inducing satiety. GLP-1 analogues are as effective as second-line therapy in improving glycaemic control in patients with T2D. ${ }^{273}$ Reductions in glycated haemoglobin from baseline with GLP-1 analogues tend to be greater than or comparable to insulin therapy. ${ }^{262,274}$ GLP-1 analogues are also consistently more effective at inducing weight loss than most oral glucose-lowering drugs and insulin. ${ }^{262,263}$ GLP-1 analogues were also shown to confer lower hypoglycemia risk versus insulin or sulfonylureas. ${ }^{262}$ Additionally, GLP-1 analogues also appear to decrease the risk of cardiovascular pathology in patients, according to some studies, and preliminary data suggest they do so to a greater degree than other oral glucose-lowering drugs. ${ }^{262,275-277}$ However, two GLP-1 analogues tested in two studies demonstrated no advantage in influencing cardiovascular outcome. ${ }^{278,279}$ Recent systematic 
reviews and meta-analyses found that GLP-1R agonists reduced major adverse cardiovascular events in T2D patients $^{280-282}$ and also had beneficial effects on kidney outcome. $^{283}$ The reported varying impacts of different GLP$1 \mathrm{R}$ agonists on blood glucose levels, weight loss, cardiovascular outcomes and adverse effects should play an integral role when determining which agonist is best to administer to a patient depending on their medical requirements. ${ }^{260}$

\section{Small Molecule Agonists}

Studies have demonstrated that GLP-1R has allosteric agonist binding sites and that these sites are distinct from the orthosteric agonist (GLP-1) binding site. ${ }^{3}$ The first allosteric agonist identified for GLP-1R was compound 1, which had a low affinity and a low potency for GLP-1R. ${ }^{3}$ Compound 2 was then produced, which has been shown to be a more potent agonist, and this molecule also increases the affinity of GLP1R for GLP-1. ${ }^{284}$ Additionally, compound 2 binding was not inhibited by the exendin (9-39) antagonist (truncated exenatide), demonstrating that this compound binding site on GLP-1R is distinct from the orthosteric GLP-1 binding site. $^{3,284}$ However, compound 2 does not stimulate insulin secretion to the same extent as GLP-1, liraglutide or exenatide in vivo, and combining liraglutide or exenatide with compound 2 did not improve insulin secretion in mice. ${ }^{285}$ Compounds $\mathrm{A}$ and $\mathrm{B}$ have also been shown to demonstrate ago-allosteric properties and induce cyclic adenosine monophosphate (cAMP) signalling, as well as increased insulin secretion in rat islets and animal studies. ${ }^{3,14}$ One study showed that compound $\mathrm{B}$ almost normalised insulin secretion in human islets isolated from a T2D donor. ${ }^{286}$ Compounds 2 and $\mathrm{B}$ bind to a distinct site from the orthosteric binding site, as GLP-1R antagonists exendin (9-39) and JANT4, as well as the V36A mutation in GLP-1R, did not inhibit cAMP production upon compound 2 or $\mathrm{B}$ administration. ${ }^{14}$ Compounds 2 and $\mathrm{B}$ induced cAMP production in human GLP-1R expressing cells but caused no intracellular $\mathrm{Ca}^{2+}$ accumulation, ERK

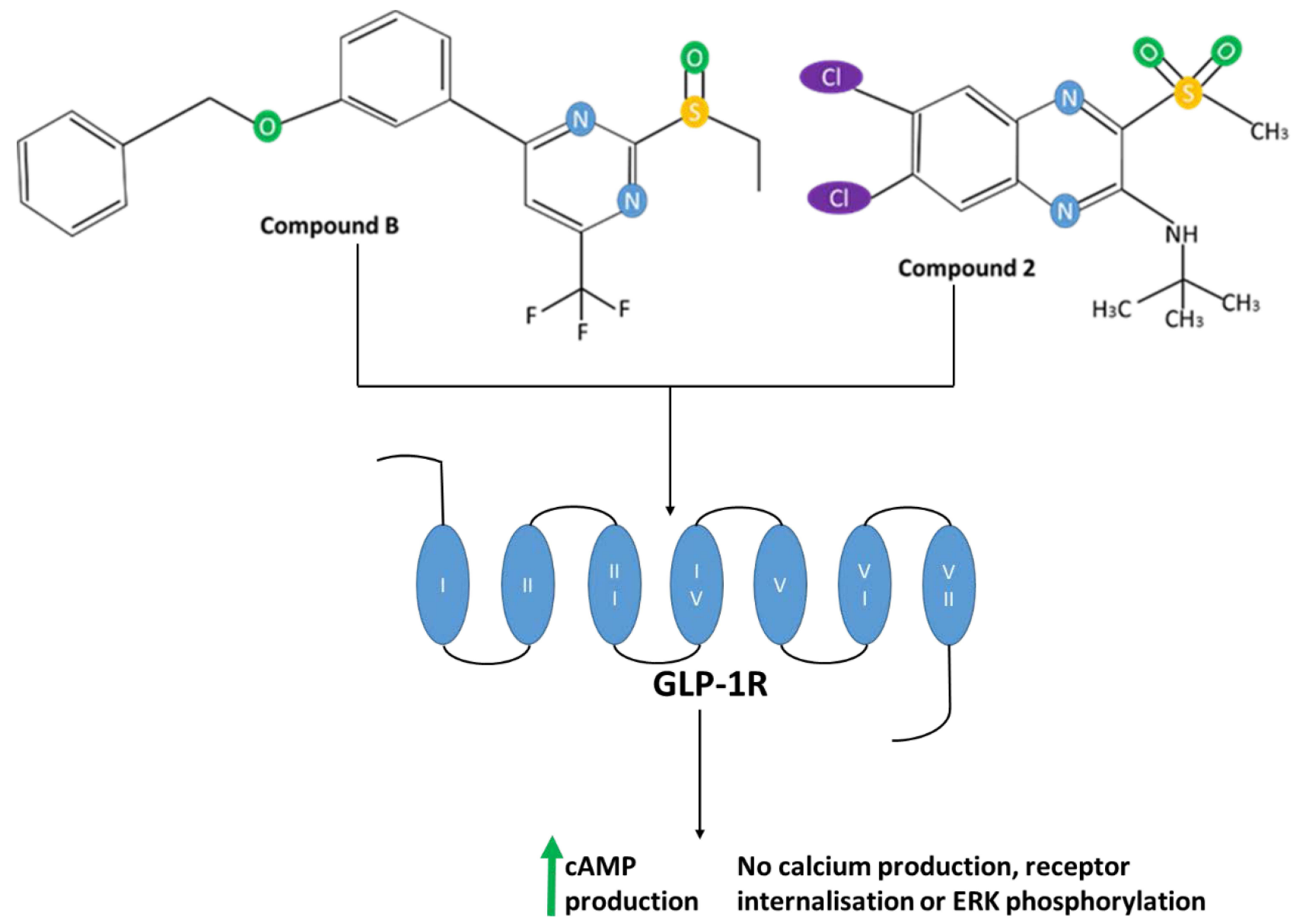

Figure 9 The chemical structure of the small molecule allosteric agonists compound 2 and compound B of GLP-IR, which shown schematically with numbered transmembrane domains. This figure is adapted with data from these studies. ${ }^{3,14}$ 
phosphorylation or receptor internalisation. ${ }^{14}$ Prevention of receptor internalisation may allow for continuous downstream signalling of the receptor, which could, in theory, raise insulin levels in T2D patients - this is an area of ongoing research. ${ }^{252}$ The K334A mutation (which affects the Gas coupling) of GLP-1R inhibited both GLP-1 and compounds 2 and B induced cAMP production, which demonstrates that GLP-1 and both compounds 2 and B induce similar conformational changes needed for the Gas activation. ${ }^{14}$ A recent study showed that compounds 2 and B bind and covalently modify residue 347 in ICL3 of GLP-1R. ${ }^{287}$ Residues 328, 351 and 335 of GLP-1R were recently demonstrated to be important for compound 2 potency, as mutagenesis of these residues reduced compound 2 activity. ${ }^{288}$ In this same study, enhanced compound 2 potency was demonstrated by GLP-1R when its residue 332 was mutated to tryptophan, which is in contrast to the effect observed with this mutation on the potency of allosteric antagonists. It was postulated that enhanced compound 2 potency was caused by increased hydrophobic interactions between the receptor and the agonist with this mutation. Figure 9 shows the chemical structures of compounds 2 and $\mathrm{B}$.

\section{GLP-IR, GIPR and GR Tri-Agonist}

In 2015, a triple agonist for GLP-1R, GIPR and GR was developed and tested on diet-induced obese (DIO) mice. ${ }^{289}$ The tri-agonist lowered body weight in these mice to a greater extent than the GLP-1R/GIPR coagonist after 20 days of treatment. Both the coagonist and tri-agonist did not induce hypoglycaemia and were equally effective at reducing blood glucose levels and improving glucose tolerance, demonstrating that surprisingly chronic GR agonism does not counteract the anti-hyperglycemic effects of GLP-1R and GIPR activity. Interestingly, tri-agonist treated mice had lower plasma insulin levels than the coagonist-treated mice, indicating improved insulin sensitivity. In theory, chronic GR activation should raise plasma glucose levels and insulin secretion would then need to be concomitantly increased to maintain normoglycaemia during tri-agonist treatment, but this was not observed in this study. Given that there was no difference in food intake between wild-type mice treated with the dual-incretin GLP-1/GIP coagonist and those treated with the tri-agonist, the greater difference in weight loss was attributed to significantly enhanced ATP expenditure in tri-agonist-treated DIO mice. The capacity of the tri-agonist to prevent the development of spontaneous diabetes compared with the dual-incretin GLP-1/GIP coagonist was tested in mouse models of T2D. Tri-agonist treatment prevented the excessive weight gain to a greater extent than the coagonist, and this difference was not due to cumulative food intake. Additionally, the tri-agonist protected these mice from fasting hyperglycaemia to a better degree than the coagonist. Interestingly, the tri-agonist also significantly reduced pancreatic alpha-cell infiltration into the core of pancreatic islets, helping to preserve the islet architecture observed in healthy pancreatic islets. The triagonist was also demonstrated to delay T2D progression in rodent models of spontaneous diabetes, as glycaemic improvements were maintained in Zucker diabetic fatty rats 3 weeks after treatment cessation, even though they had gained body weight and were comparable in mass to vehicle-treated controls. Given that weight and food intake were not altered in lean mice even after chronic treatment with the tri-agonist, this demonstrates that the effects of the tri-agonist do not manifest in the absence of excessive nutrient storage. Another recent study, ${ }^{290}$ which investigated the effects of other GLP-1, GIP and GR tri-agonist in rodents, found that this agonist ameliorated diabetic nephropathy-related disorders, as well as reduced body weight, food intake and hyperglycaemia. This suggests that these tri-agonists have the therapeutic potential to alleviate post-diagnosis complications in patients.

\section{Surgical Options for T2D: Bariatric Surgery}

Bariatric surgery includes a variety of procedures performed on the GIT in people who are severely obese (BMI $\geq 40$ ) or in individuals with a BMI of $\geq 35$ that have a condition that can be improved by losing weight such as T2D or high blood pressure. ${ }^{291}$ Weight loss is achieved by reducing the size of the stomach with a gastric band or by removing a portion of the stomach (sleeve gastrectomy or biliopancreatic diversion with duodenal switch), and resecting and re-routing the small intestine to a small stomach pouch (gastric bypass surgery) is another surgical option to promote weight loss. ${ }^{292}$ Reduction in the size of the stomach results in patients experiencing satiety with less food and the bypass means that fewer nutrients will be ingested as part of the intestine will no longer be involved in digestion. ${ }^{291,292}$ This surgery is only used when other options have not been effective for weight reduction, such as diet and lifestyle changes. ${ }^{13,291}$ The obesity epidemic in recent decades has been parallelled by an increase in 
bariatric surgery. ${ }^{292}$ Longitudinal studies have found that this surgery significantly reduces body weight over time, improves glycaemic control and prognosis in T2D patients, and reduces mortality and risk of obesity-related co-morbidities, such as cardiovascular and respiratory pathology. $^{291}$ Data collected globally revealed that the number of patients undergoing bariatric surgery rose from 40,000 in 1998 to 146,300 in $2003 .^{293}$

Bariatric surgery is known to be able to induce T2D remission, and one study found that $53 \%$ of patients were in complete $\mathrm{T} 2 \mathrm{D}$ remission three years post-surgery and another $10 \%$ were in partial remission according to the American Diabetes Association criteria, although remission rates vary between the studies, with one study reporting that $34 \%$ of patients were in complete remission 23 months post-surgery. ${ }^{294}$ The consensus in the literature is that complete remission rates decrease with time, as demonstrated in one study where $43 \%$ of patients had complete remission after 2 years post-surgery, which dropped to $24 \%$ after 5 years. ${ }^{294,295}$ Recent findings suggest that a persistent impairment in insulin secretion is a crucial factor in failure to sustain T2D remission after bariatric surgery. ${ }^{295-297}$ The improvements observed in post-surgery were originally postulated to be induced by the subsequent post-surgery weight loss, but it has become apparent that reversal of insulin resistance is induced before any significant weight loss occurs. ${ }^{298}$ Hence, it is currently unclear how T2D remission is achieved via bariatric surgery, but it is not just due to the weight loss associated with this surgery. In both T2D obese and T2D-free obese patients, bariatric surgery increases postprandial GLP-1 levels (from up to 3-fold pre-surgery and nearly 8-fold vs baseline after gastric bypass). ${ }^{297}$ Interestingly, gastric bypass and sleeve gastrectomy have been reported to induce similar improvements in glycaemic control, despite inferior GLP-1 levels and BMI decreased in patients that had undergone sleeve gastrectomy. $^{296}$

A recent study reported that bariatric surgery improves disposition index (DI), a score determined by insulin sensitivity times the amount of insulin secreted in response to blood glucose levels, in diabetes-free subjects such that after 2 years post-surgery, it almost matches general population values. ${ }^{297}$ However, insulin secretion in response to intravenously administered glucose declines in these individuals, implying that the improved DI is a result of the enhanced post-surgery GLP-1 plasma levels. In the T2D subjects of the same study $(91 \%$ remission rate at 2 years post-surgery), both disposition indices and insulin secretion in response to intravenously administered glucose improve 2 years post-surgery but are still notably lower than population norms. Fasting plasma glucose levels were reported to revert to normal levels 2 years post-surgery in over $90 \%$ of T2D subjects (from 7.30 to $5.24 \mathrm{mmol}$ ), and become comparable to non-diabetic subjects $(5.00 \mathrm{mmol})$. Although average peak glucose levels remained similar in the diabetic group 2 years after surgery (from 9.96 to $9.79 \mathrm{mmol} / \mathrm{L}$ ), peak postprandial glucose levels shifted to an earlier time point and rapidly declined to within the normoglycaemic range, meaning that the time the individual was subjected to hyperglycaemia was greatly reduced and for the majority of 4 hours following nutrient ingestion their plasma glucose levels were in the healthy range. Surprisingly, average peak glucose levels increased in nondiabetic subjects after surgery, but these individuals similarly had peak levels at an earlier time point, with a subsequent more rapid decline in plasma glucose levels. Despite this postprandial hyperglycaemia, the overall reductions in fasting and postprandial glucose exposure following bariatric surgery in nondiabetic individuals are thought to be beneficial due to the reported reduced cardiovascular complications associated with post-surgery groups compared with non-surgical control groups. ${ }^{297}$ Average peak insulin levels were notably lower in diabetic subjects (771.4 pmol/L) compared to non-diabetic (1221 pmol/L) 2 years post-surgery, although average fasting insulin levels were higher in diabetic subjects (41.5 vs $36.9 \mathrm{pmol} / \mathrm{L}$ ). In both groups, average peak insulin levels improved 2 years post-surgery: pre-surgery peak insulin levels were 491.9 and $7778.3 \mathrm{pmol} / \mathrm{L}$ in the diabetic and non-diabetic groups, respectively. Interestingly, although the average proinsulin: insulin ratio marginally improved 2 years after surgery in diabetic subjects (from 2.2 to 1.8), it remained notably higher than the value observed in the non-diabetic control group (1.1), demonstrating that bariatric surgery does not have much impact on defective insulin processing by islet beta-cells. Interestingly, average peak postprandial glucagon levels increased in both diabetic (from 102.2 to $112.3 \mathrm{ng} / \mathrm{L}$ ) and non-diabetic (from 99.2 to $109.9 \mathrm{ng} / \mathrm{L}$ ) groups after surgery, implying a beneficial role of this hormone in promoting post-surgical weight loss, and the opposite was the case for fasting glucagon levels.

Plasma GLP-1 and GIP responses, as well as insulin levels, were augmented in a pattern that mirrored the accelerated postprandial glucose appearance and disappearance 
following surgery in both diabetic and nondiabetic groups. Despite the notable benefits and reported metabolic improvements, this surgery is expensive and not always successful in inducing weight loss. Further, there are numerous post-surgery complications, such as vomiting and dumping syndrome, iron and B12 deficiency, and secondary hyperparathyroidism. ${ }^{13}$ The majority of patients develop vomiting and dumping syndrome post-surgery but this usually subsides within a year due to patients' GIT and feeding behaviours adjusting, and medication is available to treat this syndrome if necessary. ${ }^{13}$ After one year postsurgery, $\sim 30 \%$ of patients need B12 supplementation to maintain normal plasma levels of B12. ${ }^{299}$ The prevalence of B12 deficiency increases in the post-surgery population yearly, it has even been reported to be as high as $70 \%$ in one study in the long term. ${ }^{300}$ B12 supplementation usually treats this post-surgery complication, but a minority of patients require monthly intramuscular B12 injections. ${ }^{13}$ Iron deficiency is usually only seen in menstruating women after one year of post-surgery, and this complication can be overcome by intravenous iron infusion several times a year. ${ }^{13,301}$ During weight loss after surgery, many patients develop gallstones, and patients that develop gallstonerelated symptoms undergo surgery to remove the gall bladder. ${ }^{13}$ Secondary hyperparathyroidism is characterised by elevated levels of parathyroid hormone caused by excessive activity and hyperplasia of the parathyroid glands. ${ }^{302}$ This hormone has catabolic effects on bone tissue and increases vitamin D synthesis, which raises the plasma calcium levels. ${ }^{303}$ Bariatric surgery patients often develop secondary hyperparathyroidism due to malabsorption of calcium from the GIT as a result of the surgery. ${ }^{13}$ Vitamin $\mathrm{D}$ and calcium supplementation are effective treatments for this post-surgical complication. ${ }^{304}$ It has been estimated that $\sim 29 \%$ of patients that undergo bariatric surgery develop secondary hyperparathyroidism. ${ }^{13}$ Thus, it is desirable for a treatment to be developed to mimic the effects of bariatric surgery but without the aforementioned post-surgery complications.

\section{Future Perspectives}

Studies have found evidence that GLP-1 exerts multiple beneficial extrapancreatic actions on both tissues positive and negative for GLP-1R expression, ${ }^{252}$ and clinical trials have found that some GLP-1 mimetic-based therapies alleviate cardiovascular pathology associated with T2D. ${ }^{305}$ This implies that the GLP-1R agonists may be able to alleviate the systemic pathology that is associated with T2D, ${ }^{306-308}$ and not just be able to augment insulin secretion from islet beta-cells of T2D patients.

In addition to augmenting insulin secretion from islet beta-cells, both in vivo and in vitro studies have produced evidence that GLP-1 action improves islet beta-cell survival and proliferation, ${ }^{252,259}$ which is also a relevant area of research as it is well established that T2D pathology is associated with an increased rate of islet beta-cell apoptosis. $^{309}$ Given the reduced population of these cells in patients, ${ }^{310}$ enhanced proliferation would, in theory, be desirable to increase plasma insulin levels in patients to promote normoglycaemia and normolipidaemia. Therefore, comparing how GLP-1R orthosteric and allosteric agonists influence islet beta-cell survival is a desirable future area of research. Despite controversial evidence that islet alpha-cells express GLP-1R, there is substantial evidence to suggest that GLP-1 action suppresses glucagon secretion, which is also important for alleviating T2D pathology, as T2D is now considered to be a bi-hormonal disorder. ${ }^{142}$ Therefore, determining how GLP-1R orthosteric and allosteric agonists modulate islet alpha-cell activity is another area of future research. Finally, to obtain further insight into how orthosteric and allosteric GLP-1R agonists can modulate islet beta-cells, it will be necessary to determine how these agonists influence other cells in the pancreatic islets, such as alpha-cells and determine how these cells, in turn, may subsequently modulate beta-cell activity via paracrine signalling.

GLP-1R orthosteric agonism has been shown to be an effective treatment for $\mathrm{T} 2 \mathrm{D}$, and the therapeutic potential of GLP-1R allosteric agonism to provide more efficacious treatment is an ongoing area of research. Although not discussed here, modulating the activity of other cell receptors via allosteric agonism could also yield more efficacious therapeutic options for T2D. Modulating the activity of multiple receptors (including GLP-1R) simultaneously for hormones involved in metabolic homeostasis using a unimolecular agonist appears to be a promising new therapeutic option for future T2D treatment, and is an area of ongoing research. ${ }^{289,290}$ Extrapancreatic pathology associated with T2D is discussed in this review to highlight that this disease has systemic consequences on the body, and ideally, treatments should aim to alleviate this systemic pathology via direct mechanisms as well as by improving insulin secretion/action; given that GLP-1 targets multiple organs, GLP-1-based therapies could achieve this. $^{252}$ A recent longitudinal study demonstrated the potential of GLP-1R agonism to prevent T2D 
manifestation in obese individuals and individuals with a BMI of $>27$ that had hypertension or dyslipidaemia: after 160 weeks, the liraglutide treated group $(n=1472)$ had a smaller percentage of the population diagnosed with T2D ( $2 \%$ vs $6 \%$ ) than the placebo-treated control group $(\mathrm{n}=738){ }^{311}$ Additionally, time for T2D onset during the 160 -week study was found to be $2.7 x$ longer in the liraglutide treated group than in the placebo control group. The results of this study have important future implications, as GLP-1R agonism may not only be an effective treatment for T2D but also prevent or delay the disease manifestation in at-risk individuals. A recent study also found that a new GLP-1R agonist, peptide 8, had a greater insulinotropic effect (at $30 \mathrm{nM}$ ) than GLP-1 on rat islets, and this agonist was also shown to have effects similar to exendin4 in mice during an OGTT. ${ }^{312}$ However, peptide 8 had a significant glucose-lowering effect even when it was administered $30 \mathrm{~min}$ before the OGTT, in contrast to exendin-4, due to its extended duration of action. The clinical potential of peptide 8 is another area of future research, given its enhanced insulinotropic activity over GLP-1 and other GLP-1R orthosteric agonists tested in this study. Given the different structures of GLP-1R agonists, it is plausible that how they bind to GLP-1R differs, which subsequently produces differential activation of the receptor, explaining the observations from studies. ${ }^{288,312}$ Further understanding mechanistically how GLP-1R can be activated differently by different orthosteric and allosteric agonists may have clinical relevance in the future. Given the conflicting findings observed between human and animal studies investigating the activity of hormones involved in regulating metabolic homeostasis (especially GLP-1), it is important to note that observations from animal studies may have limited clinical implications for developing new T2D therapies for humans. 257,305

Interestingly, over recent years, it has become increasingly recognised that the aetiology of T2D encompasses autoimmune activity, similar to T1D. ${ }^{313}$ Strikingly, studies have demonstrated that islet-reactive T-cells can be found in phenotypic human T2D patients, and many studies have found that a subset of T2D patients test positive for islet beta-cell autoantibodies - these T-cells and antibodies are usually associated with T1D pathogenesis. ${ }^{313}$ One study found that $12 \%$ of $\mathrm{T} 2 \mathrm{D}$ patients screened for islet autoantibodies were positive for at least one islet autoantibody. ${ }^{314}$ Staggeringly, islet reactive T-cells were found in $72 \%$ of phenotypic T2D patients that participated in one study, which was an unexpected finding, especially as great care was taken to select patients that had minimal chance of being misdiagnosed with T2D and have T1D all participants were obese or had an increased waist-tohip ratio, had no history of ketoacidosis, and had not received insulin treatment. ${ }^{315}$ Convincing evidence of autoimmunity being involved in T2D pathogenesis was also provided by a study that induced B lymphocyte deficiency in New Zealand obese mice (an obese polygenic mouse model of obesity and T2D), as B lymphocyte deficient mice were found to not develop T2D - this implies that B cells may be vital for T2D pathogenesis. ${ }^{316}$ Further evidence of B lymphocyte involvement in T2D pathogenesis has been provided by the observation that the B cells of T2D patients fail to secrete IL-10 (an important negative immunoregulatory molecule) after stimulation. ${ }^{317}$ The notion that T1D and T2D may not have such distinct aetiologies as previously thought is certainly an area for future research and is of great interest. If it becomes elucidated that T2D does have an autoimmune aetiology then it can be classified as a less severe variant of T1D, as T2D patients do not exhibit the absolute insulin deficiency seen in T1D. Additionally, if both T1D and T2D have similar autoimmune aetiologies, understanding why T2D patients do not have the T1D clinical phenotype is an important area of future research.

A recent study found by using live-cell imaging that the ability of insulin vesicles to successfully dock onto the plasma membrane correlates with insulin secretion from human islet beta-cells and this was shown to be reduced in T2D. ${ }^{318}$ This study found that defective insulin secretion in T2D islet beta-cells was caused by a drastically decreased rate of successful docking events (docking events were found to be 5-fold more frequent in nondiabetic beta-cells compared to diabetic beta-cells), rather than reduced delivery of insulin vesicles to the plasma membrane, which was found to be similar between nondiabetic and diabetic beta-cells. Expression analysis found that the expression of proteins involved in granule docking was downregulated in T2D. Hence, this suggests in T2D that defective molecular attachment of insulin vesicles to the release site results in inadequate plasma insulin levels to promote normoglycaemia, and that the diabetic phenotype is not as a result of intracellular insulin content and/or the number of insulin vesicles being insufficient in diabetic islet beta-cells. Improving islet beta-cell granule docking, therefore, represents an attractive and new therapeutic target for the development of antidiabetic therapies. 
A recent systematic review and meta-analysis reported that using hematopoietic stem cells and mesenchymal stem cells derived from bone marrow, placenta or umbilical cord tissue to treat T2D is generally safe. The stem cell therapy also improves one or more of the following for T2D patients: levels of C-peptide, HbA1c, quality of life score, and insulin requirements. ${ }^{319-321}$ However, there have been inconsistencies with these findings generated in other studies and one study reported severe infections in T1D patients after the stem cell therapy. ${ }^{319,322-324}$ Additionally, the mechanism by which these stem cells exert any positive effects is debated. Also, the studies that were used to generate these findings had several design flaws with regard to deducing accurate conclusions and the total sample size was not large enough. ${ }^{319}$ The encouraging preliminary results from these studies warrant validation in larger, randomized, double-blind studies, as well as longer follow-up periods to establish the possibility of stem cell-based therapies for future T2D treatment.

\section{Conclusion}

A better understanding of metabolic homeostasis in healthy individuals and the altered metabolic phenotype in T2D will likely lead to the development of better treatments for T2D. The role of the nervous system, genetics, hormones involved in metabolic homeostasis (such as insulin, glucagon, GLP-1 and GIP), glucolipotoxicity diets and feeding behaviours, sedentary lifestyles, altered islet architecture, the immune system, altered islet-cell behaviour, UCP2, altered extrapancreatic behaviour and risk factors (such as psychological stress) have in T2D aetiology and pathogenesis remains to be mechanistically understood. Given that T2D is a multifactorial disease involving an array of hormones, their receptors and subsequent intracellular activity, future therapeutic research needs to take into account how the action of all of these hormones interact synergistically in T2D to produce the altered metabolic phenotype, and also how treatments such as GLP-1R activation-based therapies can influence this hormonal synergism to produce a metabolic phenotype more similar to that of a healthy individual. GLP-1R agonists are an attractive target to generate more effective therapies for T2D given that they have been reported to have beneficial effects on multiple organs in the body, which are involved in disease pathology.

\section{Abbreviations}

ADP/ATP, adenosine diphosphate/triphosphate; BMI, Body mass index; cAMP, cyclic adenosine monophosphate; CVD, Cardiovascular disease; CNS, Central nervous system; DN, Diabetic nephropathy; DIO, Diet-induced obese; DPP, Dipeptidyl peptidase; GIP, Gastric inhibitory peptide; GIPR, Gastric inhibitory peptide receptor; GIT, Gastrointestinal tract; GLP-1, Glucagon-like peptide-1 GLP-1, glucagon-like peptide-1; GLP-1R, GLP-1 receptor; GSIS, glucose-stimulated insulin secretion; GR, Glucagon receptor; HDL, High-density lipoprotein; IAPP, Islet amyloid polypeptide; IFG, Impaired fasting glucose; IGF, Insulin-like growth factor; IR, Insulin receptor; LDL, Low-density lipoprotein; NAFLD, Non-alcoholic fatty liver disease; NO, Nitric Oxide; PPG, Preproglucagon; PMF, Proton motive force; ROS, Reactive oxygen species; T1D/T2D, type 1/2 diabetes; UCP1/2, Uncoupler protein 1/2; WHO, World Health Organisation.

\section{Acknowledgments}

The work in VK's laboratory was supported by grants from Biotechnology and Biological Sciences Research Council (BBSRC) UK (BB/F017596/1, BB/C515455/2 and BB/ S019588/1) and Medical Research Council (MRC) UK (G0401232). JR was a recipient of the Knowledge Economy Skills Scholarship (KESS) II UK PhD studentship. We thank the members of the VK laboratory.

\section{Disclosure}

The authors report no conflicts of interest in this work.

\section{References}

1. Guariguata L, Whiting DR, Hambleton I, Beagley J, Linnenkamp U, Shaw JE. Global estimates of diabetes prevalence for 2013 and projections for 2035. Diabetes Res Clin Pract. 2014;103(2):137-149. doi:10.1016/j.diabres.2013.11.002

2. Ozougwu JC, Obimba KC, Belonwu CD, Unakalamba CB. The pathogenesis and pathophysiology of type 1 and type 2 diabetes mellitus. $J$ Physiol Pathophysiol. 2013;4:46-57. doi:10.5897/JPAP2013.0001

3. Thompson A, Kanamarlapudi V. Type 2 Diabetes mellitus and glucagon like peptide-1 receptor signalling. Clin Exp Pharmacol. 2013;1:3.

4. Maahs DM, West NA, Lawrence JM, Mayer-Davis EJ. Chapter 1: epidemiology of Type 1 Diabetes. Endocrinol Metab Clin North Am. 2010;39(3):481-497. doi:10.1016/j.ecl.2010.05.011

5. Kahn SE, Cooper ME, Del Prato S. Pathophysiology and treatment of type 2 diabetes: perspectives on the past, present, and future. Lancet. 2014;383(9922):1068-1083. doi:10.1016/S0140-6736(13)62154-6

6. Leahy JL. Pathogenesis of Type 2 Diabetes Mellitus. Arch Med Res. 2005;36(3):197-209. doi:10.1016/j.arcmed.2005.01.003

7. Chen L, Magliano DJ, Zimmet PZ. The worldwide epidemiology of type 2 diabetes mellitus[mdash]present and future perspectives. Nat Rev Endocrinol. 2012;8(4):228-236. doi:10.1038/nrendo.2011.183

8. Raz I. Guideline approach to therapy in patients with newly diagnosed type 2 diabetes. Diabetes Care. 2013;36(Suppl 2):S139-S144. doi:10.2337/dcS13-2035 
9. Golay A, Ybarra J. Link between obesity and type 2 diabetes. Best Pract Res Clin Endocrinol Metab. 2005;19(4):649-663. doi:10.1016/j.beem.2005.07.010

10. Haslam D. Obesity and diabetes: the links and common approaches. Prim Care Diabetes. 2010;4(2):105-112. doi:10.1016/j.pcd.2010.04.002

11. Horton ES, Silberman C, Davis KL, Berria R. Weight Loss, Glycemic Control, and Changes in Cardiovascular Biomarkers in Patients With Type 2 Diabetes Receiving Incretin Therapies or Insulin in a Large Cohort Database. Diabetes Care. 2010;33 (8):1759-1765. doi:10.2337/dc09-2062

12. Wilding JPH. The importance of weight management in type 2 diabetes mellitus. Int $J$ Clin Pract. 2014;68(6):682-691. doi:10.1111/ijcp.12384

13. Fujioka K. Follow-up of nutritional and metabolic problems after bariatric surgery. Diabetes Care. 2005;28(2):481-484. doi:10.2337/diacare.28.2.481

14. Thompson A, Stephens JW, Bain SC, Kanamarlapudi V. Molecular characterisation of small molecule agonists effect on the human glucagon like peptide-1 receptor internalisation. PLoS One. 2016;11 (4):e0154229-e0154229. doi:10.1371/journal.pone.0154229

15. Kyrou IRH, Weickert MO. Clinical Problems Caused by Obesity. South Dartmouth: Endotext; 2010.

16. Nguyen DM, El-Serag HB. The Epidemiology of Obesity. Gastroenterol Clin North Am. 2010;39(1):1-7. doi:10.1016/j. gtc.2009.12.014

17. Paz-Filho G, Mastronardi C, Delibasi T, Wong M-L, Licinio J. Congenital leptin deficiency: diagnosis and effects of leptin replacement therapy. Arq Bras Endocrinol Metabol. 2010;54(8):690697. doi:10.1590/S0004-27302010000800005

18. WHO. Obesity and overweight; 2014 . Available from: http://www. who.int/mediacentre/factsheets/fs311/en/. Accessed July 12, 2021.

19. Malnick SDH, Knobler H. The medical complications of obesity. QJM. 2006;99(9):565-579. doi:10.1093/qjmed/hc1085

20. Must A. The Disease Burden Associated with Overweight and Obesity. South Dartmouth: Endotext; 2012.

21. Bagdade JD, Bierman EL, Porte D. The significance of basal insulin levels in the evaluation of the insulin response to glucose in diabetic and nondiabetic subjects. J Clin Invest. 1967;46 (10):1549-1557. doi:10.1172/JCI105646

22. Ferrannini E, Natali A, Bell P, Cavallo-Perin P, Lalic N, Mingrone G. Insulin resistance and hypersecretion in obesity. European Group for the Study of Insulin Resistance (EGIR). J Clin Invest. 1997;100(5):1166-1173. doi:10.1172/JCI119628

23. Gerald R. All obese individuals are not created equal: insulin resistance is the major determinant of cardiovascular disease in overweight/obese individuals. Diabetes Vascular Dis Res. 2005;2 (3):105-112. doi:10.3132/dvdr.2005.017

24. Templeman NM, Skovsø S, Page MM, Lim GE, Johnson JD. A causal role for hyperinsulinemia in obesity. $J$ Endocrinol. 2017;2017:58.

25. Weng J, Ji L, Jia W, et al. Standards of care for type 2 diabetes in China. Diabetes Metab Res Rev. 2016;32(5):442-458. doi:10.1002/dmrr.2827

26. Hegazi R, El-Gamal M, Abdel-Hady N, Hamdy O. Epidemiology of and risk factors for type 2 diabetes in egypt. Ann Global Health. 2015;81(6):814-820. doi:10.1016/j.aogh.2015.12.011

27. Wild SH, Byrne CD. Commentary: sub-types of diabetes-what's new and what's not. Int $J$ Epidemiol. 2013;42(6):1600-1602. doi:10.1093/ije/dyt201

28. Hu FB. Globalization of Diabetes. Role Diet Lifestyle Genes. 2011;34(6):1249-1257.

29. D'Alessio D. The role of dysregulated glucagon secretion in type 2 diabetes. Diabetes Obes Metab. 2011;13:126-132. doi:10.1111/ j.1463-1326.2011.01449.x
30. Lin Y, Sun Z. Current views on type 2 diabetes. J Endocrinol. 2010;204(1):1. doi:10.1677/JOE-09-0260

31. Okon EB, Chung AWY, Zhang H, Laher I, van Breemen C. Hyperglycemia and hyperlipidemia are associated with endothelial dysfunction during the development of type 2 diabetes. Can $J$ Physiol Pharmacol. 2007;85(5):562-567. doi:10.1139/Y07-026

32. Voet D, Voet J. Biochemistry. 4th ed. New York: Wiley \& Sons; 2011.

33. Whitmore C. Type 2 diabetes and obesity in adults. Br J Nursing. 2010;19(14):880-886. doi:10.12968/bjon.2010.19.14.49041

34. Zhou X, Ji L, Ran X, et al. Prevalence of Obesity and Its Influence on Achievement of Cardiometabolic Therapeutic Goals in Chinese Type 2 Diabetes Patients: an Analysis of the Nationwide, Cross-Sectional 3B Study. PLoS One. 2016;11(1): e0144179. doi:10.1371/journal.pone.0144179

35. Mathews AEW, Mathews CE. Inherited $\beta$-Cell Dysfunction in Lean Individuals With Type 2 Diabetes. Diabetes. 2012;61 (7):1659-1660. doi:10.2337/db12-0373

36. Ali O. Genetics of type 2 diabetes. World J Diabetes. 2013;4 (4):114-123. doi:10.4239/wjd.v4.i4.114

37. Prasad RB, Groop L. Genetics of Type 2 Diabetes-Pitfalls and Possibilities. Genes. 2015;6(1):87-123. doi:10.3390/genes6010087

38. Faerch KHA, Solomon TP. Heterogeneity of Pre-diabetes and Type 2 Diabetes: implications for Prediction, Prevention and Treatment Responsiveness. Curr Diabetes Rev. 2016;12:30-41. doi:10.2174/1573399811666150416122903

39. Karalliedde J, Gnudi L. Diabetes mellitus, a complex and heterogeneous disease, and the role of insulin resistance as a determinant of diabetic kidney disease. Nephrol Dialysis Transplant. 2016;31(2):206-213.

40. Brownlee M. Biochemistry and molecular cell biology of diabetic complications. Nature. 2001;414(6865):813-820. doi:10.1038/ 414813a

41. Holman N, Young RJ, Jeffcoate WJ. Variation in the recorded incidence of amputation of the lower limb in England. Diabetologia. 2012;55(7):1919-1925. doi:10.1007/s00125-012-2468-6

42. Akter K, Lanza EA, Martin SA, Myronyuk N, Rua M, Raffa RB. Diabetes mellitus and Alzheimer's disease: shared pathology and treatment? $\mathrm{Br} \quad J$ Clin Pharmacol. 2011;71(3):365-376. doi:10.1111/j.1365-2125.2010.03830.x

43. Hu G, Jousilahti P, Bidel S, Antikainen R, Tuomilehto J. Type 2 Diabetes and the Risk of Parkinson's Disease. Diabetes Care. 2007;30(4):842-847. doi:10.2337/dc06-2011

44. Ali MK, Narayan V, Tandon N. Diabetes \& coronary heart disease: current perspectives. Indian J Med Res. 2010;132(5):584597.

45. Leal J, Gray AM, Clarke PM. Development of life-expectancy tables for people with type 2 diabetes. Eur Heart J. 2009;30 (7):834-839. doi:10.1093/eurheartj/ehn567

46. Mazzola N. Review of current and emerging therapies in type 2 diabetes mellitus. Am J Manag Care. 2012;18:17-26.

47. Olokoba AB, Obateru OA, Olokoba LB. Type 2 Diabetes Mellitus: a Review of Current Trends. Oman Med J. 2012;27 (4):269-273. doi:10.5001/omj.2012.68

48. Amiel SA, Dixon T, Mann R, Jameson K. Hypoglycaemia in Type 2 diabetes. Diabetic Med. 2008;25(3):245-254. doi:10.1111/j.1464-5491.2007.02341.x

49. Fonseca VA. Defining and Characterizing the Progression of Type 2 Diabetes. Diabetes Care. 2009;32(Suppl 2):S151-S156. doi: $10.2337 / \mathrm{dc} 09-\mathrm{S} 301$

50. Leibowitz G, Kaiser N, Cerasi E. $\beta$-Cell failure in type 2 diabetes. $J$ Diabetes Investig. 2011;2(2):82-91. doi:10.1111/j.20401124.2010.00094.x

51. Forbes JM, Cooper ME. Mechanisms of Diabetic Complications. Physiol Rev. 2013;93(1):137-188. doi:10.1152/ physrev.00045.2011 
52. Bhurosy T, Jeewon R. Overweight and Obesity Epidemic in Developing Countries: a Problem with Diet, Physical Activity, or Socioeconomic Status? Scientific World J. 2014;2014:7. doi: $10.1155 / 2014 / 964236$

53. Shaw JE, Sicree RA, Zimmet PZ. Global estimates of the prevalence of diabetes for 2010 and 2030. Diabetes Res Clin Pract. 2010;87(1):4-14. doi:10.1016/j.diabres.2009.10.007

54. Onge ES, Miller SA, Motycka C, DeBerry A. A review of the treatment of type 2 diabetes in children. J Pediatric Pharmacol Therapeutics. 2015;20(1):4-16. doi:10.5863/1551-6776-20.1.4

55. Reinehr T. Type 2 diabetes mellitus in children and adolescents. World J Diabetes. 2013;4(6):270-281. doi:10.4239/wjd.v4.i6.270

56. Atkinson MA. The pathogenesis and natural history of type 1 diabetes. Cold Spring Harb Perspect Med. 2012;2(11):a007641. doi:10.1101/cshperspect.a007641

57. Turner R, Stratton I, Horton V, et al. UKPDS 25: autoantibodies to islet-cell cytoplasm and glutamic acid decarboxylase for prediction of insulin requirement in type 2 diabetes. Lancet. 1997;350 (9087):1288-1293. doi:10.1016/S0140-6736(97)03062-6

58. Cizza G, Brown RJ, Rothe KI. Rising incidence and challenges of childhood diabetes. A mini review. J Endocrinol Invest. 2012;35 (5):541-546. doi:10.3275/8411

59. Kaufman FR. Type 2 Diabetes in Children and Young Adults: a "New Epidemic". Clin Diabetes. 2002;20(4):217-218. doi: $10.2337 /$ diaclin.20.4.217

60. D'Adamo E, Caprio S. Type 2 diabetes in youth: epidemiology and pathophysiology. Diabetes Care. 2011;34(Suppl 2):S161S165. doi:10.2337/dc11-s212

61. Liao C, Zhang D, Mungo C, Tompkins DA, Zeidan AM. Is diabetes mellitus associated with increased incidence and disease-specific mortality in endometrial cancer? A systematic review and meta-analysis of cohort studies. Gynecol Oncol. 2014;135(1):163-171. doi:10.1016/j.ygyno.2014.07.095

62. Saeedi P, Petersohn I, Salpea P, et al. Global and regional diabetes prevalence estimates for 2019 and projections for 2030 and 2045: results from the International Diabetes Federation Diabetes Atlas, 9th edition. Diabetes Res Clin Pract. 2019;2:157.

63. Ginter E, Type VS. 2 diabetes mellitus, pandemic in 21 st century. Adv Exp Med Biol. 2012;771:42-50.

64. Mi H. Diabetes in America. New York: U.S. DEPARTMENT OF HEALTH AND HUMAN SERVICES* Public Health Service* National Institutes of Health; 1985.

65. Kaveeshwar SA, Cornwall J. The current state of diabetes mellitus in India. Australas Med J. 2014;7(1):45-48. doi:10.4066/ AMJ.2014.1979

66. Sosale A, Prasanna Kumar KM, Sadikot SM, et al. Chronic complications in newly diagnosed patients with Type 2 diabetes mellitus in India. Indian J Endocrinol Metab. 2014;18(3):355360. doi:10.4103/2230-8210.131184

67. Burke JP, Williams K, Gaskill SP, Hazuda HP, Haffner SM, Stern MP. Rapid rise in the incidence of type 2 diabetes from 1987 to 1996: results from the san antonio heart study. Arch Intern Med. 1999;159(13):1450-1456. doi:10.1001/archinte.159.13.1450

68. Bos M, Agyemang C. Prevalence and complications of diabetes mellitus in Northern Africa, a systematic review. BMC Public Health. 2013;13:387. doi:10.1186/1471-2458-13-387

69. Ardisson Korat AV, Willett WC, Hu FB. Diet, lifestyle, and genetic risk factors for type 2 diabetes: a review from the Nurses' Health Study, Nurses' Health Study 2, and Health Professionals' Follow-up Study. Curr Nutr Rep. 2014;3(4):345354. doi:10.1007/s13668-014-0103-5

70. Nguyen NT, Nguyen X-MT, Lane J, Wang P. Relationship Between Obesity and Diabetes in a US Adult Population: findings from the National Health and Nutrition Examination Survey, 1999-2006. Obes Surg. 2011;21(3):351-355. doi:10.1007/ s11695-010-0335-4
71. George AM, Jacob AG, Fogelfeld L. Lean diabetes mellitus: an emerging entity in the era of obesity. World J Diabetes. 2015;6 (4):613-620. doi:10.4239/wjd.v6.i4.613

72. Ma RCW, Chan JCN. Type 2 diabetes in East Asians: similarities and differences with populations in Europe and the United States. Ann N Y Acad Sci. 2013;1281(1):64-91. doi:10.1111/nyas.12098

73. Gastaldelli A. Abdominal fat: does it predict the development of type 2 diabetes? Am J Clin Nutr. 2008;87(5):1118-1119. doi:10.1093/ajen/87.5.1118

74. Noble JA, Erlich HA. Genetics of Type 1 Diabetes. Cold Spring Harb Perspect Med. 2012;2(1):a007732. doi:10.1101/cshperspect. a007732

75. Ahlqvist E, Ahluwalia TS, Groop L. Genetics of Type 2 Diabetes. Clin Chem. 2011;57(2):241-254. doi:10.1373/clinchem.2010.157016

76. Hyttinen V, Kaprio J, Kinnunen L, Koskenvuo M, Tuomilehto J. Genetic Liability of Type 1 Diabetes and the Onset Age Among 22,650 Young Finnish Twin Pairs. Nationwide Follow Up Study. 2003;52(4):1052-1055.

77. Poulsen P, Grunnet LG, Pilgaard K, et al. Increased Risk of Type 2 Diabetes in Elderly Twins. Diabetes. 2009;58(6):1350-1355. doi: $10.2337 / \mathrm{db} 08-1714$

78. Mozaffarian D, Kamineni A, Carnethon M, Djoussé L, Mukamal KJ, Siscovick D. Lifestyle risk factors and new-onset diabetes mellitus in older adults: the cardiovascular health study. Arch Intern Med. 2009;169(8):798-807. doi:10.1001/ archinternmed.2009.21

79. Kelly SJIM. Stress and type 2 diabetes: a review of how stress contributes to the development of type 2 diabetes. Annu Rev Public Health. 2015;18:441-462. doi:10.1146/annurev-publhealth-031914-122921

80. Kautzky-Willer A, Harreiter J, Pacini G. Sex and Gender Differences in Risk, Pathophysiology and Complications of Type 2 Diabetes Mellitus. Endocr Rev. 2016;37(3):278-316.

81. Sattar N. Gender aspects in type 2 diabetes mellitus and cardiometabolic risk. Best Pract Res Clin Endocrinol Metab. 2013;27 (4):501-507. doi:10.1016/j.beem.2013.05.006

82. Doró P, Benkő R, Matuz M, Soós G. Seasonality in the Incidence of Type 2 Diabetes. Diabetes Care. 2006;29(1):173. doi:10.2337/ diacare.29.01.06.dc05-1839

83. Si J, Yu C, Guo Y, et al. Season of birth and the risk of type 2 diabetes in adulthood: a prospective cohort study of 0.5 million Chinese adults. Diabetologia. 2017;60(5):836-842. doi:10.1007/ s00125-016-4200-4

84. Corkey BE. Diabetes: have We Got It All Wrong?: insulin hypersecretion and food additives: cause of obesity and diabetes? Diabetes Care. 2012;35(12):2432-2437. doi:10.2337/dc12-0825

85. Alonso-Magdalena P, Quesada INA. Endocrine disruptors in the etiology of type 2 diabetes mellitus. Nat Rev Endocrinol. 2011;7:346-353. doi:10.1038/nrendo.2011.56

86. Sun Y, Pei W, Wu Y, Yang Y. An Association of Herpes Simplex Virus Type 1 Infection With Type 2 Diabetes. Diabetes Care. 2005;28(2):435. doi:10.2337/diacare.28.2.435

87. Wang C-S, Wang S-T, Yao W-J, Chang -T-T, Chou P. Hepatitis C Virus Infection and the Development of Type 2 Diabetes in a Community-based Longitudinal Study. Am J Epidemiol. 2007;166 (2):196-203. doi:10.1093/aje/kwm061

88. Bose SK, Ray R. Hepatitis C virus infection and insulin resistance. World J Diabetes. 2014;5(1):52-58. doi:10.4239/wjd.v5.i1.52

89. Torres DM, Harrison SA. Hepatitis C virus and insulin resistance/ diabetes mellitus. Gastroenterol Hepatol (N Y). 2008;4(8):568570.

90. Bansal N. Prediabetes diagnosis and treatment: a review. World $J$ Diabetes. 2015;6(2):296-303. doi:10.4239/wjd.v6.i2.296

91. Tabák AG, Herder C, Rathmann W, Brunner EJ, Kivimäki M. Prediabetes: a high-risk state for developing diabetes. Lancet. 2012;379(9833):2279-2290. doi:10.1016/S0140-6736(12)60283-9 
92. Tuso P. Prediabetes and lifestyle modification: time to prevent a preventable disease. Permanente J Summer. 2014;18(3):88-93. doi:10.7812/TPP/14-002

93. Davidson MB, Schriger DL, Peters AL, Lorber B. Revisiting the oral glucose tolerance test criterion for the diagnosis of diabetes. $J$ Gen Intern Med. 2000;15(8):551-555. doi:10.1046/j.15251497.2000.08024.x

94. Affourtit C. Mitochondrial involvement in skeletal muscle insulin resistance: a case of imbalanced bioenergetics. Biochimica Et Biophysica Acta. 2016;1857(10):1678-1693.

95. Muoio DM, Newgard CB. Molecular and metabolic mechanisms of insulin resistance and [beta]-cell failure in type 2 diabetes. Nat Rev Mol Cell Biol. 2008;9(3):193-205. doi:10.1038/nrm2327

96. Linnemann AK, Baan M, Davis DB. Pancreatic $\beta$-Cell Proliferation in Obesity. Adv Nutrition. 2014;5(3):278-288. doi:10.3945/an.113.005488

97. Mehran Arya E, Templeman Nicole M, Brigidi GS, et al. Hyperinsulinemia drives diet-induced obesity independently of brain insulin production. Cell Metab. 2012;16(6):723-737. doi:10.1016/j.cmet.2012.10.019

98. Boland BB, Rhodes CJ, Grimsby JS. The dynamic plasticity of insulin production in $\beta$-cells. Mol Metab. 2017;6(9):958-973.

99. Cerf ME. Beta Cell Dysfunction and Insulin Resistance. Front Endocrinol (Lausanne). 2013;4:37. doi:10.3389/fendo.2013.00037

100. Achenbach P, Hummel M, Thümer L, Boerschmann H, Höfelmann D, Ziegler AG. Characteristics of rapid vs slow progression to type 1 diabetes in multiple islet autoantibody-positive children. Diabetologia. 2013;56(7):1615-1622. doi:10.1007/s00125-013-2896-y

101. Breuer TGK, Menge BA, Banasch M, et al. Proinsulin levels in patients with pancreatic diabetes are associated with functional changes in insulin secretion rather than pancreatic $\beta$-cell area. Eur $J$ Endocrinol. 2010;163(4):551-558. doi:10.1530/EJE-10-0330

102. Pfützner A, Hermanns I, Ramljak S, et al. Elevated Intact proinsulin levels during an oral glucose challenge indicate progressive cell dysfunction and may be predictive for development of type 2 diabetes. J Diabetes Sci Technol. 2015;9(6):1307-1312. doi:10.1177/ 1932296815607862

103. Vangipurapu J, Stančáková A, Kuulasmaa T, Kuusisto J, Laakso M. Both Fasting and Glucose-Stimulated Proinsulin Levels Predict Hyperglycemia and Incident Type 2 Diabetes: a Population-Based Study of 9,396 Finnish Men. PLoS One. 2015;10(4):e0124028. doi:10.1371/journal.pone.0124028

104. Cernea S, Dobreanu M. Diabetes and beta cell function: from mechanisms to evaluation and clinical implications. Biochem Med (Zagreb). 2013;23(3):266-280. doi:10.11613/BM.2013.033

105. Wilcox G. Insulin and Insulin Resistance. Clin Biochemist Rev. 2005;26(2):19-39.

106. Perilli G, Saraceni C, Daniels MN, Ahmad A. Diabetic ketoacidosis: a review and update. Curr Emerg Hosp Med Rep. 2013;1 (1):10-17. doi:10.1007/s40138-012-0001-3

107. Woerle HJ, Carneiro L, Derani A, Göke B, Schirra J. The role of endogenous incretin secretion as amplifier of glucose-stimulated insulin secretion in healthy subjects and patients with type 2 diabetes. Diabetes. 2012;61(9):2349-2358. doi:10.2337/db11-1701

108. Atkinson MA, Eisenbarth GS, Michels AW. Type 1 diabetes. Lancet. 2014;383(9911):69-82. doi:10.1016/S0140-6736(13)60591-7

109. White H, Venkatesh B. Clinical review: ketones and brain injury. Critical Care. 2011;15(2):219. doi:10.1186/cc10020

110. Gosmanov AR, Gosmanova EO, Dillard-Cannon E. Management of adult diabetic ketoacidosis. Diabetes Metab Syndrome Obesity. 2014;7:255-264. doi:10.2147/DMSO.S50516

111. Olson AL. Regulation of GLUT4 and Insulin-Dependent Glucose Flux. ISRN Molecular Biol. 2012;2012:12. doi:10.5402/2012/856987

112. Hardy OT, Czech MP, Corvera S. What causes the insulin resistance underlying obesity? Curr Opin Endocrinol Diabetes Obes. 2012;19(2):81-87. doi:10.1097/MED.0b013e3283514e13
113. Goodpaster BH, He J, Watkins S, Kelley DE. Skeletal Muscle Lipid Content and Insulin Resistance: evidence for a Paradox in Endurance-Trained Athletes. J Clin Endocrinol Metab. 2001;86 (12):5755-5761. doi:10.1210/jcem.86.12.8075

114. van Loon LJC, Koopman R, Manders R, van der Weegen W, van Kranenburg GP, Keizer HA. Intramyocellular lipid content in type 2 diabetes patients compared with overweight sedentary men and highly trained endurance athletes. Am J Physiol. 2004;287(3): E558-E565. doi:10.1152/ajpendo.00464.2003

115. Vaag A, Lund SS. Non-obese patients with type 2 diabetes and prediabetic subjects: distinct phenotypes requiring special diabetes treatment and (or) prevention? Applied Physiol Nutrition Metab. 2007;32(5):912-920. doi:10.1139/H07-100

116. Chang SA, Kim HS, Yoon KH, et al. Body mass index is the most important determining factor for the degree of insulin resistance in non-obese type 2 diabetic patients in Korea. Metab Clin Exp. 2004;53(2):142-146. doi:10.1016/S0026-0495 (03)00314-7

117. Khaodhiar L, Cummings S, Apovian CM. Treating diabetes and prediabetes by focusing on obesity management. Curr Diab Rep. 2009;9(5):348-354. doi:10.1007/s11892-009-0055-0

118. Madeira FB, Silva AA, Veloso HF, et al. Normal Weight Obesity Is Associated with Metabolic Syndrome and Insulin Resistance in Young Adults from a Middle-Income Country. PLoS One. 2013;8 (3):e60673. doi:10.1371/journal.pone.0060673

119. Lim EL, Hollingsworth KG, Aribisala BS, Chen MJ, Mathers JC, Taylor R. Reversal of type 2 diabetes: normalisation of beta cell function in association with decreased pancreas and liver triacylglycerol. Diabetologia. 2011;54(10):2506-2514. doi:10.1007/ s00125-011-2204-7

120. Taylor R. Pathogenesis of type 2 diabetes: tracing the reverse route from cure to cause. Diabetologia. 2008;51(10):1781-1789. doi:10.1007/s00125-008-1116-7

121. DeLany JP, Dubé JJ, Standley RA, et al. Racial Differences In Peripheral Insulin Sensitivity and Mitochondrial Capacity in the Absence of Obesity. J Clin Endocrinol Metab. 2014;99(11):43074314. doi:10.1210/jc.2014-2512

122. Khoo CM, Leow MK-S, Sadananthan SA, et al. Body Fat Partitioning Does Not Explain the Interethnic Variation in Insulin Sensitivity Among Asian Ethnicity: the Singapore Adults Metabolism Study. Diabetes. 2014;63(3):1093-1102. doi: $10.2337 / \mathrm{db} 13-1483$

123. Yoshino J, Almeda-Valdes P, Patterson BW, et al. Diurnal Variation in Insulin Sensitivity of Glucose Metabolism Is Associated With Diurnal Variations in Whole-Body and Cellular Fatty Acid Metabolism in Metabolically Normal Women. J Clin Endocrinol Metab. 2014;99(9):E1666-E1670. doi:10.1210/jc.2014-1579

124. Butler AE, Janson J, Bonner-Weir S, Ritzel R, Rizza RA, Butler PC. $\beta$-Cell Deficit and Increased $\beta$-Cell Apoptosis in Humans With Type 2 Diabetes. Diabetes. 2003;52(1):102-110. doi:10.2337/diabetes.52.1.102

125. Biarnés M, Montolio M, Nacher V, Raurell M, Soler J, Montanya E. $\beta$-Cell Death and Mass in Syngeneically Transplanted Islets Exposed to Short- and Long-Term Hyperglycemia. Diabetes. 2002;51(1):66-72. doi:10.2337/diabetes.51.1.66

126. Bretherton-Watt D, Ghatei MA, Bloom SR, et al. Altered islet amyloid polypeptide (amylin) gene expression in rat models of diabetes. Diabetologia. 1989;32(12):881-883. doi:10.1007/BF00297454

127. Mulder H, Ahrén B, Sundler F. Islet amyloid polypeptide (amylin) and insulin are differentially expressed in chronic diabetes induced by streptozotocin in rats. Diabetologia. 1996;39(6):649657. doi:10.1007/BF00418536

128. Gupta D, Leahy JL. Islet amyloid and type 2 diabetes: overproduction or inadequate clearance and detoxification? J Clin Invest. 2014;124(8):3292-3294. doi:10.1172/JCI77506 
129. Alrefai HA, Latif KA, Hieronymus LB, Weakley CR, Moss RJ. Pramlintide: clinical Strategies for Success. Diabetes Spectrum. 2010;23(2):124-130. doi:10.2337/diaspect.23.2.124

130. Howard CJ. Diabetes mellitus: relationships of nonhuman primates and other animal models to human forms of diabetes. $A d v$ Vet Sci Comp Med. 1984;28:115-149.

131. Matveyenko AV, Butler PC. Islet Amyloid Polypeptide (IAPP) Transgenic Rodents as Models for Type 2 Diabetes. ILAR J. 2006;47(3):225-233. doi:10.1093/ilar.47.3.225

132. Shigihara N, Fukunaka A, Hara A, et al. Human IAPP-induced pancreatic $\beta$ cell toxicity and its regulation by autophagy. $J$ Clin Invest. 2014;124(8):3634-3644. doi:10.1172/JCI69866

133. Cnop M, Welsh N, Jonas J-C, Jörns A, Lenzen S, Eizirik DL. Mechanisms of Pancreatic $\beta$-Cell Death in Type 1 and Type 2 Diabetes. Many Differences Few Similarities. 2005;54(suppl2):S97S107.

134. Costanzo P, Cleland JF, Pellicori P, et al. The obesity paradox in type 2 diabetes mellitus: relationship of body mass index to prognosis: a cohort study. Ann Intern Med. 2015;162(9):610618. doi:10.7326/M14-1551

135. Hainer V, Aldhoon-Hainerová I. Obesity Paradox Does Exist. Diabetes Care. 2013;36(Supplement 2):S276-S281. doi:10.2337/ dcS13-2023

136. Doehner W, Erdmann E, Cairns R, et al. Inverse relation of body weight and weight change with mortality and morbidity in patients with type 2 diabetes and cardiovascular co-morbidity: an analysis of the PROactive study population. Int $J$ Cardiol. 2012;162(1):20-26. doi:10.1016/j.ijcard.2011.09.039

137. Sohn M-W, Budiman-Mak E, Oh EH, et al. Obesity Paradox in Amputation Risk Among Nonelderly Diabetic Men. Obesity. 2012;20(2):460-462. doi:10.1038/oby.2011.301

138. Coleman NJ, Miernik J, Philipson L, Fogelfeld L. Lean versus obese diabetes mellitus patients in the United States minority population. J Diabetes Complications. 2013;28(4):500-505. doi:10.1016/j.jdiacomp.2013.11.010

139. Kim JY, Song EH, Lee HJ, et al. Chronic Ethanol Consumptioninduced Pancreatic $\beta$-Cell Dysfunction and Apoptosis through Glucokinase Nitration and Its Down-regulation. J Biol Chem. 2010;285(48):37251-37262. doi:10.1074/jbc.M110.142315

140. Gerich JE. Insulin Resistance Is Not Necessarily an Essential Component of Type 2 Diabetes1. J Clin Endocrinol Metab. 2000;85(6):2113-2115.

141. Brereton MF, Vergari E, Zhang Q, Clark A. Alpha-, Delta- and PP-cells: are They the Architectural Cornerstones of Islet Structure and Co-ordination? J Histochem Cytochemistry. 2015;63(8):575-591. doi:10.1369/0022155415583535

142. Moon JS, Won KC. Pancreatic $\alpha$-Cell Dysfunction in Type 2 Diabetes: old Kids on the Block. Diabetes Metab J. 2015;39 (1):1-9. doi:10.4093/dmj.2015.39.1.1

143. Sherwin RS, Fisher M, Hendler R, Felig P. Hyperglucagonemia and Blood Glucose Regulation in Normal, Obese and Diabetic Subjects. $N$ Eng J Med. 1976;294(9):455-461. doi:10.1056/ NEJM197602262940901

144. Ivan Quesada ET, Ripoll C, Nadal Á. Physiology of the pancreatic $\alpha$-cell and glucagon secretion: role in glucose homeostasis and diabetes. $J$ Endocrinol. 2008;2:68-96.

145. Dinneen S, Alzaid A, Turk D, Rizza R. Failure of glucagon suppression contributes to postprandial hyperglycaemia in IDDM. Diabetologia. 1995;38(3):337-343. doi:10.1007/ BF00400639

146. Reaven GM, Chen YDI, Golay A, Swislocki ALM, Jaspan JB. Documentation of Hyperglucagonemia Throughout the Day in Nonobese and Obese Patients with Noninsulin-Dependent Diabetes Mellitus*. J Clin Endocrinol Metab. 1987;64(1):106110. doi:10.1210/jcem-64-1-106
147. Shah P, Vella A, Basu A, Basu R, Schwenk WF, Rizza RA. Lack of Suppression of Glucagon Contributes to Postprandial Hyperglycemia in Subjects with Type 2 Diabetes Mellitus1. $J$ Clin Endocrinol Metab. 2000;85(11):4053-4059.

148. Baron AD, Schaeffer L, Shragg P, Kolterman OG. Role of Hyperglucagonemia in Maintenance of Increased Rates of Hepatic Glucose Output in Type II Diabetics. Diabetes. 1987;36 (3):274-283. doi:10.2337/diab.36.3.274

149. Kawamori D, Kurpad AJ, Hu J, et al. Insulin Signaling in $\alpha$-cells Modulates Glucagon Secretion in vivo. Cell Metab. 2009;9 (4):350-361. doi:10.1016/j.cmet.2009.02.007

150. Elder DA, Prigeon RL, Wadwa RP, Dolan LM, D'Alessio DA. $\beta$-Cell Function, Insulin Sensitivity, and Glucose Tolerance in Obese Diabetic and Nondiabetic Adolescents and Young Adults. J Clin Endocrinol Metab. 2006;91(1):185-191. doi:10.1210/jc.2005-0853

151. Kilimnik G, Zhao B, Jo J, et al. Altered Islet Composition and Disproportionate Loss of Large Islets in Patients with Type 2 Diabetes. PLoS One. 2011;6(11):e27445. doi:10.1371/journal. pone. 0027445

152. Brereton MF, Iberl M, Shimomura K, et al. Reversible changes in pancreatic islet structure and function produced by elevated blood glucose. Nat Commun. 2014;5:4639. doi:10.1038/ncomms5639

153. Clark A, Wells CA, Buley ID, et al. Islet amyloid, increased A-cells, reduced B-cells and exocrine fibrosis: quantitative changes in the pancreas in type 2 diabetes. Diabetes Res. 1988;9:151-159.

154. Rahier J, Goebbels RM, Henquin JC. Cellular composition of the human diabetic pancreas. Diabetologia. 1983;24(5):366-371. doi:10.1007/BF00251826

155. Guardado Mendoza R, Perego C, Finzi G, et al. Delta cell death in the islet of Langerhans and the progression from normal glucose tolerance to type 2 diabetes in non-human primates (baboon, Papio hamadryas). Diabetologia. 2015;58(8):1814-1826. doi:10.1007/s00125-015-3625-5

156. Talchai C, Xuan S, Lin HV, Sussel L, Accili D. Pancreatic $\beta$-Cell Dedifferentiation As Mechanism Of Diabetic $\beta$-Cell Failure. Cell. 2012;150(6):1223-1234. doi:10.1016/j.cell.2012.07.029

157. Ahrén B. Incretin dysfunction in type 2 diabetes: clinical impact and future perspectives. Diabetes Metab. 2013;39:195-201. doi:10.1016/j.diabet.2013.03.001

158. Meier JJ, Nauck MA. Is the Diminished Incretin Effect in Type 2 Diabetes Just an Epi-Phenomenon of Impaired $\beta$-Cell Function? Diabetes. 2010;59(5):1117-1125. doi:10.2337/db09-1899

159. Pratley RE. GIP: an Inconsequential Incretin or Not? Diabetes Care. 2010;33(7):1691-1692. doi:10.2337/dc10-0704

160. Nauck MA, Heimesaat MM, Orskov C, Holst JJ, Ebert R, Creutzfeldt W. Preserved incretin activity of glucagon-like peptide 1 [7-36 amide] but not of synthetic human gastric inhibitory polypeptide in patients with type-2 diabetes mellitus. $J$ Clin Invest. 1993;91(1):301-307. doi:10.1172/JCI116186

161. Højberg PV, Vilsbøll T, Rabøl R, et al. Four weeks of nearnormalisation of blood glucose improves the insulin response to glucagon-like peptide-1 and glucose-dependent insulinotropic polypeptide in patients with type 2 diabetes. Diabetologia. 2009;52(2):199. doi:10.1007/s00125-008-1195-5

162. Højberg PV, Vilsbøll T, Zander M, et al. Four weeks of nearnormalization of blood glucose has no effect on postprandial GLP-1 and GIP secretion, but augments pancreatic B-cell responsiveness to a meal in patients with Type 2 diabetes. Diabetic Med. 2008;25(11):1268-1275. doi:10.1111/j.1464-5491.2008.02579.x

163. Thorens B. Neural regulation of pancreatic islet cell mass and function. Diabetes Obes Metab. 2014;16(S1):87-95. doi:10.1111/ dom. 12346 
164. Thorens B. Brain glucose sensing and neural regulation of insulin and glucagon secretion. Diabetes Obes Metab. 2011;13:82-88. doi:10.1111/j.1463-1326.2011.01453.x

165. Kiba T. Relationships between the autonomic nervous system and the pancreas including regulation of regeneration and apoptosis: recent developments. Pancreas. 2004;29:51-58. doi:10.1097/ 00006676-200408000-00019

166. Tarussio D, Metref S, Seyer P, et al. Nervous glucose sensing regulates postnatal $\beta$ cell proliferation and glucose homeostasis. $J$ Clin Invest. 2014;124(1):413-424. doi:10.1172/JCI69154

167. Poitout V, Amyot J, Semache M, Zarrouki B, Hagman D, Fontés G. Glucolipotoxicity of the Pancreatic Beta Cell. Biochim Biophys Acta. 2010;1801(3):289-298. doi:10.1016/j.bbalip.2009.08.006

168. Kim J-W, Yoon K-H. Glucolipotoxicity in Pancreatic $\beta$-Cells. Diabetes Metab J. 2011;35(5):444-450. doi:10.4093/ dmj.2011.35.5.444

169. Prentki M, Nolan CJ. Islet $\beta$ cell failure in type 2 diabetes. J Clin Invest. 2006;116(7):1802-1812. doi:10.1172/JCI29103

170. Mason TM, Goh T, Tchipashvili V, et al. Prolonged elevation of plasma free fatty acids desensitizes the insulin secretory response to glucose in vivo in rats. Diabetes. 1999;48(3):524-530. doi:10.2337/diabetes.48.3.524

171. Kashyap S, Belfort R, Gastaldelli A, et al. A Sustained Increase in Plasma Free Fatty Acids Impairs Insulin Secretion in Nondiabetic Subjects Genetically Predisposed to Develop Type 2 Diabetes. Diabetes. 2003;52(10):2461-2474. doi:10.2337/ diabetes.52.10.2461

172. Barlow J, Affourtit C. Novel insights into pancreatic $\beta$-cell glucolipotoxicity from real-time functional analysis of mitochondrial energy metabolism in INS-1E insulinoma cells. Biochemical J. 2013;456(3):417-426. doi:10.1042/BJ20131002

173. Barlow J, Jensen Verena H, Jastroch M, Affourtit C. Palmitateinduced impairment of glucose-stimulated insulin secretion precedes mitochondrial dysfunction in mouse pancreatic islets. Biochemical J. 2016;473(4):487-496. doi:10.1042/BJ20151080

174. Hogan AE, Tobin AM, Ahern T, et al. Glucagon-like peptide-1 (GLP-1) and the regulation of human invariant natural killer $\mathrm{T}$ cells: lessons from obesity, diabetes and psoriasis. Diabetologia. 2011;54(11):2745-2754. doi:10.1007/s00125-011-2232-3

175. Wang Z, Thurmond DC. Mechanisms of biphasic insulin-granule exocytosis - roles of the cytoskeleton, small GTPases and SNARE proteins. J Cell Sci. 2009;122(7):893. doi:10.1242/ jes.034355

176. Athauda D, Maclagan K, Skene SS, et al. Exenatide once weekly versus placebo in Parkinson's disease: a randomised, doubleblind, placebo-controlled trial. Lancet. 2017;390(10103):16641675. doi:10.1016/S0140-6736(17)31585-4

177. Lynn FC, Pamir N, Ng EHC, McIntosh CHS, Kieffer TJ, Pederson RA. Defective Glucose-Dependent Insulinotropic Polypeptide Receptor Expression in Diabetic Fatty Zucker Rats. Diabetes. 2001;50(5):1004-1011. doi:10.2337/diabetes.50.5.1004

178. Affourtit C, Brand martin D. Uncoupling protein-2 contributes significantly to high mitochondrial proton leak in INS-1E insulinoma cells and attenuates glucose-stimulated insulin secretion. Biochemical J. 2008;409(1):199-204. doi:10.1042/BJ20070954

179. Affourtit $C$, Brand MD. On the role of uncoupling protein-2 in pancreatic beta cells. Biochimica et Biophysica Acta. 2008;1777 (7-8):973-979. doi:10.1016/j.bbabio.2008.03.022

180. Affourtit C, Jastroch M, Brand MD. Uncoupling protein-2 attenuates glucose-stimulated insulin secretion in INS-1E insulinoma cells by lowering mitochondrial reactive oxygen species. Free Radic Biol Med. 2011;50(5):609-616. doi:10.1016/j.freeradbiomed.2010.12.020

181. Chan CB, De Leo D, Joseph JW, et al. Increased uncoupling protein-2 levels in $\beta$-cells are associated with impaired glucosestimulated insulin secretion: mechanism of action. Diabetes. 2001;50(6):1302-1310. doi:10.2337/diabetes.50.6.1302
182. Chan CB, MacDonald PE, Saleh MC, Johns DC, Marbàn E, Wheeler MB. Overexpression of uncoupling protein 2 inhibits glucose-stimulated insulin secretion from rat islets. Diabetes. 1999;48(7):1482-1486. doi:10.2337/diabetes.48.7.1482

183. Pi J, Collins S. Reactive oxygen species and uncoupling protein 2 in pancreatic $\beta$-cell function. Diabetes Obes Metab. 2010;12 (s2):141-148. doi:10.1111/j.1463-1326.2010.01269.x

184. Robson-Doucette CA, Sultan S, Allister EM, et al. $\beta$-Cell Uncoupling Protein 2 Regulates Reactive Oxygen Species Production, Which Influences Both Insulin and Glucagon Secretion. Diabetes. 2011;60 (11):2710-2719. doi:10.2337/db11-0132

185. Schrauwen P, Hesselink M. UCP2 and UCP3 in muscle controlling body metabolism. $J$ Exp Biol. 2002;205(15):2275. doi:10.1242/jeb.205.15.2275

186. Bensellam M, Laybutt DR, Jonas J-C. The molecular mechanisms of pancreatic $\beta$-cell glucotoxicity: recent findings and future research directions. Mol Cell Endocrinol. 2012;364(1-2):1-27.

187. Hirschberg Jensen V, Affourtit C. Mitochondrial uncoupling protein-2 is not involved in palmitate-induced impairment of glucosestimulated insulin secretion in INS-1E insulinoma cells and is not needed for the amplification of insulin release. Biochemistry Biophysics Rep. 2015;1:8-15. doi:10.1016/j.bbrep.2015.03.008

188. Vozza A, Parisi G, De Leonardis F, et al. UCP2 transports C4 metabolites out of mitochondria, regulating glucose and glutamine oxidation. Proc Natl Acad Sci U S A. 2014;111(3):960-965. doi:10.1073/pnas.1317400111

189. Mailloux RJ, Fu A, Robson-Doucette C, et al. Glutathionylation State of Uncoupling Protein-2 and the Control of Glucose-stimulated Insulin Secretion. J Biol Chem. 2012;287(47):39673-39685. doi:10.1074/jbc.M112.393538

190. Mailloux RJ, Seifert EL, Bouillaud F, Aguer C, Collins S, Harper M-E. Glutathionylation Acts as a Control Switch for Uncoupling Proteins UCP2 and UCP3. J Biol Chem. 2011;286(24):2186521875. doi:10.1074/jbc.M111.240242

191. Basu R, Barosa C, Jones J, et al. Pathogenesis of Prediabetes: role of the Liver in Isolated Fasting Hyperglycemia and Combined Fasting and Postprandial Hyperglycemia. J Clin Endocrinol Metab. 2013;98(3):E409-E417. doi:10.1210/jc.2012-3056

192. Phielix E, Mensink M. Type 2 Diabetes Mellitus and Skeletal Muscle Metabolic Function. Physiol Behav. 2008;94(2):252-258. doi:10.1016/j.physbeh.2008.01.020

193. De Macedo G, Maria C, Nunes S, Barreto T. Skin disorders in diabetes mellitus: an epidemiology and physiopathology review. Diabetol Metab Syndr. 2016;8(1):63. doi:10.1186/s13098-0160176-y

194. Krishnan B, Babu S, Walker J, Walker AB, Pappachan JM. Gastrointestinal complications of diabetes mellitus. World $J$ Diabetes. 2013;4(3):51-63. doi:10.4239/wjd.v4.i3.51

195. Sharaf El Din A, Abdulazim DO. Diabetic nephropathy: time to withhold development and progression - A review. J Adv Res. 2017;8(4):363-373. doi:10.1016/j.jare.2017.04.004

196. Sanad E, ElFangary M, Sorour N, ElNemisy N. Skin manifestations in Egyptian diabetic patients: a case series study. Egypt J Dermatol Venerology. 2013;33(2):56-62. doi:10.4103/1110-6530.123941

197. DeFronzo RA, Tripathy D. Skeletal Muscle Insulin Resistance Is the Primary Defect in Type 2 Diabetes. Diabetes Care. 2009;32 (Suppl 2):S157-S163. doi:10.2337/dc09-S302

198. Blaak EE, van Aggel-leijssen DP, Wagenmakers AJ, Saris WH, van Baak MA. Impaired oxidation of plasma-derived fatty acids in type 2 diabetic subjects during moderate-intensity exercise. Diabetes. 2000;49(12):2102. doi:10.2337/diabetes.49.12.2102

199. Mensink M, Blaak EE, van Baak MA, Wagenmakers AJM, Saris WHM. Plasma Free Fatty Acid Uptake and Oxidation Are Already Diminished in Subjects at High Risk for Developing Type 2 Diabetes. Diabetes. 2001;50(11):2548. doi:10.2337/ diabetes.50.11.2548 
200. Holloszy JO. "Deficiency" of Mitochondria in Muscle Does Not Cause Insulin Resistance. Diabetes. 2013;62(4):1036. doi:10.2337/db12-1107

201. van de Weijer T, Sparks LM, Phielix E, et al. Relationships between Mitochondrial Function and Metabolic Flexibility in Type 2 Diabetes Mellitus. PLoS One. 2013;8(2):e51648. doi:10.1371/journal.pone.0051648

202. Galgani JE, Heilbronn LK, Azuma K, et al. Metabolic Flexibility in Response to Glucose Is Not Impaired in People With Type 2 Diabetes After Controlling for Glucose Disposal Rate. Diabetes. 2008;57(4):841-845. doi:10.2337/db08-0043

203. Goodpaster BH, Katsiaras A, Kelley DE. Enhanced Fat Oxidation Through Physical Activity Is Associated With Improvements in Insulin Sensitivity in Obesity. Diabetes. 2003;52(9):2191. doi:10.2337/diabetes.52.9.2191

204. Færch K, Vaag A. Metabolic inflexibility is a common feature of impaired fasting glycaemia and impaired glucose tolerance. Acta Diabetol. 2011;48(4):349-353. doi:10.1007/s00592-010-0245-x

205. Park SW, Goodpaster BH, Lee JS, et al. Excessive Loss of Skeletal Muscle Mass in Older Adults With Type 2 Diabetes. Diabetes Care. 2009;32(11):1993-1997. doi:10.2337/dc09-0264

206. Perry BD, Caldow MK, Brennan-Speranza TC, et al. Muscle atrophy in patients with Type 2 Diabetes Mellitus: roles of inflammatory pathways, physical activity and exercise. Exerc Immunol Rev. 2016;22:94-109.

207. Ciaraldi TP, Ryan AJ, Mudaliar SR, Henry RR. Altered Myokine Secretion Is an Intrinsic Property of Skeletal Muscle in Type 2 Diabetes. PLoS One. 2016;11(7):e0158209. doi:10.1371/journal. pone.0158209

208. Bouzakri K, Plomgaard P, Berney T, Donath MY, Pedersen BK, Halban PA. Bimodal Effect on Pancreatic $\beta$-Cells of Secretory Products From Normal or Insulin-Resistant Human Skeletal Muscle. Diabetes. 2011;60(4):1111-1121. doi:10.2337/db101178

209. Hancock CR, Han D-H, Chen M, et al. High-fat diets cause insulin resistance despite an increase in muscle mitochondria Proc National Acad Sci. 2008;105(22):7815-7820. doi:10.1073/ pnas.0802057105

210. Turner N, Bruce CR, Beale SM, et al. Excess Lipid Availability Increases Mitochondrial Fatty Acid Oxidative Capacity in Muscle. Diabetes. 2007;56(8):2085. doi:10.2337/db07-0093

211. Sreekumar R, Unnikrishnan J, Fu A, et al. Impact of high-fat diet and antioxidant supplement on mitochondrial functions and gene transcripts in rat muscle. Am J Physiol Endocrinol Metabo. 2002;282(5):E1055-E1061. doi:10.1152/ajpendo.00554.2001

212. Beck-Nielsen H, Hother-Nielsen O, Staehr P. Is hepatic glucose production increased in type 2 diabetes mellitus? Curr Diab Rep. 2002;2(3):231-236. doi:10.1007/s11892-002-0088-0

213. Bhatt HB, Smith RJ. Fatty liver disease in diabetes mellitus. Hepatobiliary Surg Nutr. 2015;4(2):101-108. doi:10.3978/j. issn.2304-3881.2015.01.03

214. Mazzotti A, Caletti MT, Marchignoli F, Forlani G, Marchesini G. Which treatment for type 2 diabetes associated with non-alcoholic fatty liver disease? Digestive Liver Dis. 2017;49(3):235-240. doi:10.1016/j.dld.2016.12.028

215. Targher G, Day CP, Bonora E. Risk of Cardiovascular Disease in Patients with Nonalcoholic Fatty Liver Disease. $N$ Eng $J$ Med. 2010;363(14):1341-1350. doi:10.1056/NEJMra0912063

216. Rijkelijkhuizen JM, Doesburg T, Girman CJ, et al. Hepatic fat is not associated with beta-cell function or postprandial free fatty acid response. Metab Clin Exp. 2009;58(2):196-203. doi:10.1016/j.metabol.2008.09.013

217. Gurgul-Convey E, Mehmeti I, Lortz S, Lenzen S. Cytokine toxicity in insulin-producing cells is mediated by nitro-oxidative stressinduced hydroxyl radical formation in mitochondria. $\mathrm{J} \mathrm{Mol} \mathrm{Med}$. 2011;89(8):785-798. doi:10.1007/s00109-011-0747-1
218. Makki K, Froguel P, Wolowczuk I. Adipose Tissue in ObesityRelated Inflammation and Insulin Resistance: cells, Cytokines, and Chemokines. ISRN Inflammation. 2013;2013:139239. doi: $10.1155 / 2013 / 139239$

219. Frayn KN. Adipose tissue and the insulin resistance syndrome. Proc Nutrition Soc. 2007;60(3):375-380. doi:10.1079/PNS200195

220. Blaak EE. Fatty acid metabolism in obesity and type 2 diabetes mellitus. Proc Nutrition Soc. 2007;62(3):753-760. doi:10.1079/ PNS2003290

221. Moreno-Indias I, Cardona F, Tinahones FJ, Queipo-Ortuño MI. Impact of the gut microbiota on the development of obesity and type 2 diabetes mellitus. Front Microbiol. 2014;5:190. doi:10.3389/fmicb.2014.00190

222. Rubin MR, Patsch JM. Assessment of bone turnover and bone quality in type 2 diabetic bone disease: current concepts and future directions. Bone Res. 2016;4:16001. doi:10.1038/ boneres.2016.1

223. Dobnig H, Piswanger-Sölkner JC, Roth M, et al. Type 2 Diabetes Mellitus in Nursing Home Patients: effects on Bone Turnover, Bone Mass, and Fracture Risk. J Clin Endocrinol Metab. 2006;91 (9):3355-3363. doi:10.1210/jc.2006-0460

224. Yamamoto M, Yamaguchi T, Nawata K, Yamauchi M, Sugimoto T. Decreased PTH Levels Accompanied by Low Bone Formation Are Associated with Vertebral Fractures in Postmenopausal Women with Type 2 Diabetes. $J$ Clin Endocrinol Metab. 2012;97(4):1277-1284. doi:10.1210/jc.2011-2537

225. Wrighten SA, Piroli GG, Grillo CA, Reagan LP. A look inside the diabetic brain: contributors to diabetes-induced brain aging Biochim Biophys Acta. 2009;1792(5):444-453. doi:10.1016/j. bbadis.2008.10.013

226. Ten Kulve JS, van Bloemendaal L, Balesar R, et al. Decreased Hypothalamic Glucagon-Like Peptide-1 Receptor Expression in Type 2 Diabetes Patients. J Clin Endocrinol Metab. 2016;101 (5):2122-2129. doi:10.1210/jc.2015-3291

227. Pirart J. Diabetes mellitus and its degenerative complications: a prospective study of 4400 patients observed. Diabetes Care. 1978;1:168-188. doi:10.2337/diacare.1.3.168

228. Yagihashi S, Mizukami H, Sugimoto K. Mechanism of diabetic neuropathy: where are we now and where to go? J Diabetes Investig. 2011;2(1):18-32. doi:10.1111/j.2040-1124.2010.00070.x

229. Duby JJ, Campbell RK, Setter SM. Diabetic neuropathy: an intensive review. Am J Health Sys Pharmacy. 2004;61(2):160. doi:10.1093/ajhp/61.2.160

230. Tracy JA, Dyck PJB. The Spectrum of Diabetic Neuropathies. Phys Med Rehabil Clin N Am. 2008;19(1):1-26. doi:10.1016/j. pmr.2007.10.010

231. Nesto R, Fain R, Li Y, Shanahan W. Evaluation of lorcaserin on progression of prediabetes to type 2 diabetes and reversion to euglycemia. Postgrad Med. 2016;128(4):364-370. doi:10.1080/ 00325481.2016.1178590

232. Dokken BB. The Pathophysiology of Cardiovascular Disease and Diabetes: beyond Blood Pressure and Lipids. Diabetes Spectrum. 2008;21(3):160. doi:10.2337/diaspect.21.3.160

233. Funk SD, Ory AW. Hyperglycemia and Endothelial Dysfunction in Atherosclerosis: lessons from Type 1 Diabetes. Int J Vasc Med. 2012;2012. doi:10.1155/2012/569654

234. Wu G, Meininger CJ. Nitric oxide and vascular insulin resistance. BioFactors. 2009;35(1):21-27. doi:10.1002/biof.3

235. Lastra G, Syed S, Kurukulasuriya LR, Manrique C, Sowers JR. Type 2 diabetes mellitus and hypertension: an update. Endocrinol Metab Clin North Am. 2014;43(1):103-122. doi:10.1016/j. ecl.2013.09.005

236. Tate M, Chong A, Robinson E, Green BD, Grieve DJ. Selective targeting of glucagon-like peptide-1 signalling as a novel therapeutic approach for cardiovascular disease in diabetes. $\mathrm{Br} J$ Pharmacol. 2015;172(3):721-736. doi:10.1111/bph.12943 
237. Verrotti A, Prezioso G, Scattoni R, Chiarelli F. Autonomic Neuropathy in Diabetes Mellitus. Front Endocrinol (Lausanne). 2014;5:205. doi:10.3389/fendo.2014.00205

238. Nourooz-Zadeh J, Rahimi A, Tajaddini-Sarmadi J, et al. Relationships between plasma measures of oxidative stress and metabolic control in NIDDM. Diabetologia. 1997;40(6):647-653. doi:10.1007/s001250050729

239. Kawaguchi M, Techigawara M, Ishihata T, et al. A comparison of ultrastructural changes on endomyocardial biopsy specimens obtained from patients with diabetes mellitus with and without hypertension. Heart Vessels. 1997;12(6):267-274. doi:10.1007/ BF02766802

240. Cao Z, Cooper ME. Pathogenesis of diabetic nephropathy. $J$ Diabetes Investig. 2011;2(4):243-247. doi:10.1111/j.20401124.2011.00131.x

241. Nitzan O, Elias M, Chazan B, Saliba W. Urinary tract infections in patients with type 2 diabetes mellitus: review of prevalence, diagnosis, and management. Diabetes Metab Syndrome Obesity. 2015;8:129-136. doi:10.2147/DMSO.S51792

242. Colberg SR, Sigal RJ, Fernhall B, et al. Exercise and Type 2 Diabetes: the American College of Sports Medicine and the American Diabetes Association: joint position statement. Diabetes Care. 2010;33(12):e147-e167. doi:10.2337/dc109990

243. Keshel TE, Coker RH. Exercise Training and Insulin Resistance: a Current Review. J Obes Weight Loss Ther. 2015;5(5):S5-003.

244. Chiasson J-L. Early Insulin Use in Type 2 Diabetes: what are the cons? Diabetes Care. 2009;32(Suppl 2):S270-S274. doi:10.2337/ dc09-S321

245. Taylor R. Type 2 Diabetes. Diabetes Care. 2013;36(4):1047. doi:10.2337/dc12-1805

246. Zhou X, Wu H, Long R, et al. Oral delivery of insulin with intelligent glucose-responsive switch for blood glucose regulation. J Nanobiotechnology. 2020;18(1):96. doi:10.1186/s12951020-00652-Z

247. Xiao Y, Tang Z, Wang J, et al. Oral Insulin Delivery Platforms: strategies To Address the Biological Barriers. Angewandte Chemie Int Edition. 2020;59(45):19787-19795. doi:10.1002/ anie. 202008879

248. Eldor ROY, Fleming GA, Neutel J, Homer KE, Kidron M, Rosenstock J. 105-LB: evening Oral Insulin (ORMD-0801) Glycemic Effects in Uncontrolled T2DM Patients. Diabetes. 2020;69(Supplement 1):105-LB. doi:10.2337/db20-105-LB

249. Bahman F, Taurin S, Altayeb D, Taha S, Bakhiet M, Greish K. Oral Insulin Delivery Using Poly (Styrene Co-Maleic Acid) Micelles in a Diabetic Mouse Model. Pharmaceutics. 2020;12 (11):1026. doi:10.3390/pharmaceutics 12111026

250. Gallwitz B. The evolving place of incretin-based therapies in type 2 diabetes. Pediatric Nephrol. 2010;25(7):1207-1217. doi:10.1007/s00467-009-1435-z

251. Brunton S. GLP-1 receptor agonists vs. DPP-4 inhibitors for type 2 diabetes: is one approach more successful or preferable than the other? Int J Clin Pract. 2014;68(5):557-567. doi:10.1111/ ijcp. 12361

252. De Graaf C, Donnelly D, Wootten D, et al. Glucagon-Like Peptide-1 and Its Class B G Protein-Coupled Receptors: a Long March to Therapeutic Successes. Pharmacol Rev. 2016;68 (4):954-1013. doi:10.1124/pr.115.011395

253. Holst JJ. The Physiology of Glucagon-like Peptide 1. Physiol Rev. 2007;87(4):1409-1439. doi:10.1152/physrev.00034.2006

254. Prasad-Reddy L, Isaacs D. A clinical review of GLP-1 receptor agonists: efficacy and safety in diabetes and beyond. Drugs Context. 2015;4:212283. doi:10.7573/dic. 212283

255. Edavalath M, Stephens JW. Liraglutide in the treatment of type 2 diabetes mellitus: clinical utility and patient perspectives. Patient Prefer Adherence. 2010;4:61-68. doi:10.2147/ppa.s6358
256. Eng J, Kleinman W, Singh L, Singh G, Raufman J. Isolation and characterization of exendin-4, an exendin-3 analogue, from Heloderma suspectum venom. Further evidence for an exendin receptor on dispersed acini from guinea pig pancreas. $J$ Biol Chem. 1992;267:7402-7405. doi:10.1016/S0021-9258(18)425318

257. Reed J, Bain S, Kanamarlapudi V. Recent advances in understanding the role of glucagon-like peptide 1 [version 1; peer review: 2 approved]. F1000Research. 2020;9:239. doi:10.12688/ f1000research.20602.1

258. Wang M, Yao P, Gao M, Jin J, Yu Y. Novel fatty chain-modified GLP-1R G-protein biased agonist exerts prolonged anti-diabetic effects through targeting receptor binding sites. RSC Adv. 2020;10 (14):8044-8053. doi:10.1039/C9RA10593J

259. Reed J, Kanamarlapudi V. GLP-1. In: Choi S, editor. Encyclopedia of Signaling Molecules. Cham: Springer International Publishing; 2018:2098-2106.

260. Trujillo JM, Nuffer W, Smith BA. GLP-1 receptor agonists: an updated review of head-to-head clinical studies. Ther $A d v$ Endocrinol Metab. 2021;12:2042018821997320. doi:10.1177/ 2042018821997320

261. Seino Y, Fukushima M, Yabe D. GIP and GLP-1, the two incretin hormones: similarities and differences. J Diabetes Investig. 2010;1(1-2):8-23. doi:10.1111/j.2040-1124.2010.00022.x

262. Levin PA, Nguyen H, Wittbrodt ET, Kim SC. Glucagon-like peptide-1 receptor agonists: a systematic review of comparative effectiveness research. Diabetes Metab Syndrome Obesity. 2017;10:123-139. doi:10.2147/DMSO.S130834

263. Potts JE, Gray LJ, Brady EM, Khunti K, Davies MJ, Bodicoat DH. The Effect of Glucagon-Like Peptide 1 Receptor Agonists on Weight Loss in Type 2 Diabetes: a Systematic Review and Mixed Treatment Comparison Meta-Analysis. PLoS One. 2015;10(6): e0126769. doi:10.1371/journal.pone.0126769

264. Tamura K, Minami K, Kudo M, Iemoto K, Takahashi H, Seino S. Liraglutide improves pancreatic Beta cell mass and function in alloxan-induced diabetic mice. PLoS One. 2015;10(5):e0126003e0126003. doi:10.1371/journal.pone. 0126003

265. Garber AJ. Incretin effects on $\beta$-cell function, replication, and mass: the human perspective. Diabetes Care. 2011;34 Suppl 2 (Supp12):S258-S263. doi:10.2337/dc11-s230

266. Xu G, Kaneto H, Lopez-Avalos MD, Weir GC, Bonner-Weir S. GLP-1/exendin-4 facilitates $\beta$-cell neogenesis in rat and human pancreatic ducts. Diabetes Res Clin Pract. 2006;73(1):107-110. doi:10.1016/j.diabres.2005.11.007

267. Drucker DJ, Sherman SI, Gorelick FS, Bergenstal RM, Sherwin RS, Buse JB. Incretin-Based Therapies for the Treatment of Type 2 Diabetes: evaluation of the Risks and Benefits. Diabetes Care. 2010;33(2):428-433. doi:10.2337/dc09-1499

268. Nauck MA, Friedrich N. Do GLP-1-Based Therapies Increase Cancer Risk? Diabetes Care. 2013;36(Supplement 2):S245-S252. doi: $10.2337 / \mathrm{dcS} 13-2004$

269. Finan B, Ma T, Ottaway N, et al. Unimolecular Dual Incretins Maximize Metabolic Benefits in Rodents, Monkeys, and Humans. Sci Transl Med. 2013;5(209):209ra151-209ra151. doi:10.1126/ scitranslmed.3007218

270. Patel V, Joharapurkar A, Kshirsagar S, et al. Coagonist of GLP-1 and glucagon decreases liver inflammation and atherosclerosis in dyslipidemic condition. Chem Biol Interact. 2018;282:13-21. doi:10.1016/j.cbi.2018.01.004

271. Wang A, Li T, An P, et al. Exendin-4 Upregulates Adiponectin Level in Adipocytes via Sirt1/Foxo-1 Signaling Pathway. PLoS One. 2017;12(1):e0169469. doi:10.1371/journal.pone.0169469

272. Lihn AS, Pedersen SB, Richelsen B. Adiponectin: action, regulation and association to insulin sensitivity. Obesity Rev. 2005;6 (1):13-21. doi:10.1111/j.1467-789X.2005.00159.x 
273. Tomkin GH. Treatment of type 2 diabetes, lifestyle, GLP1 agonists and DPP4 inhibitors. World J Diabetes. 2014;5(5):636-650. doi:10.4239/wjd.v5.i5.636

274. Aroda VR. A review of GLP-1 receptor agonists: evolution and advancement, through the lens of randomised controlled trials. Diabetes Obes Metab. 2018;20(Suppl 1):22-33. doi:10.1111/ dom. 13162

275. Marso SP, Bain SC, Consoli A, et al. Semaglutide and Cardiovascular Outcomes in Patients with Type 2 Diabetes. $N$ Eng $J$ Med. 2016;375(19):1834-1844. doi:10.1056/NEJM oa 1607141

276. Marso SP, Daniels GH, Brown-Frandsen K, et al. Liraglutide and Cardiovascular Outcomes in Type 2 Diabetes. $N$ Eng $J$ Med. 2016;375(4):311-322. doi:10.1056/NEJMoa1603827

277. Forst T, Matthias MW, Andreas P. Cardiovascular Benefits of GLP-1-Based Therapies in Patients with Diabetes Mellitus Type 2: effects on Endothelial and Vascular Dysfunction beyond Glycemic Control. Exp Diabetes Res. 2012;2012. doi:10.1155/ 2012/635472

278. Holman RR, Bethel MA, Mentz RJ, et al. Effects of Once-Weekly Exenatide on Cardiovascular Outcomes in Type 2 Diabetes. $N$ Eng $J$ Med. 2017;377(13):1228-1239. doi:10.1056/NEJMoa1612917

279. Pfeffer MA, Claggett B, Diaz R, et al. Lixisenatide in Patients with Type 2 Diabetes and Acute Coronary Syndrome. $N$ Eng $J$ Med. 2015;373(23):2247-2257. doi:10.1056/NEJMoa1509225

280. Strain W, Griffiths J. A systematic review and meta-analysis of the impact of GLP-1 receptor agonists and SGLT-2 inhibitors on cardiovascular outcomes in biologically healthy older adults. $\mathrm{Br} \mathrm{J}$ Diabetes. 2021;21:30-35. doi:10.15277/bjd.2021.292

281. Karagiannis T, Tsapas A, Athanasiadou E, et al. GLP-1 receptor agonists and SGLT2 inhibitors for older people with type 2 diabetes: a systematic review and meta-analysis. Diabetes Res Clin Pract. 2021;174:108737. doi:10.1016/j.diabres.2021.108737

282. Marsico F, Paolillo S, Gargiulo P, et al. Effects of glucagon-like peptide-1 receptor agonists on major cardiovascular events in patients with Type 2 diabetes mellitus with or without established cardiovascular disease: a meta-analysis of randomized controlled trials. Eur Heart J. 2020;41(35):3346-3358. doi:10.1093/eurheartj/ehaa082

283. Kristensen SL, Rørth R, Jhund PS, et al. Cardiovascular, mortality, and kidney outcomes with GLP-1 receptor agonists in patients with type 2 diabetes: a systematic review and meta-analysis of cardiovascular outcome trials. Lancet Diabetes Endocrinol. 2019;7(10):776-785. doi:10.1016/S2213-8587(19)30249-9

284. Knudsen LB, Kiel D, Teng M, et al. Small-molecule agonists for the glucagon-like peptide 1 receptor. Proc Natl Acad Sci U S A. 2007;104(3):937-942. doi:10.1073/pnas.0605701104

285. Irwin N, Flatt PR, Patterson S, Green BD. Insulin-releasing and metabolic effects of small molecule GLP-1 receptor agonist 6,7dichloro-2-methylsulfonyl-3-N-tert-butylaminoquinoxaline. Eur $J$ Pharmacol. 2010;628(1-3):268-273. doi:10.1016/j. ejphar.2009.11.022

286. Sloop KW, Willard FS, Brenner MB, et al. Novel Small Molecule Glucagon-Like Peptide-1 Receptor Agonist Stimulates Insulin Secretion in Rodents and From Human Islets. Diabetes. 2010;59 (12):3099. doi:10.2337/db10-0689

287. Nolte WM, Fortin J-P, Stevens BD, et al. A potentiator of orthosteric ligand activity at GLP-1R acts via covalent modification. Nat Chem Biol. 2014;10(8):629-631. doi:10.1038/nchembio.1581

288. Song G, Yang D, Wang Y, et al. Human GLP-1 receptor transmembrane domain structure in complex with allosteric modulators. Nature. 2017;546:312. doi:10.1038/nature22378

289. Finan B, Yang B, Ottaway N, et al. A rationally designed monomeric peptide triagonist corrects obesity and diabetes in rodents. Nat Med. 2015;21(1):27-36. doi:10.1038/nm.3761
290. Cui J, Shang A, Wang W, Chen W. Rational design of a GLP-1/ GIP/Gcg receptor triagonist to correct hyperglycemia, obesity and diabetic nephropathy in rodent animals. Life Sci. 2020;260:118339. doi:10.1016/j.lfs.2020.118339

291. Elder KA, Wolfe BM. Bariatric Surgery: a Review of Procedures and Outcomes. Gastroenterology. 2007;132(6):2253-2271. doi:10.1053/j.gastro.2007.03.057

292. Eldar S, Heneghan HM, Brethauer SA, Schauer PR. Bariatric surgery for treatment of obesity. Int J Obes. 2011;35(S3):S16S21. doi:10.1038/ijo.2011.142

293. Buchwald H, Williams SE. Bariatric Surgery Worldwide 2003. Obes Surg. 2004;14(9):1157-1164. doi:10.1381/ 0960892042387057

294. Singh AK, Singh R, Kota SK. Bariatric surgery and diabetes remission: who would have thought it? Indian $J$ Endocrinol Metab. 2015;19(5):563-576. doi:10.4103/2230-8210.163113

295. Brethauer SA, Aminian A, Romero-Talamás H, et al. Can Diabetes Be Surgically Cured?: long-Term Metabolic Effects of Bariatric Surgery in Obese Patients with Type 2 Diabetes Mellitus. Ann Surg. 2013;258(4):628-637. doi:10.1097/ SLA.0b013e3182a5034b

296. Koliaki C, Liatis S, le Roux CW, Kokkinos A. The role of bariatric surgery to treat diabetes: current challenges and perspectives. BMC Endocr Disord. 2017;17(1):50. doi:10.1186/s12902017-0202-6

297. Shah A, Laferrère B. Diabetes after Bariatric Surgery. Can J Diabetes. 2017;41(4):401-406. doi:10.1016/j.jcjd.2016.12.009

298. Khalaf KI, Taegtmeyer H. Clues from Bariatric Surgery: reversing Insulin Resistance to Heal the Heart. Curr Diab Rep. 2013;13(2):245-251. doi:10.1007/s11892-013-0364-1

299. Provenzale D, Reinhold RB, Golner B, et al. Evidence for diminished B12 absorption after gastric bypass: oral supplementation does not prevent low plasma B12 levels in bypass patients. J Am Coll Nutr. 1992;11:29-35. doi:10.1080/ 07315724.1992 .10718193

300. Halverson J. Micronutrient deficiencies after gastric bypass for morbid obesity. Am Surg. 1986;52:594-598.

301. Avinoah EOA, Charuzi I. Nutritional status seven years after Roux-en-Y gastric bypass surgery. Surgery. 1992;111:137142.

302. Saliba W, El-Haddad B. Secondary Hyperparathyroidism: pathophysiology and Treatment. J Am Board Family Med. 2009;22 (5):574-581. doi:10.3122/jabfm.2009.05.090026

303. Potts JT. Parathyroid hormone: past and present. J Endocrinol. 2005;187(3):311-325. doi:10.1677/joe.1.06057

304. Toh SY, Zarshenas N, Jorgensen J. Prevalence of nutrient deficiencies in bariatric patients. Nutrition. 2009;25(11):1150-1156. doi:10.1016/j.nut.2009.03.012

305. Reed J, Kanamarlapudi V, Bain S. Mechanism of cardiovascular disease benefit of glucagon-like peptide 1 agonists. Cardiovascular Endocrinol Metab. 2018;7(1):18-23.

306. Alicic RZ, Rooney MT, Tuttle KR. Diabetic Kidney Disease. Clin J Am Soc Nephrol. 2017;12(12):2032. doi:10.2215/CJN.11491116

307. Duh EJ, Sun JK, Stitt AW. Diabetic retinopathy: current understanding, mechanisms, and treatment strategies. JCI Insight. 2017;2(14):e93751. doi:10.1172/jci.insight.93751

308. Leon BM, Maddox TM. Diabetes and cardiovascular disease: epidemiology, biological mechanisms, treatment recommendations and future research. World J Diabetes. 2015;6(13):12461258. doi:10.4239/wjd.v6.i13.1246

309. Tomita T. Apoptosis in pancreatic $\beta$-islet cells in Type 2 diabetes. Bosn J Basic Med Sci. 2016;16(3):162-179. doi:10.17305/ bjbms.2016.919

310. Cho J-H, Kim J-W, Shin J-A, Shin J, Yoon K-H. $\beta$-cell mass in people with type 2 diabetes. J Diabetes Investig. 2011;2(1):6-17. doi:10.1111/j.2040-1124.2010.00072.x 
311. le Roux CW, Astrup A, Fujioka K, et al. 3 years of liraglutide versus placebo for type 2 diabetes risk reduction and weight management in individuals with prediabetes: a randomised, double-blind trial. Lancet. 2017;389(10077):1399-1409. doi:10.1016/ S0140-6736(17)30069-7

312. Jazayeri A, Rappas M, Brown AJH, et al. Corrigendum: crystal structure of the GLP-1 receptor bound to a peptide agonist. Nature. 2017;548:122. doi:10.1038/nature23311

313. Itariu BK, Stulnig TM. Autoimmune Aspects of Type 2 Diabetes Mellitus - A Mini-Review. Gerontology. 2014;60(3):189-196. doi: $10.1159 / 000356747$

314. Pietropaolo M, Barinas-Mitchell E, Pietropaolo SL, Kuller LH, Trucco M. Evidence of islet cell autoimmunity in elderly patients with type 2 diabetes. Diabetes. 2000;49(1):32-38. doi:10.2337/ diabetes.49.1.32

315. Brooks-Worrell BM, Reichow JL, Goel A, Ismail H, Palmer JP. Identification of Autoantibody-Negative Autoimmune Type 2 Diabetic Patients. Diabetes Care. 2011;34(1):168-173. doi: $10.2337 / \mathrm{dc} 10-0579$

316. Haskell BDFK, Duffy TM, Sargent EE, Leiter EH. The diabetesprone NZO/HILt strain. I. Immunophenotypic comparison to the related $\mathrm{NZB} / \mathrm{BINJ}$ and $\mathrm{NZW/LacJ}$ strains. Lab Invest. 2002;82:833-842. doi:10.1097/01.LAB.0000018915.53257.00

317. Jagannathan M, McDonnell M, Liang Y, et al. Toll-like receptors regulate B cell cytokine production in patients with diabetes. Diabetologia. 2010;53(7):1461-1471. doi:10.1007/s00125-010$1730-\mathrm{z}$

318. Gandasi NR, Yin P, Omar-Hmeadi M, Ottosson laakso E, Vikman P, Glucose-Dependent Granule BS. Docking Limits Insulin Secretion and Is Decreased in Human Type 2 Diabetes. Cell Metab. 2018;27 (2):470-478.e474. doi:10.1016/j.cmet.2017.12.017

319. Zhang Y, Chen W, Feng B, Cao H. The Clinical Efficacy and Safety of Stem Cell Therapy for Diabetes Mellitus: a Systematic Review and Meta-Analysis. Aging Dis. 2020;11(1):141-153. doi:10.14336/AD.2019.0421

320. El-Badawy A, El-Badri N. Clinical Efficacy of Stem Cell Therapy for Diabetes Mellitus: a Meta-Analysis. PLoS One. 2016;11(4): e0151938. doi:10.1371/journal.pone.0151938

321. Bhansali A, Upreti V, Khandelwal N, et al. Efficacy of autologous bone marrow-derived stem cell transplantation in patients with type 2 diabetes mellitus. Stem Cells Dev. 2009;18(10):1407-1416. doi:10.1089/scd.2009.0164
322. D'Addio F, Valderrama Vasquez A, Ben Nasr M, et al. Autologous nonmyeloablative hematopoietic stem cell transplantation in new-onset type 1 diabetes: a multicenter analysis. Diabetes. 2014;63(9):3041-3046. doi:10.2337/db14-0295

323. Rahim F, Arjmand B, Shirbandi K, Payab M, Larijani B. Stem cell therapy for patients with diabetes: a systematic review and meta-analysis of metabolomics-based risks and benefits. Stem Cell Investig. 2018;5:40. doi:10.21037/sci.2018.11.01

324. Bhansali S, Dutta P, Kumar V, et al. Efficacy of Autologous Bone Marrow-Derived Mesenchymal Stem Cell and Mononuclear Cell Transplantation in Type 2 Diabetes Mellitus: a Randomized, Placebo-Controlled Comparative Study. Stem Cells Dev. 2017;26 (7):471-481. doi:10.1089/scd.2016.0275

325. World Health Organization. Body Mass Index (BMI). Available from: https://www.who.int/data/gho/data/themes/theme-details/ GHO/body-mass-index-(bmi)?introPage=intro_3.html. Accessed August 03, 2021.

326. Dimitriadis G, Mitrou P, Lambadiari V, Maratou E, Raptis SA. Insulin effects in muscle and adipose tissue. Diabetes Res Clin Pract. 2011;93:S52-S59. doi:10.1016/S0168-8227(11)70014-6

327. Huang S, Czech MP. The GLUT4 Glucose Transporter. Cell Metab. 2007;5(4):237-252. doi:10.1016/j.cmet.2007.03.006

328. Steiner DJ, Kim A, Miller K, Hara M. Pancreatic islet plasticity: interspecies comparison of islet architecture and composition. Islets. 2010;2(3):135-145. doi:10.4161/isl.2.3.11815

329. Henquin J-C. The dual control of insulin secretion by glucose involves triggering and amplifying pathways in beta-cells. Diabetes Res Clin Pract. 2011;93:S27-S31. doi:10.1016/S01688227(11)70010-9

330. Mailloux RJ, Harper M-E. Mitochondrial proticity and ROS signaling: lessons from the uncoupling proteins. Trends Endocrinol Metab. 2012;23(9):451-458. doi:10.1016/j. tem.2012.04.004

331. Reed J, Kanamarlapudi V. GLP-1R. In: Choi S, editor. Encyclopedia of Signaling Molecules. New York: Springer New York; 2017:2106-2117.

332. Lorenz M, Evers A, Wagner M. Recent progress and future options in the development of GLP-1 receptor agonists for the treatment of diabesity. Bioorg Med Chem Lett. 2013;23(14):40114018. doi:10.1016/j.bmcl.2013.05.022

\section{Publish your work in this journal}

Diabetes, Metabolic Syndrome and Obesity: Targets and Therapy is an international, peer-reviewed open-access journal committed to the rapid publication of the latest laboratory and clinical findings in the fields of diabetes, metabolic syndrome and obesity research. Original research, review, case reports, hypothesis formation, expert opinion and commentaries are all considered for publication. The manuscript management system is completely online and includes a very quick and fair peer-review system, which is all easy to use. Visit http://www.dovepress.com/testimonials.php to read real quotes from published authors. 